\title{
Initial Report on Stress- Corrosion-Cracking Experiments Using Zircaloy-4 Spent Fuel Cladding C-Rings
}

\author{
H. D. Smith \\ Date Published \\ September 1988
}

Prepared for the U.S. Department of Energy Office of Civilian Radioactive Waste Management

$\begin{array}{ll}\text { Westinghouse } & \text { P.O. Box } 1970 \\ \text { Hanford Company } & \text { Richland, Washington } 99352\end{array}$

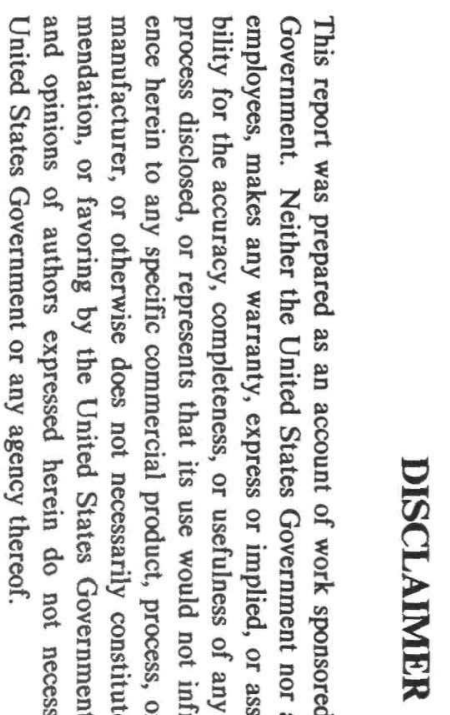

Hanford Operations and Engineering Contractor for the

U.S. Department of Energy under Contract DE-AC06-87RL10930

\footnotetext{
Nevada Nuclear Waste Storage Investigations Prepared by NNWSI Project participants as part of the Civilian

Radioactive Waste Management Program (CRWM). The NNWS Project is m Project work is sponsored by the Office of

Office (WMPO) of the USDOE, Nevada Operations of Civilian Radioactive Waste Management (OCRWM)
} 


\section{DISCLAIMER}

This report was prepared as an account of work sponsored by an agency of the United States Government. Neither the United States Government nor any agency Thereof, nor any of their employees, makes any warranty, express or implied, or assumes any legal liability or responsibility for the accuracy, completeness, or usefulness of any information, apparatus, product, or process disclosed, or represents that its use would not infringe privately owned rights. Reference herein to any specific commercial product, process, or service by trade name, trademark, manufacturer, or otherwise does not necessarily constitute or imply its endorsement, recommendation, or favoring by the United States Government or any agency thereof. The views and opinions of authors expressed herein do not necessarily state or reflect those of the United States Government or any agency thereof. 


\section{DISCLAIMER}

Portions of this document may be illegible in electronic image products. Images are produced from the best available original document. 


\section{CONTENTS}

\section{Page}

Figures iv

Tables vi

$\begin{array}{lll}1.0 & \text { SUMMARY } & 1\end{array}$

2.0 INTRODUCTION 3

3.0 GEOMETRIC AND MATERIAL CONSIDERATIONS IN EVALUATING

$\begin{array}{ll}\text { THE C-RING SCOPING EXPERIMENT RESULTS } & 7\end{array}$

3.1 GEOMETRIC CONSIDERATIONS

3.2 SPENT FUEL CLADDING SPECIMENS 9

$\begin{array}{lll}4.0 & \text { EXPERIMENT EQUIPMENT } & 11\end{array}$

$\begin{array}{lll}5.0 & \text { EXPERIMENTAL APPROACH } & 15\end{array}$

5.1 AN EMPIRICAL DETERMINATION OF THE ELASTIC PROPERTIES 15

5.2 CHOOSING EXPERIMENT STRESS LEVELS 24

6.0 THE $90 \%+$ STRESS LEVEL EXPERIMENTS 27

$\begin{array}{lll}7.0 & \text { EXPERIMENT RESULTS } & 31\end{array}$

$\begin{array}{lll}8.0 & \text { DISCUSSION OF RESULTS } & 51\end{array}$

8.1 STRESS CORROSION CRACKING EVIDENCE

8.2 A POTENTIAL MODEL $\quad 54$

$\begin{array}{lll}9.0 & \text { CONCLUSIONS } & 61\end{array}$

$\begin{array}{lll}10.0 & \text { REFERENCES } & 63\end{array}$

$\begin{array}{lll}\text { APPENDIX } & \text { A CRITICAL REVIEW OF THE SHORT CRACK } & \\ & \text { PROBLEM IN FATIGUE } & A-1\end{array}$ 


\section{FIGURES}

Figure

Page

1 "C-Ring" Schematic Drawing I1lustrating the Point of Maximum Stress and the Radial Parameters that are Included in the Model of Fernandez and Tisinai for Calculating the Stress at the Outside Surface of the Ring

2 Schematic Cross Section of the "C-Ring" Stress Corrosion Cracking Experiment Apparatus with the Anvils in Position Stressing a "C-Ring" Specimen

3 "C-Ring" Stress Corrosion Scoping Experiment Apparatus in Operation

$4 \quad$ Elastic Limit Curve for Turkey Point Spent Fuel

Cladding Specimen G7-11-1

5 Elastic Limit Curve for Turkey Point Spent Fuel

Cladding Specimen I9-3-4

6 Elastic Limit Curve for Turkey Point Spent Fuel Cladding Specimen G7-34-2

7 Elastic Limit Curve for an Unirradiated Zircaloy-4 Specimen ZIRC-1

8 Observed Stress-Strain Curves for Turkey Point Spent Fuel Cladding Specimens (1ines) and for As-Formed Unirradiated Zircaloy-4 Cladding (squares)

9 Mechanical Properties of a Well-Characterized 316 Type SS (HEDL TC-2185) Determined Using the C-Ring Apparatus

10 Typical Six Hours of Data Recorded by the Datalogger

11 Change in Diameter as a Function of Time for Each of the Seven C-Rings that were Stressed in the Presence of Well "J-13" Water

12 Change in Diameter as a Function of Time for Each of the Two C-Rings that were Stressed in the Presence of Hot Cell Air

13 Schematic Diagram of a C-Ring after the Experiment Showing a Typical Cracking Pattern and the Area Sampled 


\section{FIGURES (Cont'd)}

Figure

Page

14 Scanning Electron Microscope Micrographs of Cracked Areas for the C-Rings that were Removed from the Experiment Prior to Breaking

15 Scanning Electron Microscope Micrographs Showing Some of the Details of the Cracking Pattern Shown in Figure 14

16 Scanning Electron Microscope Micrographs of the Fracture Surface of the C-Rings that Broke

17 Scanning Electron Microscope Micrographs Showing Detail of the Fracture Surface at the Outside Diameter

18 Metallographic Polished and "B" Etched Cross Sections of Cracks at the Center of Unbroken C-Rings

19 Metallographic Polished and "B" Etched Cross Sections of Cracks from the Ends of each Unbroken C-Ring

20 Metallographic Polished and "B" Etched Cross Sections of the Fracture Surface of Broken C-Rings

21 Metallographic Polished and "B" Etched Cross Sections of Cracks Oriented Parallel to the Fracture Surface of G7-11-7 Shown in Figure 20

22 Empirical Relationship Between Observed Time to Failure and Stress Level Defined as the Percentage of the Measured Elastic Limit

23 Schematic $K_{I}$ - a Diagram

24 Interpretative Plot of the Experimental Data on a $\sigma$ - a Diagram 


\section{$\underline{\text { TABLES }}$}

$\underline{\text { Table }}$

Page

$1 \quad$ Estimated Elastic Limit Stress

23

2 A Comparison of Elastic Limit and Elastic Coefficient for a 316 SS Using the C-Ring Apparatus with Published Values

23

$390+\%$ Stress Level Experiment Specimens

25

$4 \quad$ Observed Water Chemistry During the C-Ring Stress Corrosion Cracking Experiments

$5 \quad$ Observed Experimental Data from C-Ring Stress Corrosion Cracking Experiments 


\section{$1.0 \quad \underline{\text { SUMMARY }}$}

The Nevada Nuclear Waste Storage Investigations (NNWSI) Project, through Lawrence Livermore National Laboratory (LLNL), is sponsoring C-ring stress corrosion cracking scoping experiments as a first step in evaluating the potential for stress corrosion cracking of spent fuel cladding in a potential tuff repository environment. The objective is to scope the approximate behavior so that more precise pressurized tube testing can be performed over an appropriate range of stress, without expanding the long-term effort needlessly. The experiment consists of stressing, by compression with a dead weight load, C-rings fabricated from spent fuel cladding exposed to an environment of Well $\mathrm{J}-13$ water held at $90{ }^{\circ} \mathrm{C}$. The results indicate that stress corrosion cracking occurs at the high stress levels employed in the experiments. The cladding $\mathrm{C}$-rings, tested at $90 \%$ of the stress at which elastic behavior is obtained in these specimens, broke in 25 to $64 \mathrm{~d}$ when tested in water. This was about one third of the time required for control tests to break in air. This is apparently the first observation of stress corrosion under the test conditions of relatively low temperature, benign environment but very high stress. The $150 \mathrm{ksi}$ test stress could be applied as a result of the particular specimen geometry. By comparison, the uniaxial tensile yield stress is about 100 to $120 \mathrm{ksi}$ and the ultimate stress is about $150 \mathrm{ksi}$. When a general model that fits the high stress results is extrapolated to lower stress levels, it indicates that the C-rings in experiments now running at $-80 \%$ of the yield strength should take 200 to $225 \mathrm{~d}$ to break. It is clear that the conclusions made so far must be validated at lower stress levels such as in the experiment now in progress so that an effective set of pressurized tubing tests can be run that provide stress corrosion cracking data that can be extrapolated to stress levels of $15 \mathrm{ksi}$ or less expected for cladding under repository conditions.

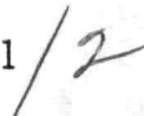


WHC-EP-0096

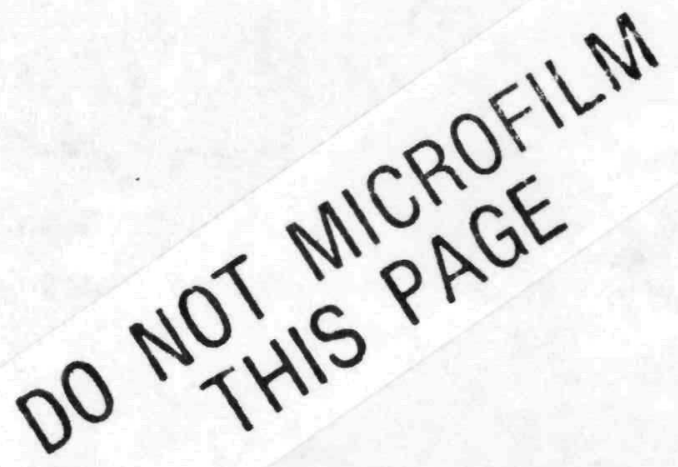




\section{$2.0 \quad$ INTRODUCTION}

Spent nuclear fuel is one of the waste forms expected to be placed in a nuclear waste repository. As such, its reaction with the various environments it wi11 encounter during 10,000 yr of repository residence must be characterized so that its ability to retard the release of radionuclides can be modeled. Spent fuel cladding, which is an integral part of the spent fuel, will influence the time behavior of spent fuel as a source of radionuclides. The integrity of the cladding will control the access of the oxidizing atmosphere and liquid water to the spent fuel pellets and also provide a barrier to the transport of radionuclides away from the fuel via gaseous or 1 iquid phase mechanisms. Other than fuel oxidation in a breached rod, oxidative corrosion of Zircaloy is the only probable mechanism that would seriously alter the cladding integrity as a result of exposure to the repository environment. (1) For this reason, LLNL, as part of the NNWSI Project, sponsored this Zircaloy cladding corrosion degradation study by the Hanford Engineering Development Laboratory (HEDL).

The NNWSI Project is investigating the suitability of the Topopah Spring Member of the Paintbrush Tuff at Yucca Mountain, Nye County, Nevada, for potential siting of a high-level nuclear waste repository. An evaluation of the projected environments of a tuff repository identified two periods during which corrosion of the Zircaloy might occur, but these conditions are so benign that they only rate consideration because of the hundreds or thousands of years that they may last. (1) Zircaloy cladding will be experimentally tested under the most severe conditions representative of these two environments: (1) exposing the cladding to $\sim 120 \mathrm{lb} / \mathrm{in}^{2}, 170{ }^{\circ} \mathrm{C}$ water in an autoclave, and (2) exposing the cladding to $90{ }^{\circ} \mathrm{C}$ tuff-equilibrated groundwater. Both general corrosion and stress corrosion cracking will be investigated in those environments.

To study the various combinations of environments and corrosion mechanisms, six experiments or tests were planned. The first two, which are complete or now in progress, are scoping experiments designed to produce initial data and 
refine the experimental procedure. This report presents the results from the $90+\%$-stress C-ring stress corrosion cracking scoping experiment and discusses its implications for those experiments now in progress and yet to be started.

Stress corrosion cracking is the failure of a material at stress levels lower than the mechanical strength of the material due to the environment in contact with the material. Often the environment would cause little, if any, measurable bulk corrosion of the material, but when a stress that may be only a fraction of the measured mechanical strength is applied cracks often develop and propagate. Unfortunately, theoretical models of stress corrosion are not good enough to reliably predict the conditions under which a particular material will undergo stress corrosion cracking. For these reasons, it is general practice to fabricate representative specimens of the material and expose them to the extreme environments expected in the service while stressing them to maximum anticipated levels. (2)

Spent fuel cladding, in particular, must be empirically characterized for additional reasons. Because cladding is thin-walled, the cracks in the cladding cannot be analyzed quantitatively by the available fracture mechanics models. The stress intensity factor $K_{I}$ is a theoretical concept relating to the actual stress which develops at the crack tip. It can only be reliably calculated for geometries for which the crack length and the region around the crack tip can completely contain the plastic zone associated with the crack tip. In the case of spent fuel cladding, the crack is believed to be the classic case of a "short crack problem" (see the Appendix). The cladding is too thin to completely contain the plastic zone associated with the crack tip. $(3,4,5)$ Both of these conditions support the empirical approach employed in this scoping study.

Another important factor is the multilayer/multiphase makeup of the spent fuel cladding. As described by Einziger and Kohli, (6) typical cladding consists of an outer layer of $\mathrm{ZrO}_{2}$ and an inner layer of oxygen-saturated, oxygen stabilized $\alpha$-Zircaloy on a substrate of Zircaloy. The inside diameter surface may also be oxygen saturated and include other phases resulting from 
pellet-cladding interaction. The presence of the oxide film has been shown to modify the apparent ductility of Zircaloy-4 in tension, apparently by suppressing the void production process that leads to necking and rupture of the material. (7)

Finally, the surface of the spent fuel cladding was observed to have been scratched during emplacement in the fuel assembly hardware. There are longitudinal grooves running perpendicular to circumferential machining scratches. They are expected to act as stress risers on the surface of the cladding. Some of the experimental samples were observed to crack in these grooves, particularly when the grooves coincide very closely with the maximum stress position on the C-ring.

In summary, C-ring specimens made from actual spent fuel cladding are used for this stress corrosion cracking study so that the many characteristics specific to spent fuel cladding will be included in the experiment. The one drawback in doing this is the small material dimensions of the specimens which make them difficult to model reliably. For that reason, the study was empirically based on parameters such as the yield strength, that were measured directly on sibling cladding specimens. This allowed the relative behavior of the cladding at different stress levels to be clearly demonstrated. Finally, this study was performed in the $90{ }^{\circ} \mathrm{C}$ We11 $\mathrm{J}-13$ water, which is representative of one of the two water environments that might occur in a tuff repository. 
WHC-EP-0096

DO NOT MICROFILM
THIS PAGE 


\section{$3.1 \quad$ GEOMETRIC CONSIDERATIONS}

The C-rings were fabricated from 3/8-in.-long sections of Turkey Point spent fuel cladding ${ }^{(8)}$ by removing a chord section (see Figure 1). Specimens are produced using a slow-speed saw so that the metal texture is essentially unmodified. The C-ring is compressed under a constant load using the weightloaded anvil device described in HEDL-TC-7546. (9) The C-ring deforms as it is squeezed between the anvils in such a way that the outer layers ("fibers") of the "C" stretch, while the inner layers are compressed. Fernandez and Tisinai ${ }^{(10)}$ have analyzed this geometry and have produced a formula that relates the stress produced in the outer (or inner) layers to the load applied to the C-ring. The formula for the tensional stress in the outer surface is given by:

$$
\sigma \mathrm{R}=\frac{4 \mathrm{Ee}}{\pi \mathrm{R}^{2}}\left[\frac{\mathrm{h}_{1} \mathrm{R}}{\mathrm{ea}}-1\right] \quad \delta \sin \alpha
$$

where:

$$
\begin{aligned}
a & =\text { Outside radius } \\
e & =h^{2} / 2 R \\
E & =\text { Elastic modulus } \\
h= & \text { Thickness of the ring material } \\
h_{1}= & (h / 2-e) \\
R= & \text { Inside radius plus one-half the thickness } \\
\sigma R= & \text { Radial tensile stress } \\
\delta= & \text { One-half the vertical deflection of the ring } \\
\alpha= & \text { Angular position on the ring measure from the axis } \\
& \text { of compression. }
\end{aligned}
$$




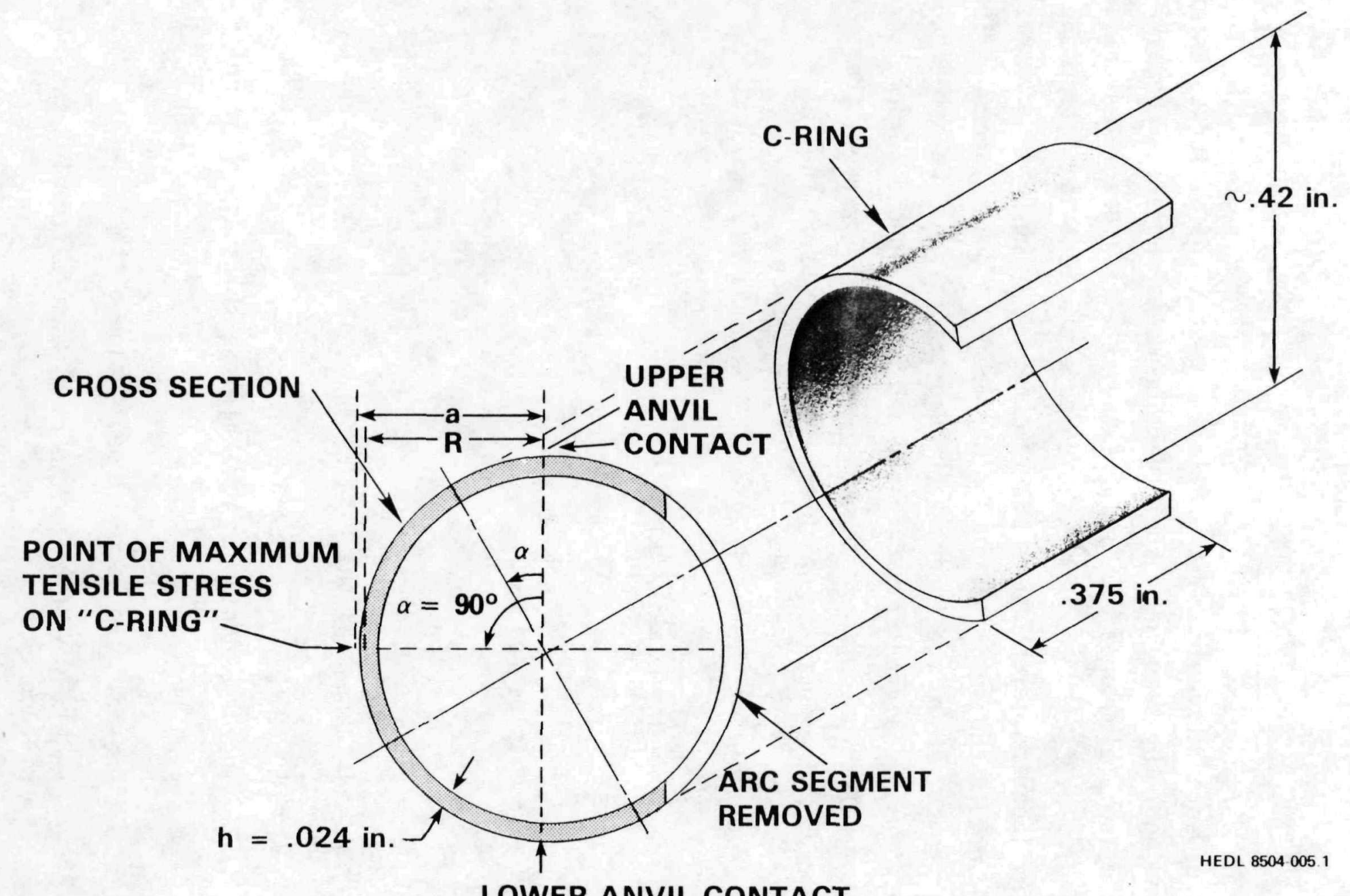

FIGURE 1. "C-Ring" Schematic Drawing Illustrating the Point of Maximum Stress and the Radial Parameters that are Included in the Model of Fernandez and Tisinai for Calculating the Stress at the Outside Surface of the Ring. 
American Society for Testing and Materials (ASTM) Procedure G38-73, (11) "Making and Using C-Ring Stress-Corrosion Test Specimens" is based on this analysis. The C-ring produced from cladding has a smaller diameter than the minimum that ASTM recommends $(0.625 \mathrm{in}$. versus $0.420 \mathrm{in.})$. The smaller diameter results in a lower precision because the resulting displacements are proportionally smaller. This made it more difficult to determine the proportional limit of the spent fuel cladding material.

The stress field in the compressed C-ring varies greatly in the radial direction; from tensile on the surface of the ring, to compression of a similar magnitude on the inside diameter. In the spent fuel cladding $\mathrm{C}$-ring, this takes place over a distance of $\sim 0.024 \mathrm{in}$. Hence, once the $\mathrm{C}$-ring begins to stress-corrosion crack, the stress field will be strongly perturbed (increased) leading to catastrophic cracking as has been observed and is discussed in the results section.

\subsection{SPENT FUEL CLADDING SPECIMENS}

Turkey Point spent fuel cladding from Fuel Assembly B-17, which was discharged in 1975, was used for this study. The C-rings were fabricated from lengths of cladding that were defueled and alpha decontaminated by ultrasonic cleaning and nitric acid washes as described in HEDL-TME $80-85 .{ }^{(8)}$ The C-ring identification numbers used in this study refer to a specific spent fuel rod (i.e., G7 or I9) and position along the rod (i.e., G7-11 or G7- 34 ). The last number refers to the fact that each of the three $\sim 5$-in. rod sections were cut into eleven or twelve $3 / 8-i n$. rings. The $C$-rings were fabricated from these rings by cutting off an arc segment of the ring. This cladding was chosen because it is believed to be generally representative of the bulk of pressurized water reactor (PWR) spent fuel cladding.

The microstructure of the Turkey Point cladding used in this study is the same as other extensively cold-worked, spent-fue1, Zircaloy-4 cladding. Grain boundaries are strongly distorted and, as shown by Lowry et a1., (12) are 
elongated along the axis of the tubing. The texture displayed by the Turkey Point material in cross section perpendicular to the fuel rod axis (see Figure 11) is identical to that shown in Lowry et a1. (12) for "Point Beach" spent fuel cladding, which is also Zircaloy-4. 


\subsection{EXPERIMENT EQUIPMENT}

The background and design of the C-ring apparatus and the scoping experiment is discussed in HEDL-TC-7546. ${ }^{(9)}$ A synopsis is given here.

The C-rings are stressed by a hanging weight in a lever arm (see Figure 2). The weight produces a known load on the anvil that compresses the $\mathrm{C}$-ring, stressing the outside surface of the C-ring. The maximum stress occurs along the line farthest from the line of contact with the anvils. It is important to emphasize the point that this experiment is studying stress corrosion cracking in the outer surface of the cladding, not on the inner surface.

Figure 3 shows the experiment in progress. The $\mathrm{C}$-rings, stressing anvils, and water bath all reside in the oil bath, which is a box-shaped instrument with controls on the front. The numbers on the weights correspond to the experiment position. In the background, the connector panel can be seen; the Linear Variable Differential Transformer (LVDT) and level probe, which controls the water level in the water bath, connect to cables visible to the right of the apparatus. All of the equipment in the photograph is currently located in a hot ce11. The cables penetrate the hot cell wal1 and connect with LVDT signal conditioners, solenoid water valve, and thermocouple readout. The LVDT and thermocouple output are being recorded by a data logger.

The water bath and anvils are constructed from 304L SS. Spring clips that hoid the C-ring specimens in place are made from 302 SS spring wire. A 1-mi1 thick Kapton* polyimide tape with a silicone adhesive was used to insulate the C-ring specimens at the anvil and spring contacts. The water bath level was maintained using a Dyna-Sense* level sensor that opened and closed a solenoid (brass) valve that controlled the water feed to the water bath. The water reservoir was a 5-gal polyethylene/polypropylene jug outside the hot ce11. The water bath is fed from the reservoir through a Tygon* tube to a

* Kapton is a trademark of E.I. duPont de Nemours and Company. *Dyna-Sense is a trademark of Scientific Instruments, Inc.

*Tygon is a trademark of the Norton Company. 


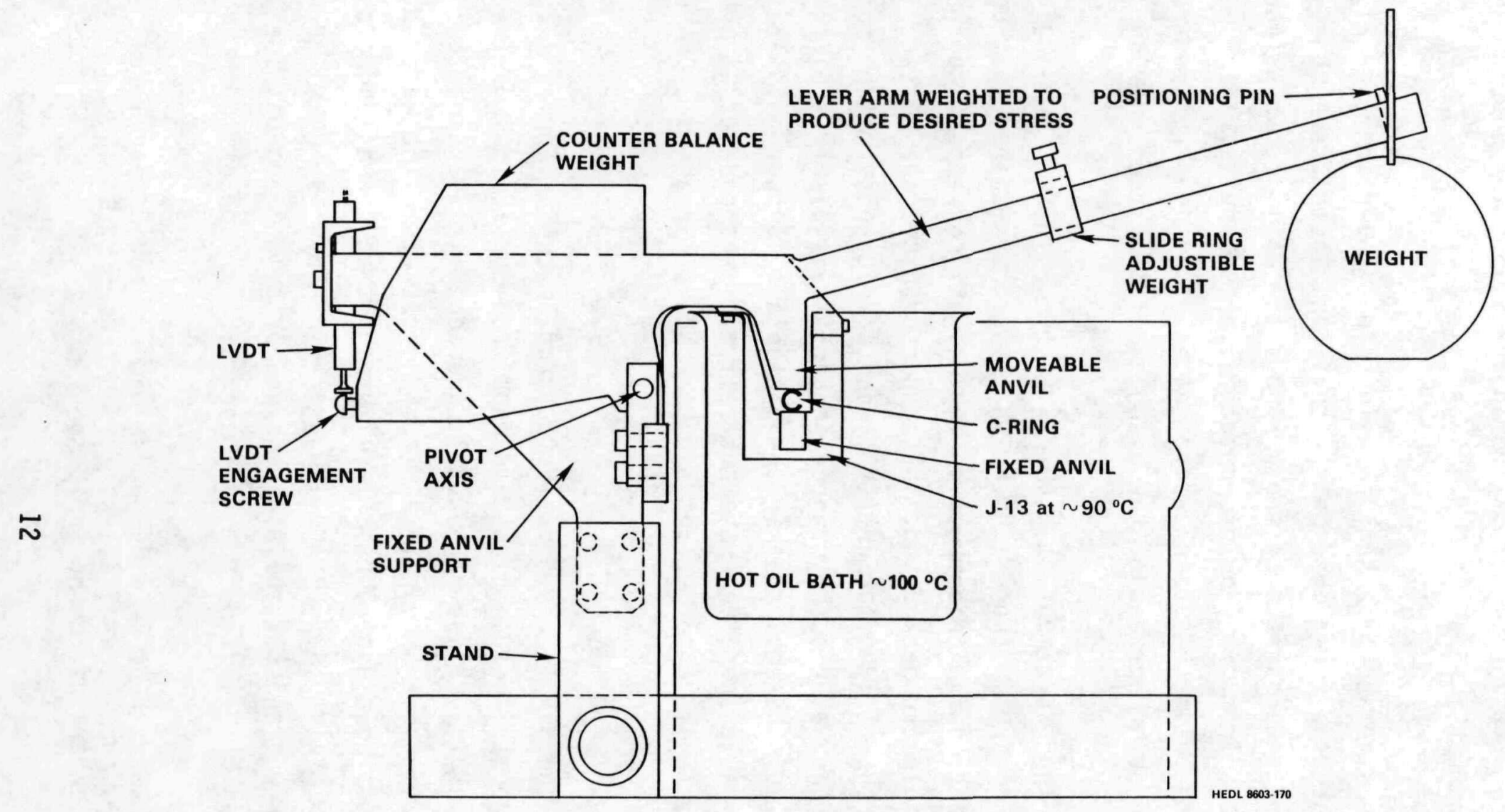

FIGURE 2. Schematic Cross Section of the "C-Ring" Stress Corrosion Cracking Experiment Apparatus with the Anvils in Position Stressing a "C-Ring" Specimen. (Note: The temperature in the water bath is less than the oil bath because of water evaporation and conduction heat loss.) 


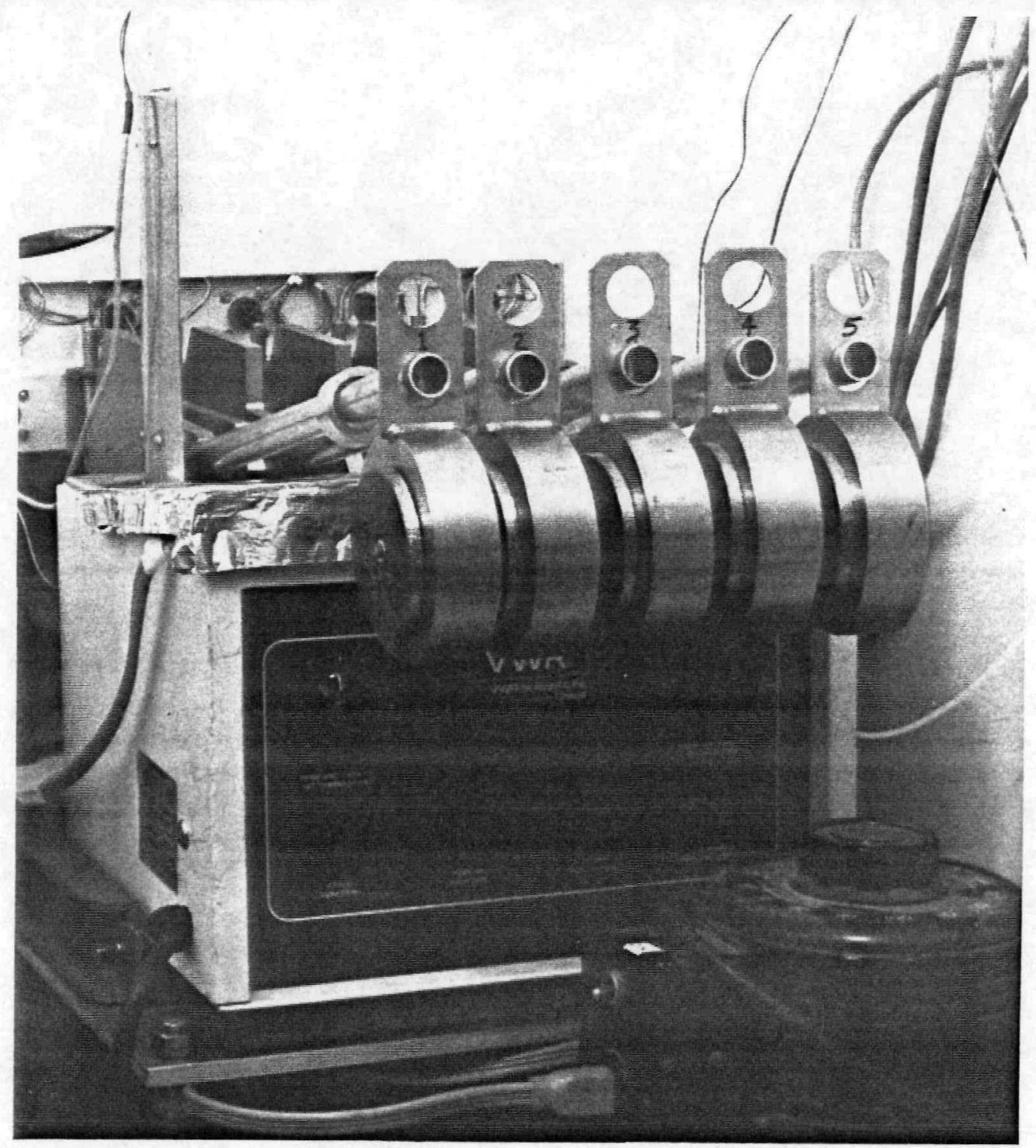

FIGURE 3. "C-Ring" Stress Corrosion Scoping Experiment Apparatus in Operation. (Each position holds a "C-Ring" (not visible) which is covered by wel1 $\mathrm{J}-13$ water at $-90{ }^{\circ} \mathrm{C}$ and stressed to $-140 \mathrm{ksi}$ at the outside diameter of the specimen.) 
stainless steel shutoff valve through the brass solenoid valve, then through a 1/8-in. medical-grade polyethylene tube to a 304 SS fill tube that actually delivers the water to the water bath. 


\subsection{EXPERIMENTAL APPROACH}

The objective for this scoping experiment is to establish a stress versus time-to-failure (via stress corrosion cracking) relationship for typical spent fuel cladding. The first stage was to determine the approximate yield strength of the cladding so that stress levels for the experiment could be chosen in order to produce stress corrosion cracking and not plastic deformation. This was done by determining an elastic limit for a number of C-ring specimens. Once the elastic limit(s) were established, stress corrosion cracking experiments were performed at known fractions of the previously determined elastic limit (i.e., the $90 \%$ to $98 \%$ stress level experiments that were presented as part of this report).

In addition to the work with spent fuel cladding, the elastic limit and approximate elastic coefficient of a specimen of unirradiated Zircaloy and a we11-characterized 316 SS were determined. This was done to demonstrate the ability of the apparatus to produce data consistent with the properties of well-characterized materials and $\mathrm{place}$ in perspective the values determined for the irradiated spent fuel cladding.

\subsection{AN EMPIRICAL DETERMINATION OF THE ELASTIC PROPERTIES}

The elastic limit is the deformation limit that a material can experience without exhibiting a permanent change of shape. Lowry et al. (12) have made measurements on similar irradiated and unirradiated Zircaloy cladding; however, their measurements were primarily concerned with axial directions in the cladding, while the C-rings in this experiment are stressed in the circumferential direction with the outside diameter (0.D.) in tension when the C-ring is compressed. This may be important because the texture of the cladding is strongly anisotropic with the crystal grains elongated along the axis of the cladding. This difference in texture may influence the elastic/ plastic behavior of the material. Therefore, the empirical determination for cladding described below was carried out. 
The elastic limit of a series of $C$-ring specimens was determined from a plot of $\mathrm{C}$-ring diameter versus stress. This was produced by mounting the rings in the C-ring apparatus (see Figure 2) and cycling them to higher and higher stress. Figures 4 through 7 illustrate the results of this procedure for several Turkey Point cladding samples and a specimen of unirradiated Zircaloy. In these figures, the unloaded (unstressed) position of the specimen has been plotted as a function of the stress level that the sample had experienced during the previous cycle. In each case, the plot begins with an approximately linear trend that slopes gently downward and is believed due to deformation of the Kapton tape, insulating the anvils and to "machine drift" in response to the load. (This phenomenon was also observed when using incompressible thick-walled steel tubing or bar-stock specimens.) At some stress leve1, the plot deviates from the gentle linear slope and this is interpreted as the onset of plastic deformation in the C-ring. A linear regression on the linear portion of the plot (below $-130 \mathrm{ksi}$ irradiated and below $\sim 50 \mathrm{ksi}$ unirradiated Zircaloy) was made. Note that the spent fuel cladding has been irradiated to a level where the yield strength is very close to the ultimate strength. The point at which the plot first deviates from the linear trend is taken as the elastic limit. Table 1 contains the elastic limit determined by this procedure.

As expected, the stress-strain slopes were identical for irradiated and unirradiated material as shown in Figure 8, again indicating a consistency in the results obtained using the C-ring apparatus. As an independent check, this procedure was repeated using a well-characterized material to see how well the apparatus reproduced values determined by other methods. A 316 SS Alloy D9-C1 was selected because well-characterized tubing specimens of an appropriate diameter ( 0.330 in. $x 0.370$ in.) were available for C-ring fabrication. The above procedure was repeated on seven $\mathrm{C}$-rings of this material. The "unload position versus stress" plots for these rings are shown in Figure 9. (One plot shows a large step because it was loaded too rapidly, causing excess plastic deformation during that cycle.) All rings gave very similar plots, and the elastic limit determined from them compares well with the elastic limit and elastic modulus determined by standard techniques as can be seen in Table 2 . 


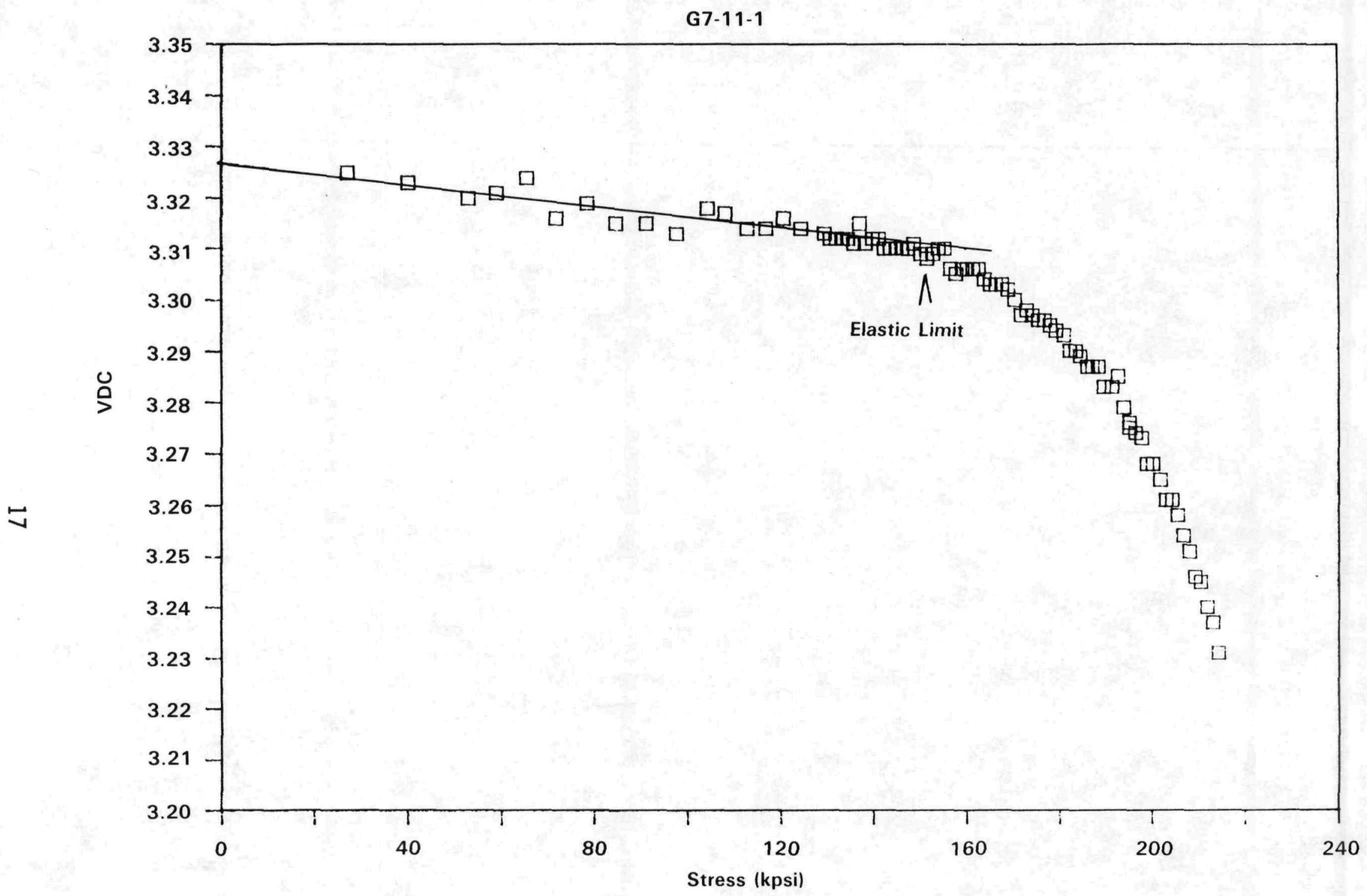

FIGURE 4. Elastic Limit Curve for Turkey Point Spent Fuel Cladding Specimen G7-11-1. (Pointer indicates estimated limit at $\sim 152 \mathrm{kpsi}$. The sloping straight line represents the purely elastic response. $V D C=$ volt $D C$ and .020 volts $D C$ is equivalent to a $1 \mathrm{mil}$ change in diameter of the C-ring.) 


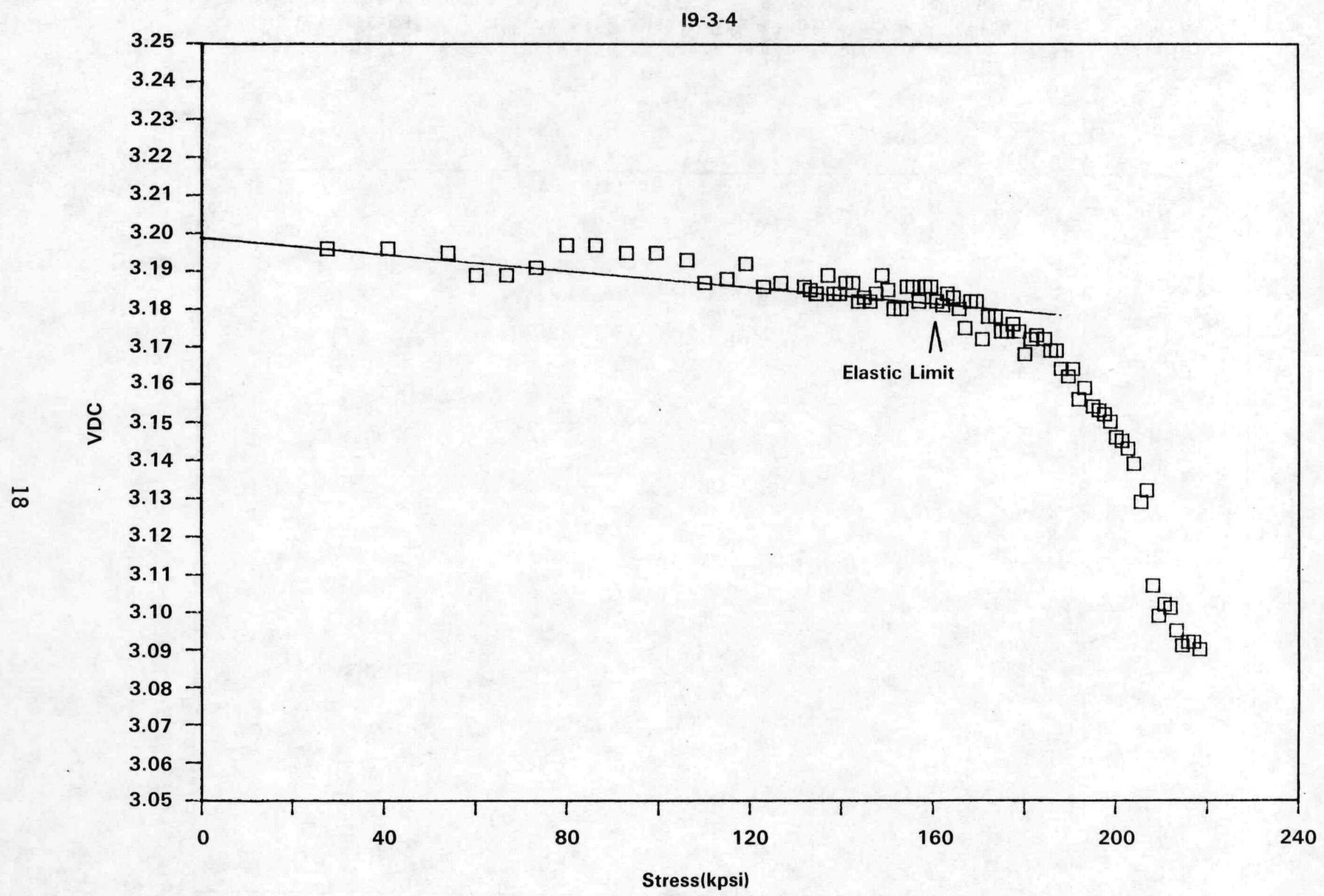

FIGURE 5. Elastic Limit Curve for Turkey Point Spent Fuel Cladding Specimen 19-3-4. (Pointer indicates estimated limit at $\sim 160 \mathrm{kpsi}$.) 


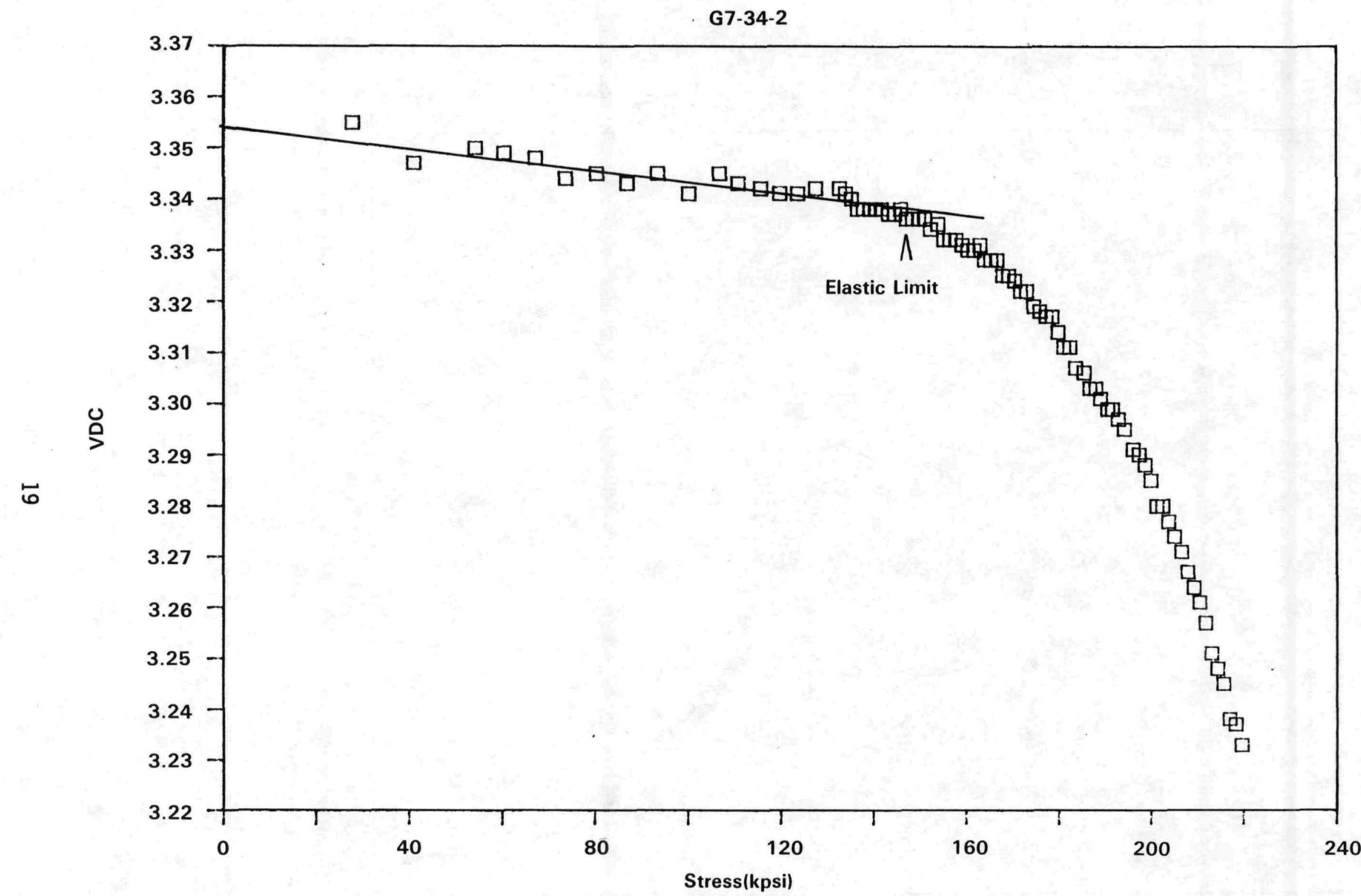

FIGURE 6. Elastic Limit Curve for Turkey Point Spent Fuel Cladding Specimen G7-34-2. (Pointer indicates estimated limit at -147 kpsi:) 


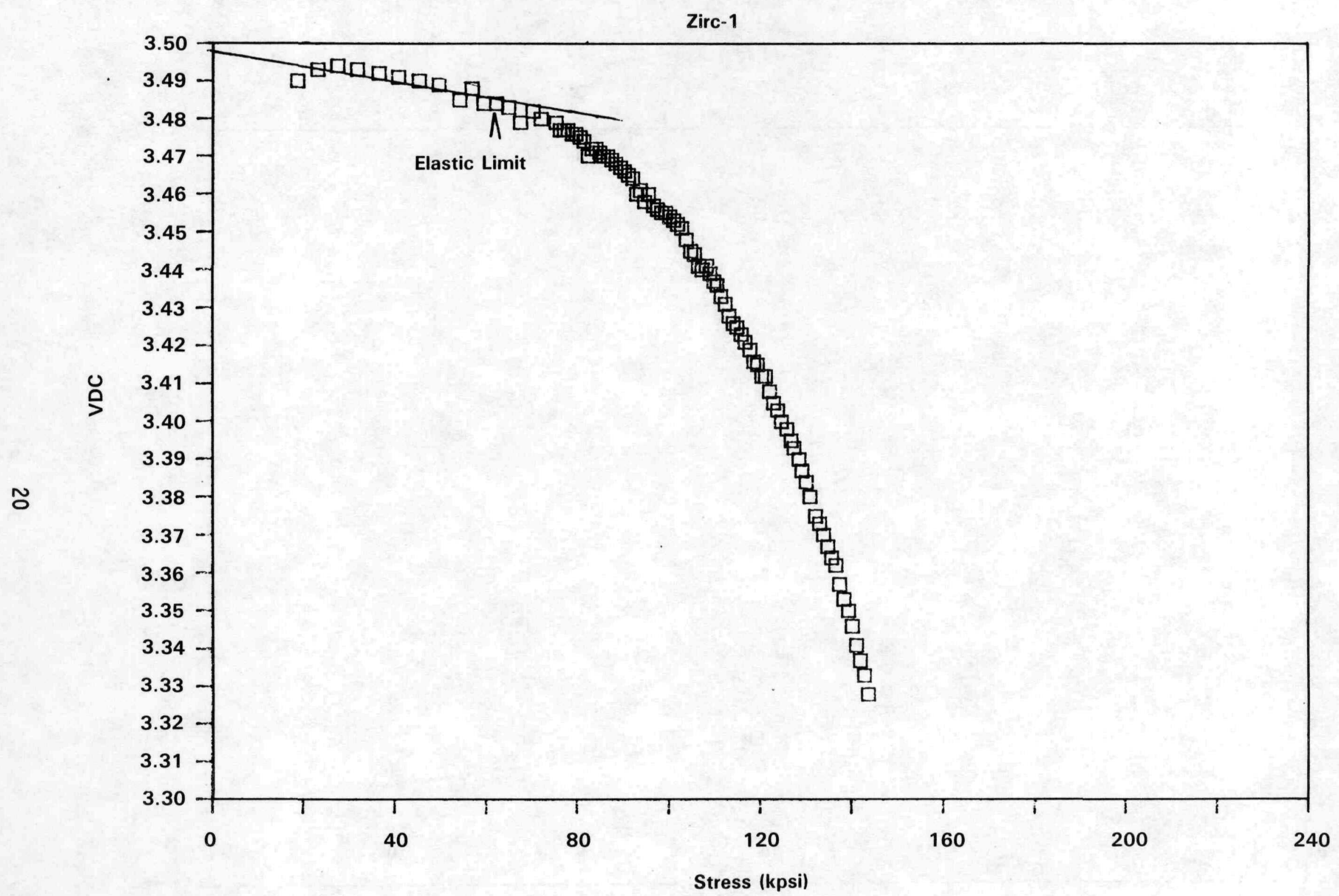

FIGURE 7. Elastic Limit Curve for an Unirradiated Zircaloy-4 Specimen ZIRC-1. (Pointer Indicates Estimated Limit at $\sim 62 \mathrm{kpsi}$.) 


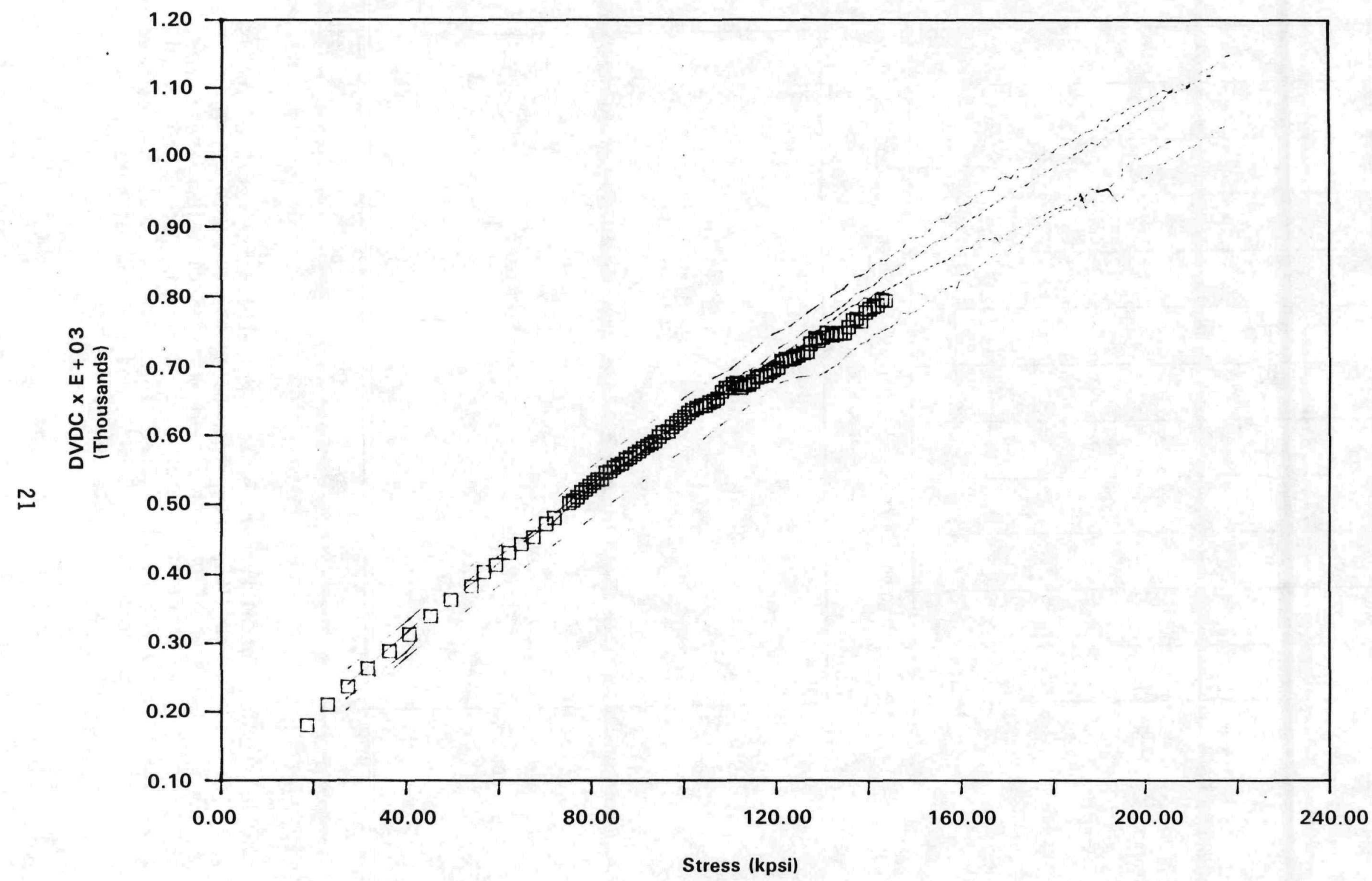

FIGURE 8. Observed Stress-Strain Curves for Turkey Point Spent Fuel Cladding Specimens (1 ines) and for As-Formed Unirradiated Zircaloy-4 Cladding (squares). (They appear to be identical.) 
(a)
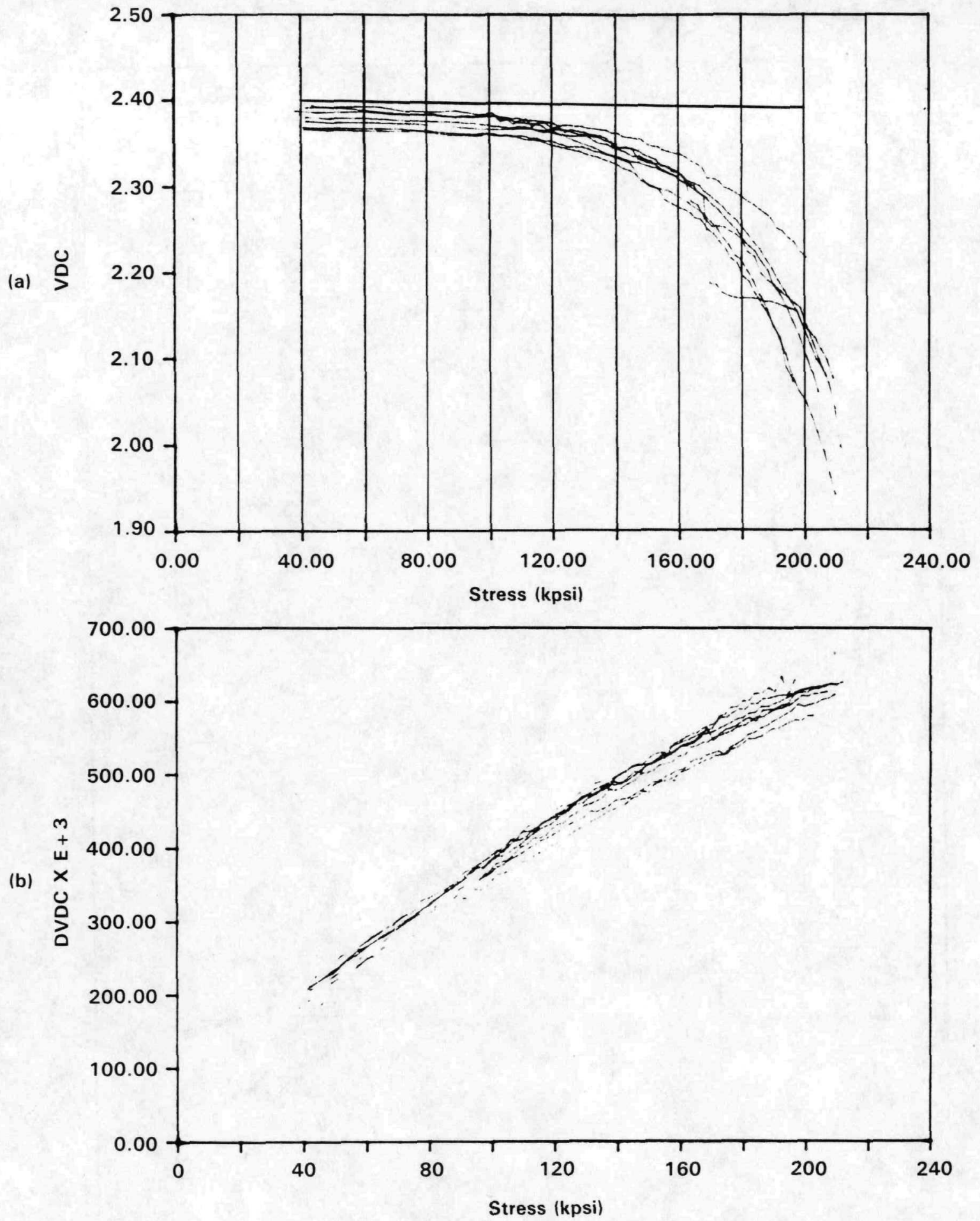

FIGURE 9. Mechanical Properties of a Well-Characterized 316 Type SS (HEDL TC-2185) Determined Using the C-Ring Apparatus

(a) Proportional or Elastic Limit Indicating Stress Level at Which Plastic Deformation Begins to Occur; an Approximation to the Yield Stress; (b) Stress-Strain Curves Give an Estimate of the Elastic Modulus. Results for Seven Specimens are Plotted on Each Graph. 
TABLE 1

ESTIMATED ELASTIC LIMIT STRESS

\begin{tabular}{|c|c|c|c|}
\hline $\begin{array}{c}\text { C-Ring } \\
\text { Inside Diameter }\end{array}$ & & $\begin{array}{l}\text { Calculatec } \\
\text { Estimated }\end{array}$ & $\begin{array}{l}\text { Stress at } \\
\text { lastic Limit }\end{array}$ \\
\hline $\begin{array}{l}\text { G7 }-34-4 \\
\text { G7 }-34-3 \\
\text { G7 }-34-2\end{array}$ & $\begin{array}{l}\text { Thick } \\
\text { oxide film } \\
(\sim 10 \mu \mathrm{m})\end{array}$ & $\begin{array}{l}147 \mathrm{ksi}^{*} \\
149 \mathrm{ksi} \\
147 \mathrm{ksi}\end{array}$ & $\begin{array}{l}\text { av } 148 \mathrm{ksi} \\
\pm 1(1 \sigma)\end{array}$ \\
\hline $\begin{array}{l}\text { G7-11-3 } \\
\text { G7-11-1 } \\
\text { I9-3-4 } \\
\text { I9-3-1 }\end{array}$ & $\begin{array}{l}\text { Thin } \\
\text { oxide film } \\
(3-5 \mu \mathrm{m})\end{array}$ & $\begin{array}{ll}160 & \mathrm{ksi} \\
152 & \mathrm{ksi} \\
160 & \mathrm{ksi} \\
150 \mathrm{ksi}\end{array}$ & $\begin{array}{l}\text { av } 156 \mathrm{ksi} \\
\pm 5(1 \sigma)\end{array}$ \\
\hline Zirc-1 & Film $(-100 \AA)$ & $62 \mathrm{ksi}$ & \\
\hline
\end{tabular}

TABLE 2

A COMPARISON OF ELASTIC LIMIT AND ELASTIC COEFFICIENT FOR A 316 SS USING THE C-RING APPARATUS WITH PUBLISHED VALUES

\begin{tabular}{|c|c|c|c|}
\hline Specimen & $\begin{array}{c}\text { Elastic Limit } \\
\text { (kpsi) }\end{array}$ & $\begin{array}{l}\text { Young's Modulus } \\
\left(10^{6} \mathrm{lb} / \mathrm{in}^{2}\right)\end{array}$ & $\begin{array}{l}\text { Published } \\
\text { Yield Strength } \\
\text { Yield }\end{array}$ \\
\hline $\begin{array}{l}\text { HDS-1 } \\
\text { HDS-2 } \\
\text { HDS-3 }\end{array}$ & $\begin{array}{r}106 \\
116 \\
99\end{array}$ & $\begin{array}{l}29.7 \\
28.4 \\
29.4\end{array}$ & $\begin{array}{l}690-700 \mathrm{MPA} \\
100-102 \mathrm{kpsi}\end{array}$ \\
\hline HDS-4 & 99 & 29.9 & $\begin{array}{l}\text { Published } \\
\text { Young's Modulus } 14\end{array}$ \\
\hline $\begin{array}{l}\text { HDS }-5 \\
\text { HDS-6 } \\
\text { HDS-7 }\end{array}$ & $\begin{array}{l}109 \\
101 \\
102\end{array}$ & $\begin{array}{l}30.2 \\
28.4 \\
26.7\end{array}$ & \\
\hline $\begin{array}{l}\text { AVERAGE } \\
( \pm 1 \sigma)\end{array}$ & $\begin{array}{l}104.6 \\
\pm 6.2\end{array}$ & 29.0 & $28.4 \times 10$ \\
\hline
\end{tabular}


The elastic coefficient was determined from the slope of the stress-strain curve shown in Figure 9 (b) over the $\sim 40$ to $80 \mathrm{ksi}$ stress range using the formula for the elastic coefficient for the C-ring configuration and a $12 \%$ thin sheet correction (i.e., the "stiffness" of a thin, wide plate is about $12 \%$ greater than a narrow bar). (14) Again, the measured elastic coefficient is close to that found by standard techniques reported in the literature (see Table 2).

\subsection{CHOOSING EXPERIMENT STRESS LEVELS}

Based on the elastic limit determination, the Turkey Point cladding C-rings with the thicker-oxide film (G7-34 series) displayed an estimated elastic limit of $148 \mathrm{ksi}$, while those with the thinner oxide film (G7-11 and I9-3 series) had an estimated elastic limit of $156 \mathrm{ksi}$ (see Table 1). The experiments were intended to begin at stress levels within $10 \%$ of the elastic 1 imit, so that cracking might occur in a relatively short time and then progressively lower stress. levels in small increments so that the stress level versus time to cracking failure dependence could be determined empirically.

The stress levels that were actually used in these experiments are given in Table 3. The differences in the length of the C-ring specimens resulted in much of the variation of stress levels employed in these experiments. Two experimental runs, one at an anvil force of $27.5 \mathrm{lb}$ and the second at $26.5 \mathrm{lb}$ were performed with "thick oxide" C-rings. The calculated stress is determined from the formula given earlier:

$$
\sigma=5081 \mathrm{lb} / \mathrm{in}^{2} / 1 \mathrm{~b} \times \text { anvil force }(1 \mathrm{~b}) \times \frac{0.375}{\text { C-ring length }} .
$$


TABLE 3

$90+\%$ STRESS LEVEL EXPERIMENT SPECIMENS

Ring Anvil Calculated Avg. Elastic Average Elastic Specimen Length Force Stress (ksi) Limit (ksi) Limit (\%)

THIN OXIDE

G7-11-4

G7 $-11-6$

I9-3-6

0.379

0.370

0.366

27.5

27.5

27.5

THICK OXIDE

G7-34-5 0.365

G7-34-6 $\quad 0.369$

G7-34-7 0.372

G7-34-8

0.372

27.5

27.5

26.5

26.5

"DRY" THIN OXIDE

G7-11-7

0.363

I9-3-7
27.5

27.5
138

142

143

144

142

136

136

144

144
156

156

156

148

148

148

148

156

156
88.6

90.7

91.8

97.3

95.9

91.9

91.9

92.5

92.0 
WHC-EP-0096

DO NOT MICROFILM THIS PAGE 


\subsection{THE $90 \%+$ STRESS LEVEL EXPERIMENTS}

Properly insulated C-rings (see Table 3 ) were clipped to the upper anvil of the C-ring stressing apparatus, then lowered into position onto the lower anvil in the water bath. The water bath had been prefilled with Well J-13 water and brought up to a temperature of $90^{\circ} \mathrm{C} \pm 2{ }^{\circ} \mathrm{C}$. Finally, the loading weight was gently placed on the lever arm of the C-ring apparatus (see Figure 2). At this point, the experiment was in progress.

The experiment was continually monitored by a thermocouple in the oil bath, a thermocouple in the water bath, and by LVDTs that indicated the position of the upper anvil (any changes in the C-ring diameter) to less than 0.001 in. In addition, a Dyna-Sense water-level sensor operated the bath refill system which maintained the level of the water bath to within $1 / 4$ in. The $C$-rings were thus always fully submerged. The thermocouple readings and LVDT voltages were continually recorded on a data logger. The water chemistry was monitored periodically and measured for anions, cations, $\mathrm{pH}$, and carbon to determine the consistency of the Well J-13 water chemistry. Certain components tended to precipitate, resulting in loss of certain elements (see Table 4). An attempt to compensate for this loss was made by refilling the tank with fresh Well J-13 water. As can be seen from Table 4, this increased the concentrations of all the species analyzed, but they clearly decreased again after only $7 \mathrm{~d}$. It appears that the white deposit observed forming above the water level on the wall of the water bath tank acted as a sink for these elements, i.e., even soluble components appear to be deposited above the high water line in the bath, thereby being removed from solution with the insoluble. This will probably be an ongoing problem during this experiment and it will be counteracted by refilling the bath more frequently with fresh Well J-13 water. At other times, the water level in the tank was maintained with deionized water (18 $\mathrm{m} \Omega)$. 


\section{TABLE 4}

\section{OBSERVED WATER CHEMISTRY DURING THE C-RING} STRESS CORROSION CRACKING EXPERIMENTS

Accumulated Time (d) Initial $\mathrm{J}-13$

9
24
36
42
49
56
64
70

Organic $C$ $\mathrm{pH}(\mathrm{pm})$

7.3

9.75

8.57

8.13

8.30

8.82

8.72

6.86

7.44
7.0

$--$

26.6

$--$

30.5

54.9

-.

44.0

45.4
$\mathrm{Na}^{+}(\mathrm{pm})$

49.5

30

18

7.23

7.09

$22.3^{*}$

20.4

12.0

11.0
$\mathrm{Cl}^{-}(\mathrm{pm})$

$\underline{F^{-}(p m)} \quad \underline{S O}_{4}=(\mathrm{pm})$

7.3
7.2
2.04
3.13
1.93
7.10
4.59
3.30
2.80

\section{7}

1.38

0.56

0.59

0.53

1.23

1.37

1.30

1.30
19

58

6.9

4.4

3.0

8.7

6.0

3.9

3.63

*Water bath refilled with fresh Well J-13 water on Day 43.

During each water level adjustment, the temperature dropped about $5{ }^{\circ} \mathrm{C}$, but recovered in about 5 to $7 \mathrm{~min}$. The "saw-tooth" temperature profile observed in both the oil and water baths is shown in Figure 10. Figure 10 also shows a typical LVDT signal trace for Specimen G7-34-8 as it was beginning to show signs of cracking. Each division on the graph equals $5 \mathrm{mV}$; therefore, during the 6 -h period shown in the figure, the ring compressed far enough to change the signal about $3 \mathrm{mV}$; equivalent to $0.15 \mathrm{mil}$. The precision based on the signal noise width appears to be about $2 \mathrm{mV}( \pm 0.1 \mathrm{mil})$. 


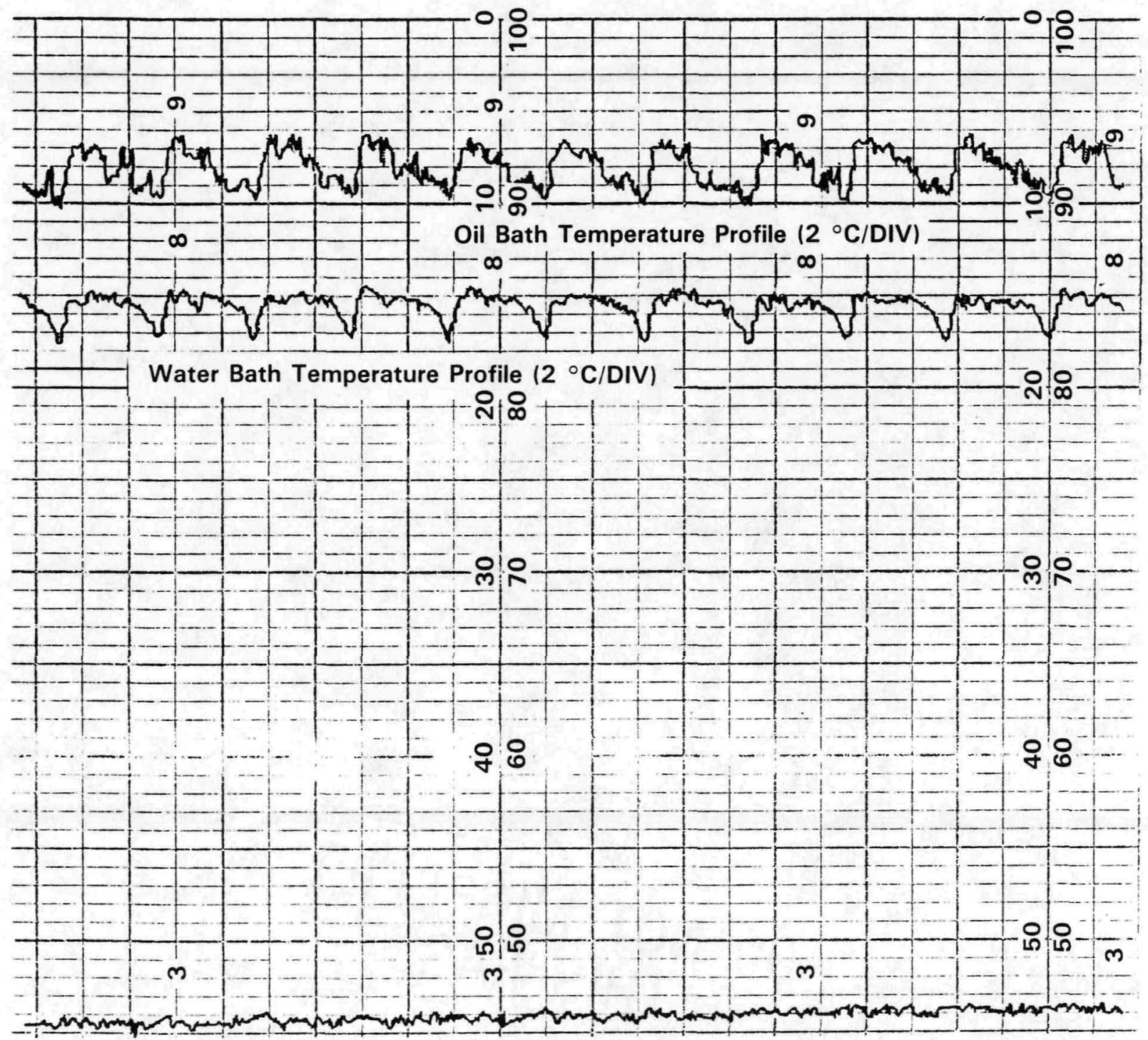

LVDT Voltage Profile Indicating Position of Anvil Compressing C-Ring (5 MV/DIV)

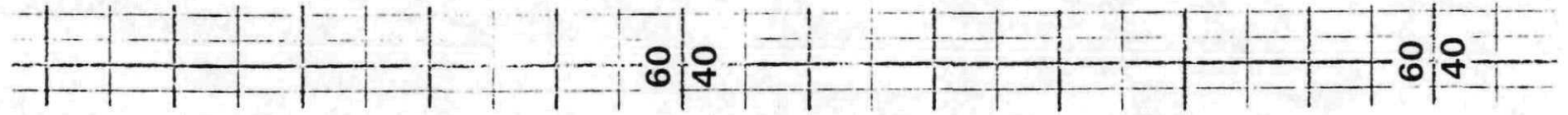

FIGURE 10. Typical Six Hours of Data Recorded by the Datalogger. (The cyclic temperature profiles for both the oil and water baths clearly reflect the periodic refilling of the water bath. Channel 3 is recording the response of specimen G7-34-8 which is beginning to show signs of increased cracking rate. Time flows from right to left.) 


\section{O NOT MICROFILM DO NOT MHS PAGE}




\section{$7.0 \quad$ EXPERIMENT RESULTS}

The observed "C-ring" diameter as a function of time under stress for each C-ring is listed in Table 3, and shown in Figures 11 and 12 . The decrease in diameter (mils) has been plotted so that the small variations in zero signal level from station-to-station and sample-to-sample are removed. The plot for Sample G7-11-6 was translated to $-5 \mathrm{mil}$ because of the noisiness of the signal from that signal conditioner. (It was demonstrated it was the signal conditioner by changing signal conditioners from station to station.) The noise was due to day-night variations in line voltage. This variation could be detected on two other conditioners also. However, even in the worst case ( $0.5 \mathrm{mil})$, the measurement was adequate for what it was originally intended, an indication of when and how rapidly the C-ring deflected during stress corrosion cracking.

Each response-to-stress curve in Figures 11 and 12 appears to consist of three periods. First, there is an initial "relaxation" which may represent an initial machine drift, seating of the sample into the Kapton insulation and/or a small amount of plastic deformation in the C-ring that allows internal stresses to homogenize in the metal. The second is a period of very slow change during which actual cracks are initiated and grow slowly. The third and final period appears to be a time during which the cracks grow with ever-increasing speed until finally the actual stress in the C-ring greatly exceeds the yield stress, resulting in the rapid collapse of the ring.

During the course of the experiment, step changes in the indicated diameter of the C-ring were sometimes observed, but in every case, a contributing cause could be identified (i.e., when Specimen G7-34-5 broke at $\sim 630 \mathrm{~h}$, the shock caused Specimens G7-34-6 and G7-11-4 to compress a few mils).

Specimen G7-11-4 appeared to expand slightly when Specimen G7-34-6 was taken off the experiment at about $680 \mathrm{~h}$, but appeared to compress again when Specimens G7-34-7 and G-34-8 were included in the experiment (see Figure 11). In each case, the apparatus appeared to be responding to the decrease or increase of stress as lever arms were unloaded and reloaded. Those traces 


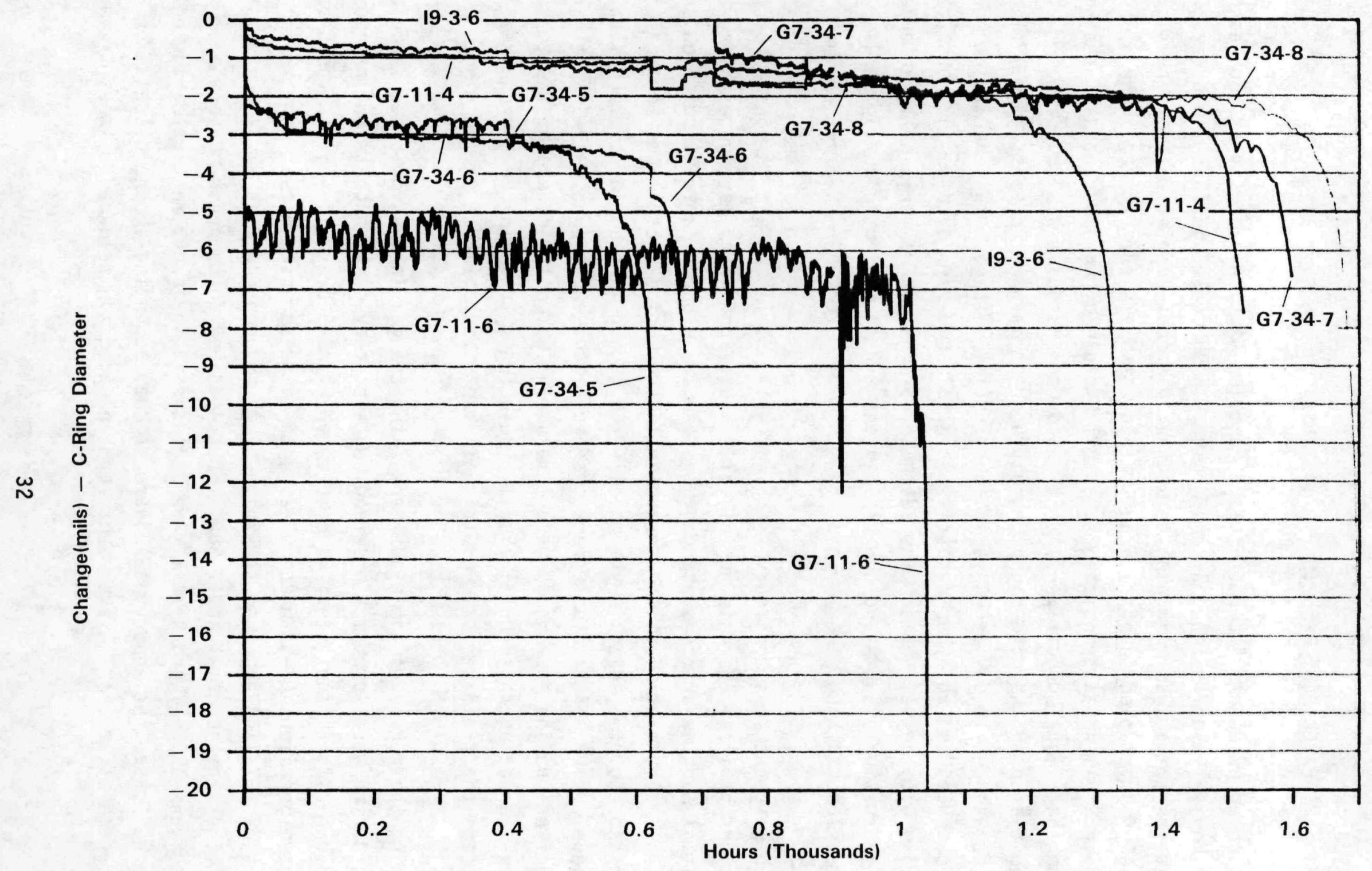

FIGURE 11. Change in Diameter as a Function of Time for Each of the Seven C-Rings that were Stressed in the Presence of Well "J-13" Water. (Noisy channel (G7-11-6) was translated to -5 mils. Specimens G7-34-7 and G7-34-8 were started at $\sim 717$ hours.) 


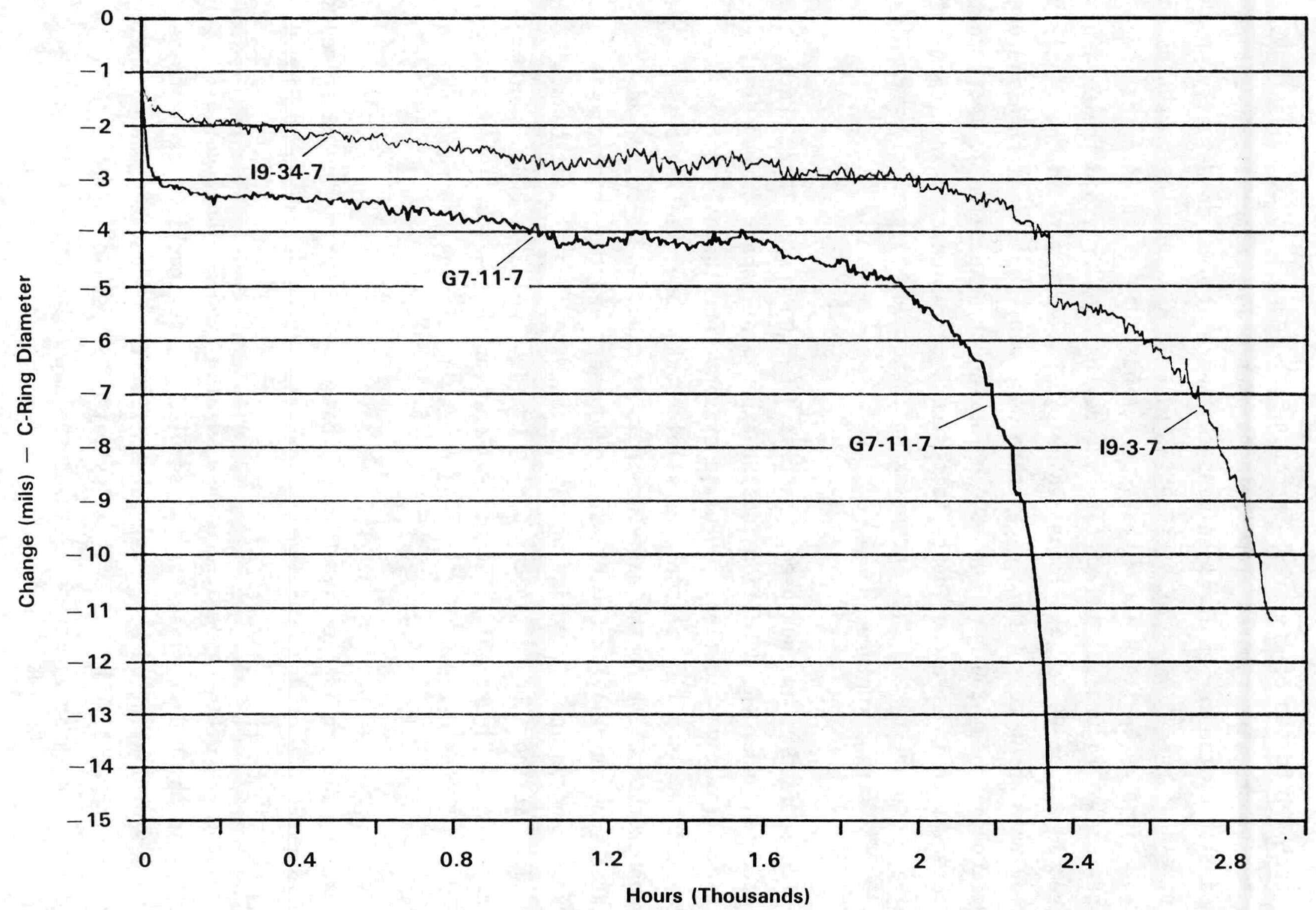

FIGURE 12. Change in Diameter as a Function of Time for Each of the Two C-Rings that were Stressed in the Presence of Hot Cell Air. (See Figure 11. Note discontinuity in profile for specimen 19-3-7 occurred when G7-11-7 broke.) 
that reach the bottom of the graph represent specimens that actually broke while the others were removed from the apparatus prior to actually breaking. A comparison of the curves for specimens that were allowed to actually break and those that were stopped prior to breaking indicate that the unbroken, but cracked, rings were within a few hours to one-half day of breaking completely. A comparison of Figures 11 and 12 also showed that not only did the $C$-rings stressed in air at $90^{\circ} \mathrm{C}$ take longer to crack, but they were in the final cracking mode about four times longer than comparable specimens stressed under the wet conditions ( $200 \mathrm{~h}$ versus $\sim 800 \mathrm{~h}$ for the dry experiment). Note that this observation is strong evidence that stress corrosion cracking (chemical process) is occurring and that the cracking is not due to a purely mechanical failure like stress rupture.

The outer surface of an unexposed, unstressed C-ring and one that cracked but did not break under the conditions of the experiment appear to be essentially the same at low magnification. On close examination, the only difference between the two is a line of small parallel cracks about halfway between the two ends of the "C" where the maximum stress is expected to occur, as indicated schematically in Figure 13. The "break" and the cracking was observed to occur in this region on all of the experimental specimens. The schematic also shows how a typical C-ring was sectioned for post-experiment examination (see Figure 13). The central section that was believed to contain most or all of the cracking was removed by sawing off the top and bottom of the "C".

The cracking pattern in the five C-rings that cracked during the experiments but were taken out of the experiment before they broke are shown in Figure 14 . In the four cases from the wet environment, the cracks are observed to be very straight and are often associated with a scratch running longitudinally (parallel to the rod axis) across the sample. These cracks appeared to be in the process of linking up by "shear zones" that formed between the ends of the straight cracks. This is well illustrated by Specimen G7-34-6 shown in Figure 15. The shearing movement causes the zirconium oxide film on the 


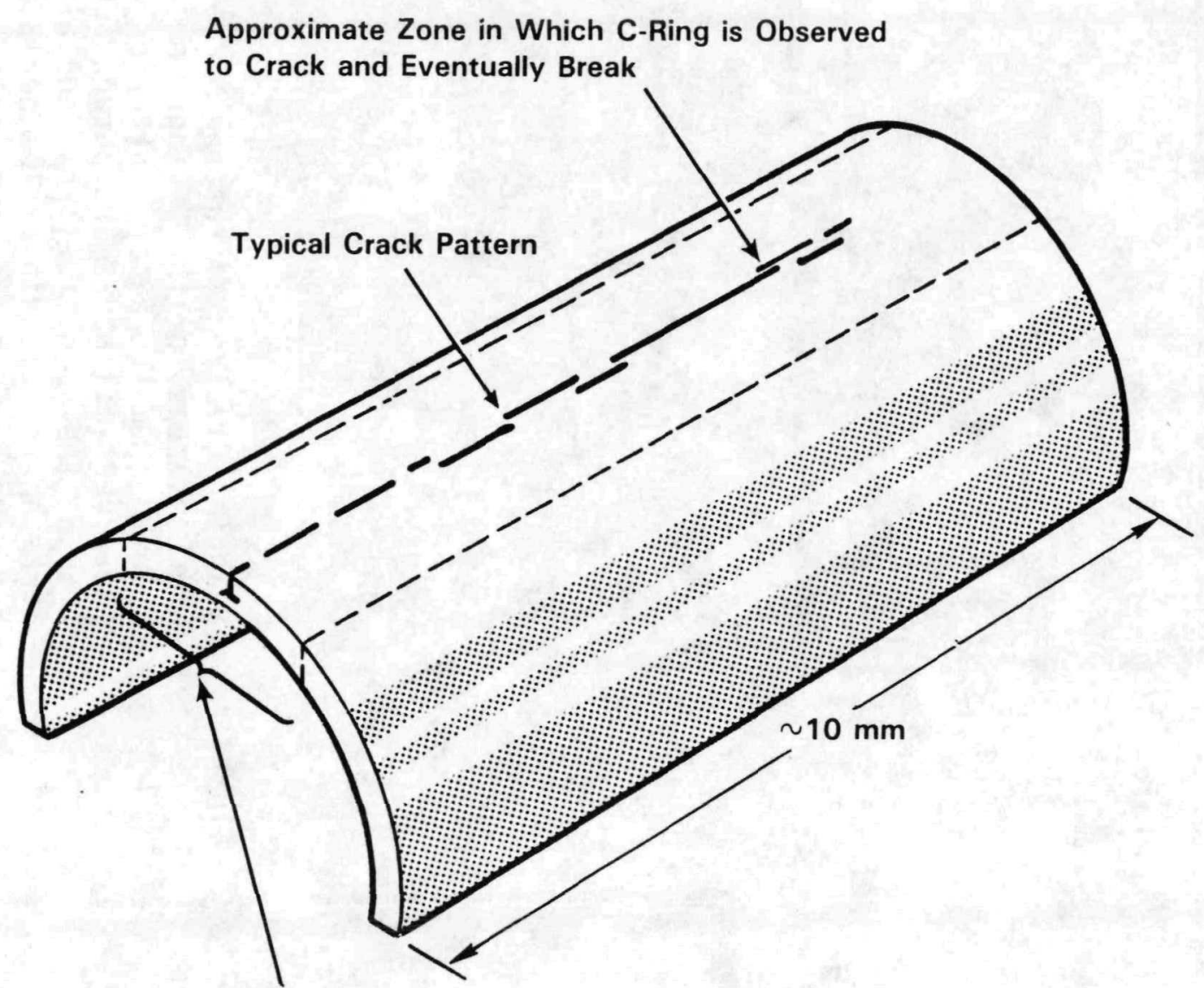

Section Removed for SEM and

Metallographic Evaluation After

SEM Evaluation, the Sample Cross-

Sectioned in the Center and

0.040 in. in from Each End.

Metallography Applied to:

- Fracture Cross-Sections

- Crack Cross-Sections

SEM Applied to:

- Crack Pattern on Outside Surface

- Fracture Surface on C-Rings That Broke Completely

HEDL 8705-015.1

FIGURE 13. Schematic Diagram of a C-Ring after the Experiment Showing a Typical Cracking Pattern and the Area Sampled. 


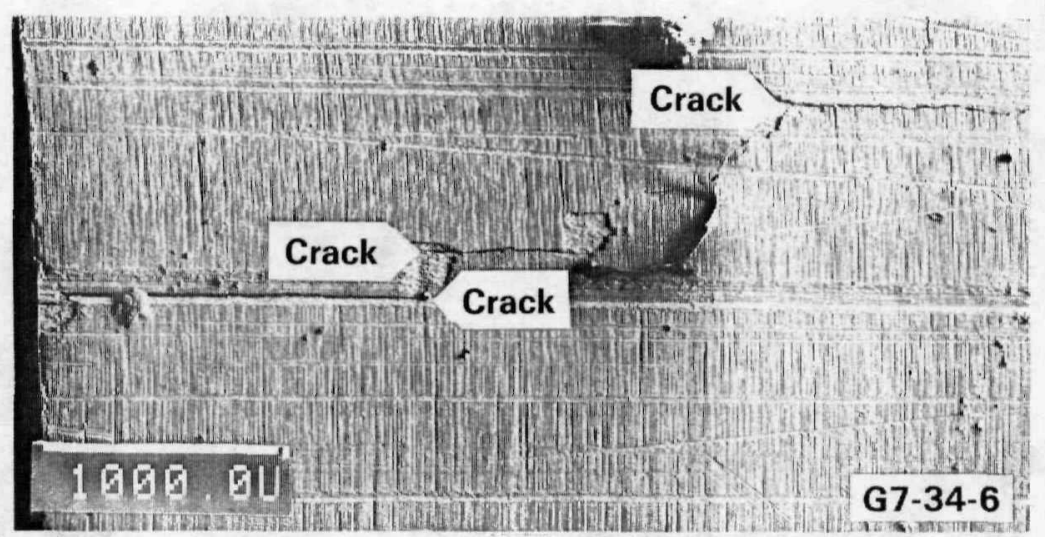

$\stackrel{\omega}{o}$
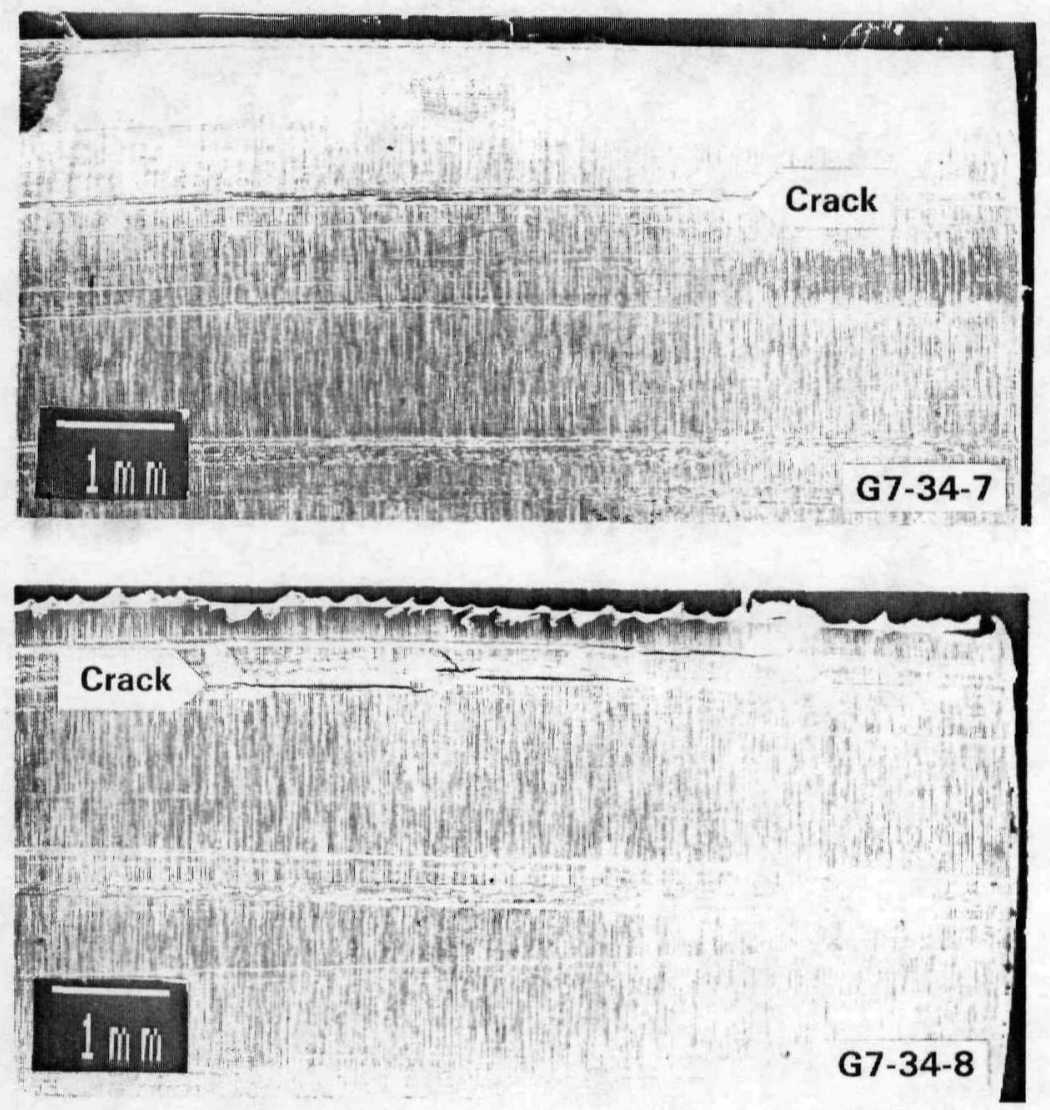
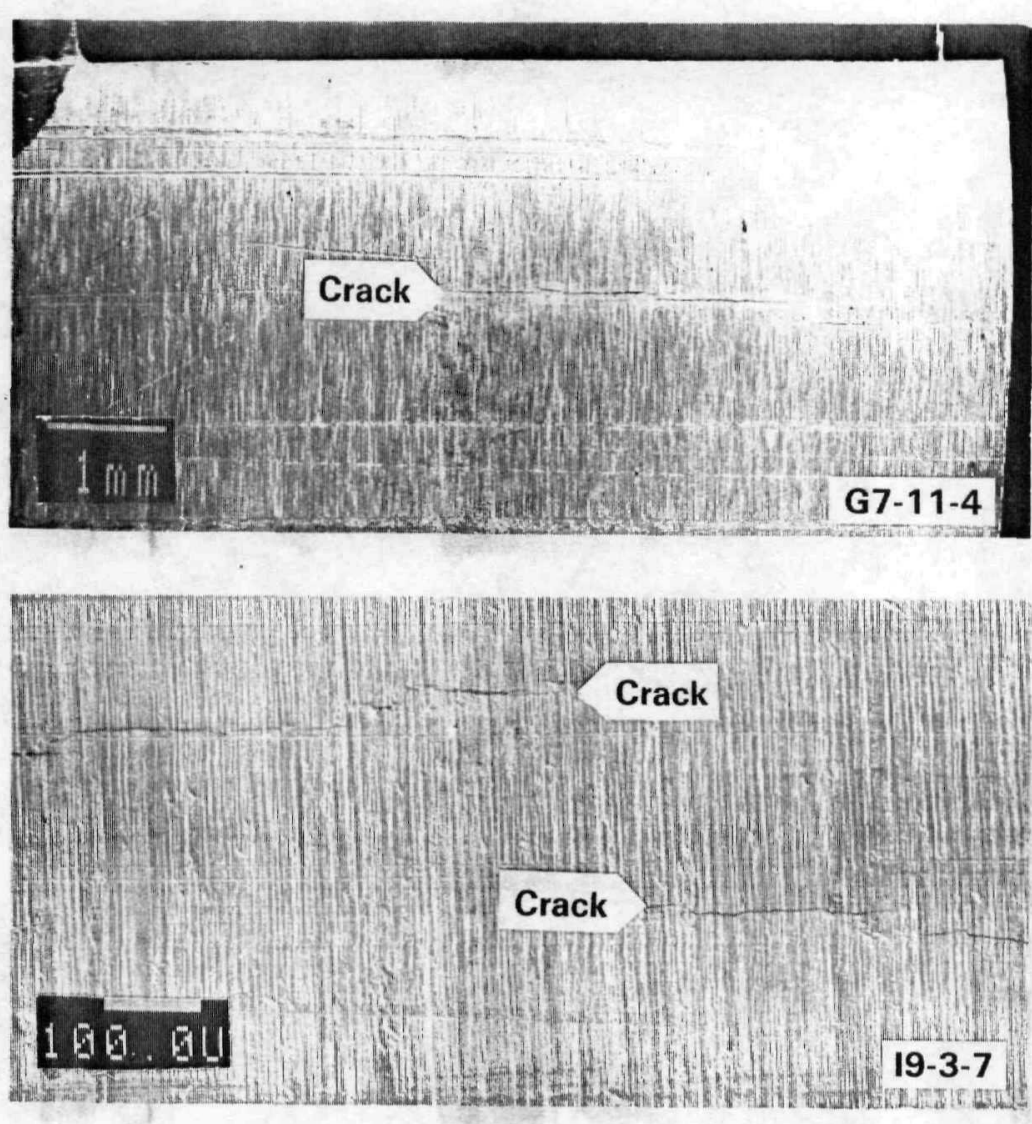

FIGURE 14. Scanning Electron Microscope Micrographs of Cracked Areas for the C-Rings that were

Removed from the Experiment Prior to Breaking. (Note vertical marks are perpendicular to the axis of the spent fuel rod, and are machining marks on the cladding. The horizontal grooves are scratches running parallel with the axis of the fuel rod that were probably the result of the fuel assembly fabrication. $19-3-7$ is the "dry" experiment.) 


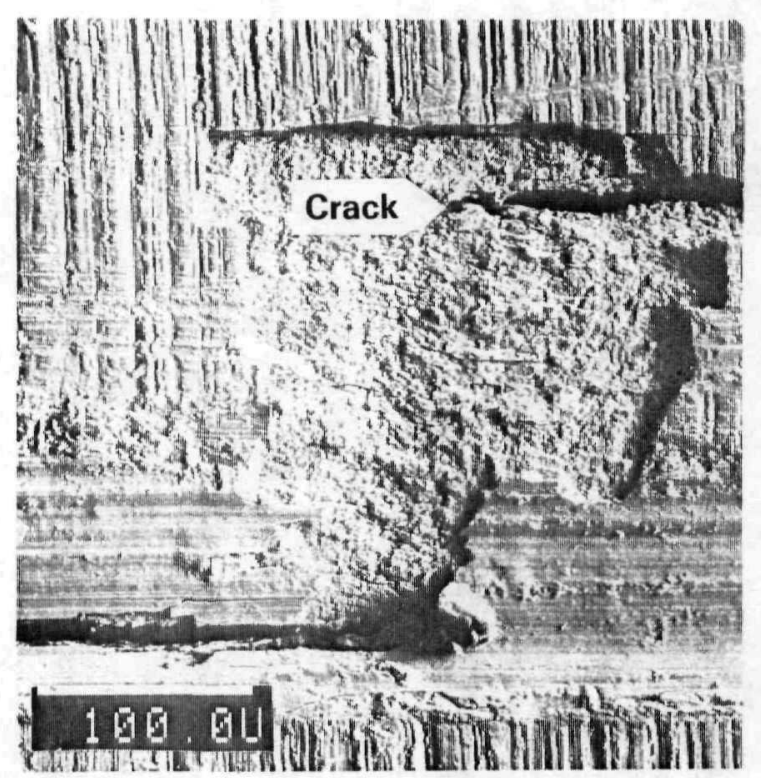

$\omega$

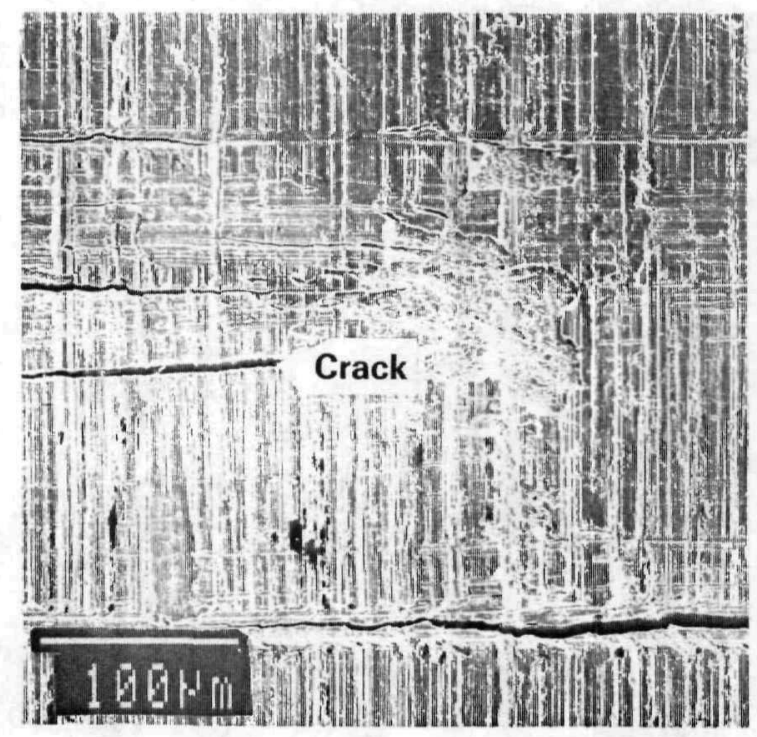

G7-11-4
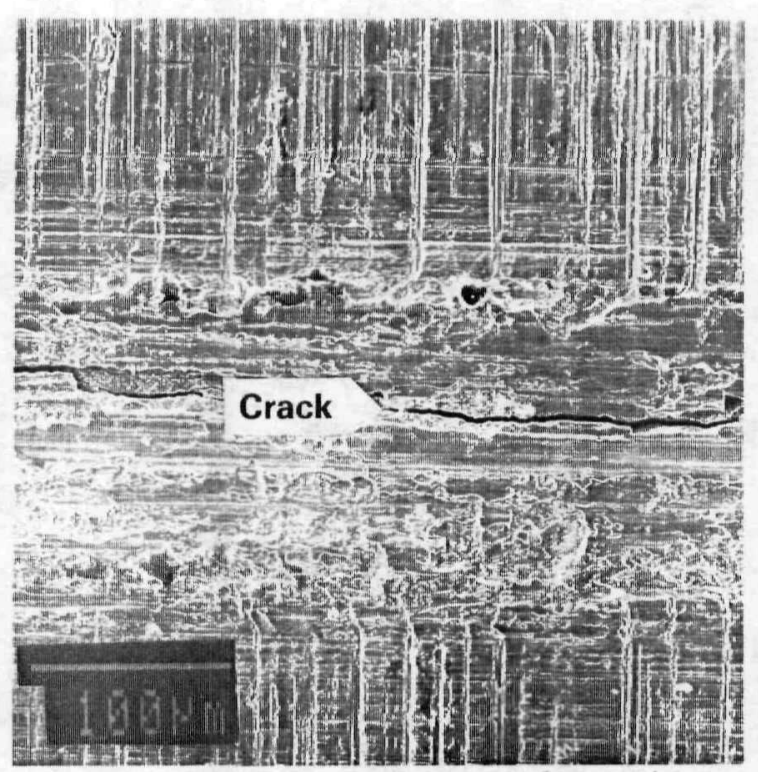

G7-34-7

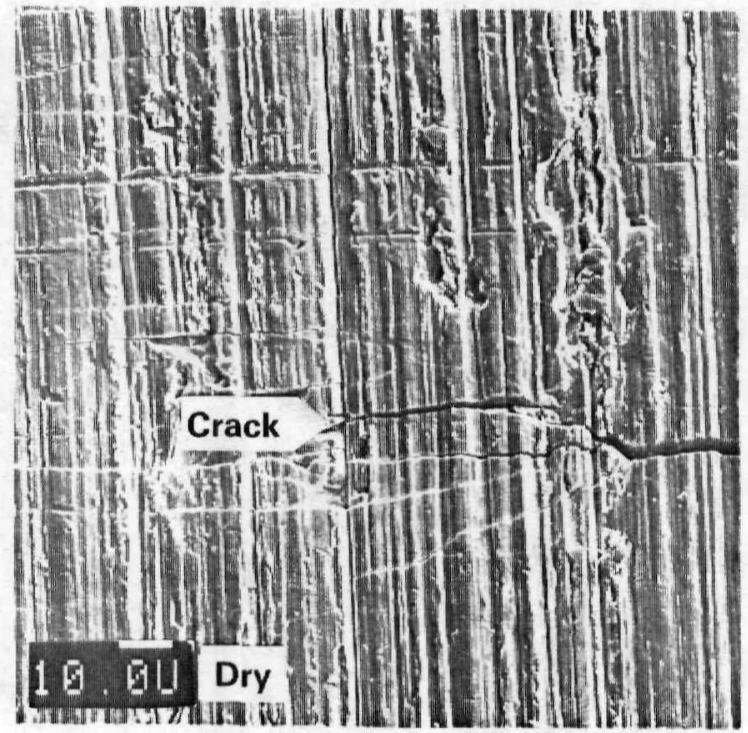

19-3-7

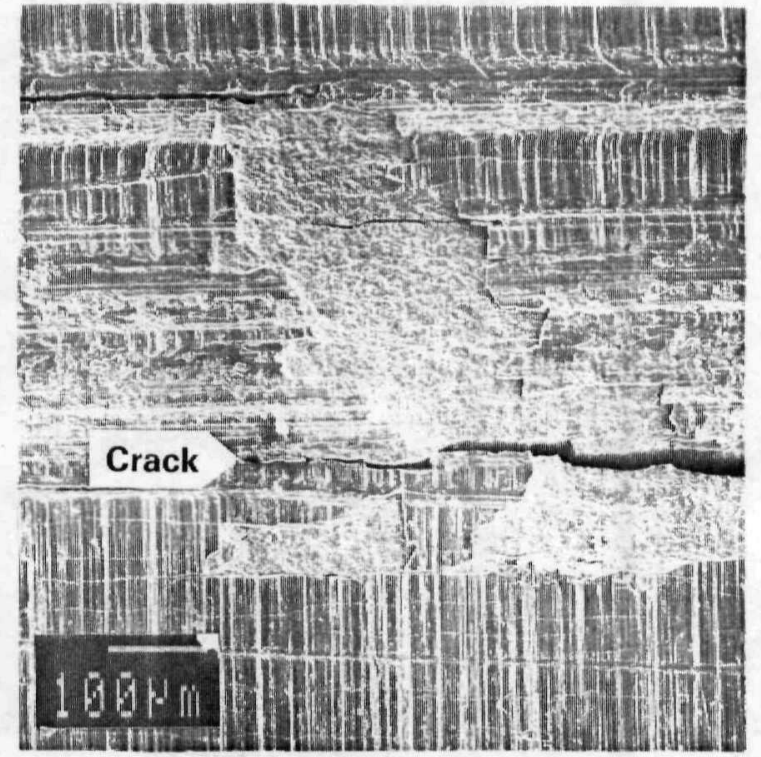

G7-34-8

FIGURE 15. Scanning Electron Microscope Micrographs Showing Some of the Details of the Cracking Pattern Shown in

Figure 14. (The orientation of the micrographs is the same as Figure 14. Note scale on micrographs. I9-3-7 is the "dry" experiment.) 
surface to spal1 off as seen there. In contrast to this, Specimen 19-3-7, one of the two rings run under "dry" conditions, produced smaller, less welldefined cracks that appear to be more randomly spaced than those formed under wet conditions. At higher magnifications (Figure 15), cracking in the specimens, run under wet conditions again, is usually seen to be associated with longitudinal grooves. The cracking pattern for the single dry case does not show this correlation.

The fracture surfaces of the four C-ring specimens that broke completely during the experiments are shown in Figure 16, and specific areas are shown in more detail in Figure 17. This fracture surface can be described in terms of three areas extending outward from the inside diameter. Starting from the inside surface, there is a band that was abraded when the C-ring collapsed and the inner edge was driven into the upper or lower anvil of the apparatus (i.e., Figure 16, upper edge of 19-3-6 or G7-11-7). The intermediate area appears rough, with many secondary cracks running perpendicular to the fracture surface and to the $C$-ring surface. Much of this surface displays the "dimpled" texture characteristic of ductile fracture, which, in some places, extends close to the outside surface of the cladding C-ring (Figure 17, Sample 19-3-6). The fracture surface near the outside diameter is generally less rough, having a surface texture that is more faceted in appearance and directional, different from the dimpled regions mentioned above. In this case, the texture appears to radiate both perpendicular to (Figure 16, I9-3-6, G7-11-6, and G7-34-5), and parallel with (Figure 17, G7-34-5 and G7-11-7) the outside surface of the cladding. In some cases, the width of this region is very narrow ( $-20 \mu \mathrm{m}$ as shown in Figure 17, 19-3-6). In other areas, there appear to be elliptical crack surfaces that extend inward 150 to $200 \mu \mathrm{m}$ (Figure 16, G7-34-5). It appears likely that this outer section was the part of the cracking that developed during the nearly flat part of the deformation versus time curves (i.e., Figures 11 and 12).

Figures 18, 19, 21, and 22 show fractures from both the unbroken and broken $c$-rings in cross section. These cross sections were made in the center and on both ends of the specimen as indicated in Figure 13. There does not seem to 


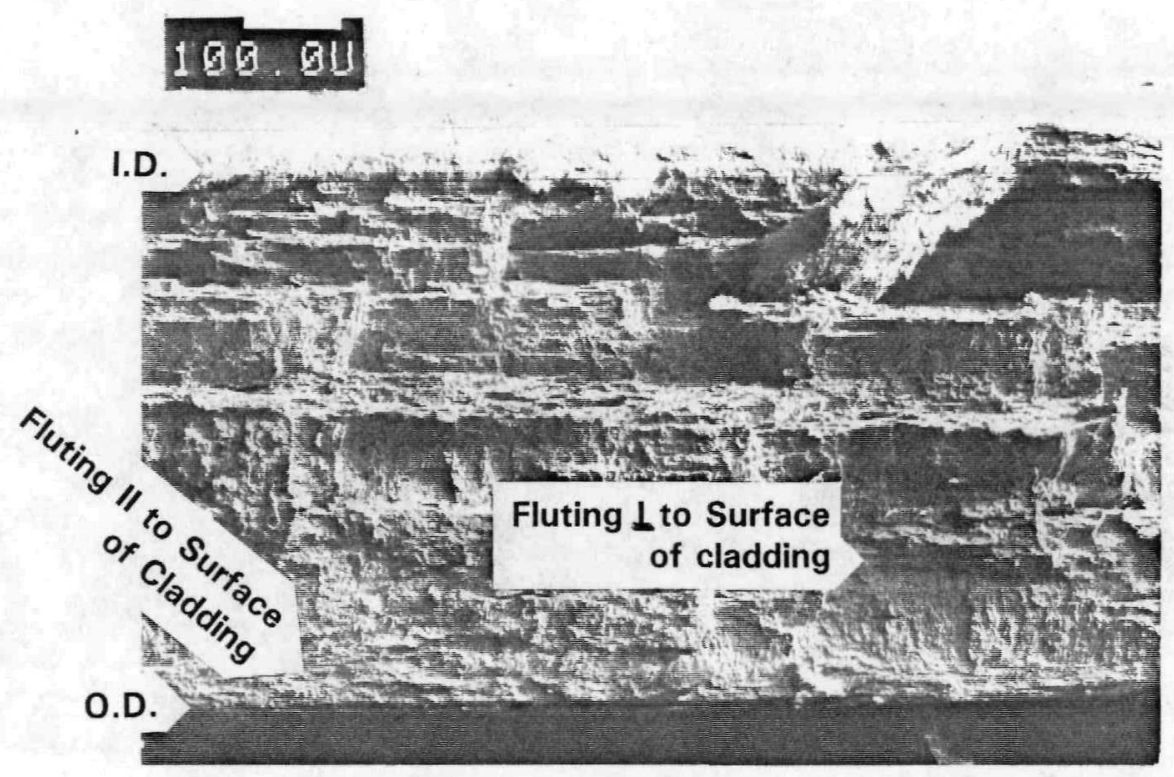

G7-34-5

\section{0u}

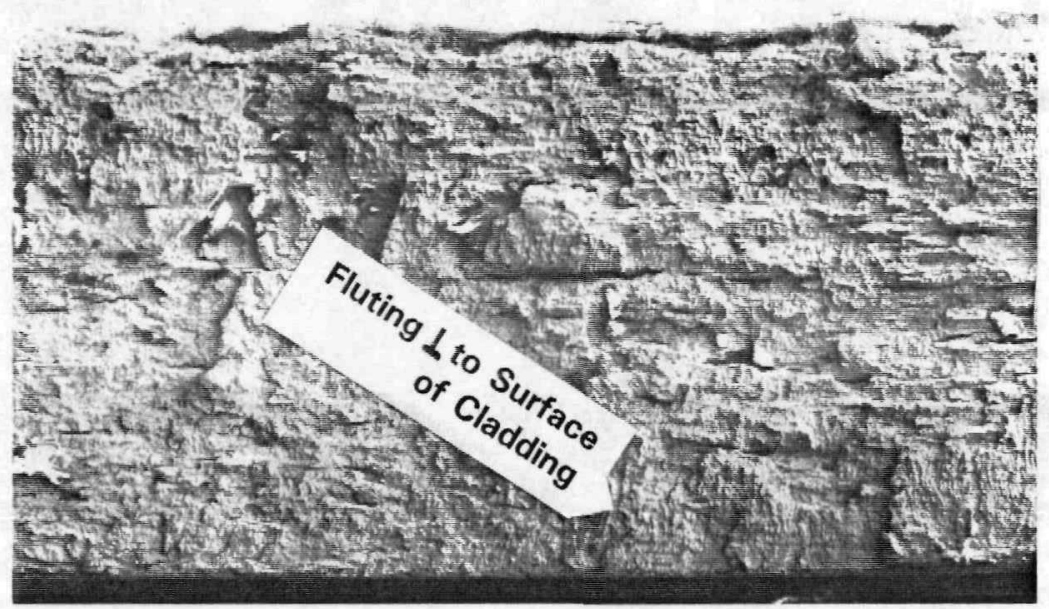

G7-11-6

FIGURE 16. Scanning Electron Microscope Micrographs of the Fracture Surface of the C-Rings that Broke. [Fracture begins at outside diameter (bottom) and appears to propagate upward toward the inside diameter as well as laterally (indicated by orientation of fluting on the fracture surface). Smoothed areas at inside diameter were caused by abrasion at the time of C-ring collapse.] (sheet 1 of 2) 


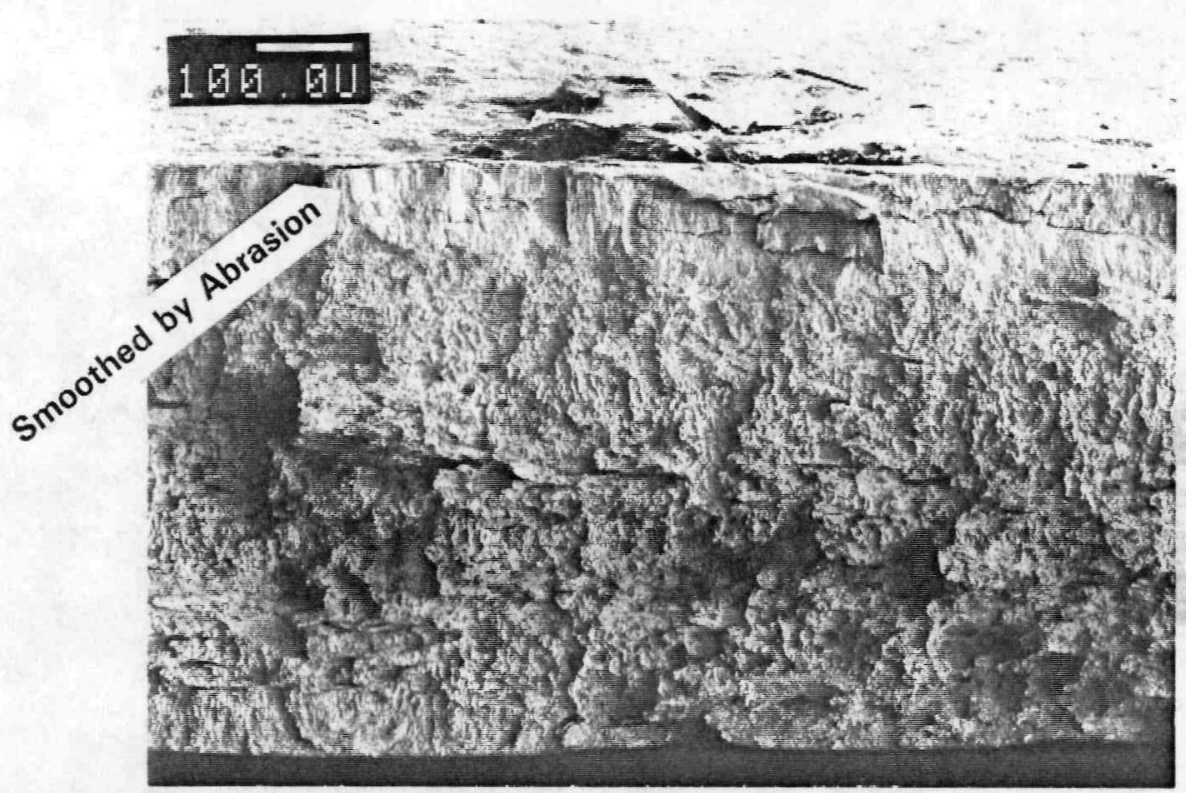

$19-3-6$

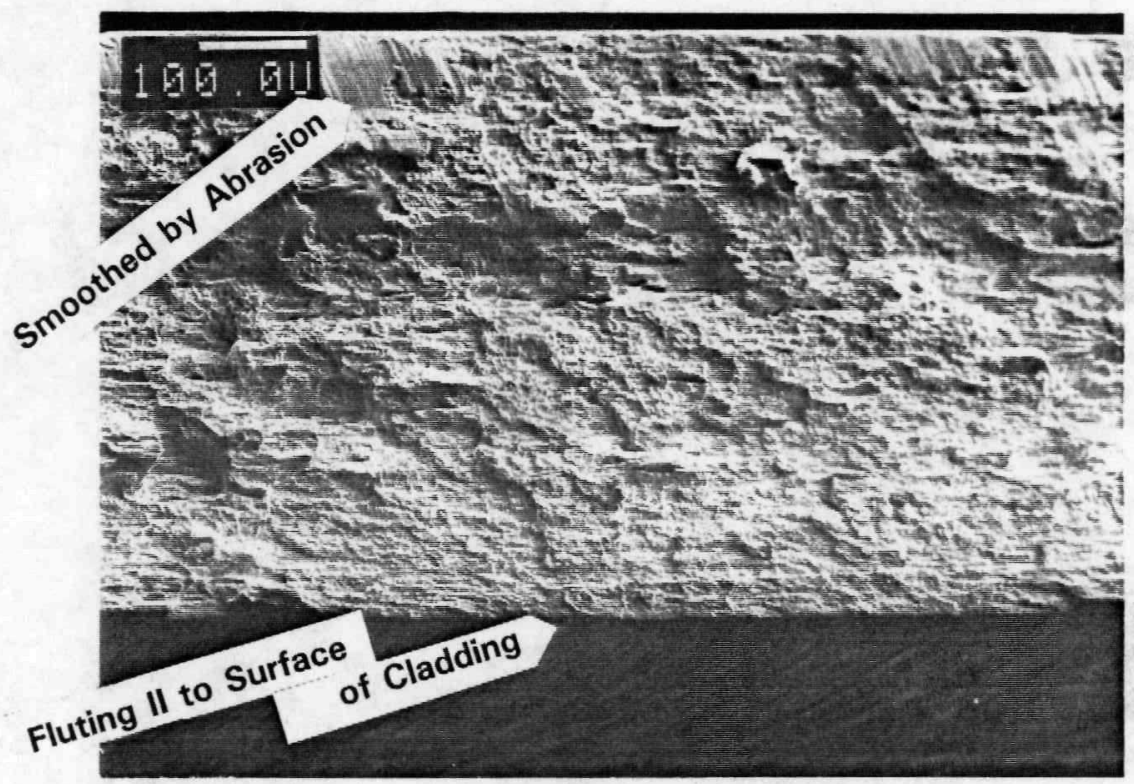

G7-11-7

FIGURE 16. Scanning Electron Microscope Micrographs of the Fracture Surface of the C-Rings that Broke. [Fracture begins at outside diameter (bottom) and appears to propagate upward toward the inside diameter as well as laterally (indicated by orientation of fluting on the fracture surface). Smoothed areas at inside diameter were caused by abrasion at the time of C-ring collapse.] (sheet 2 of 2) 


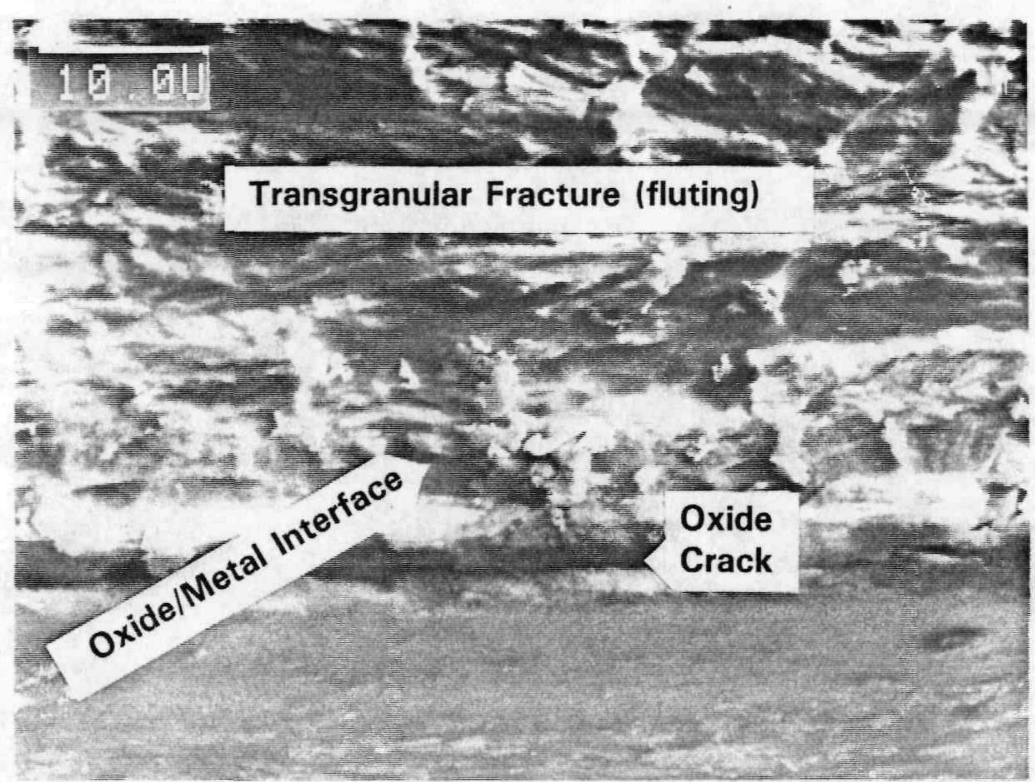

G734-5

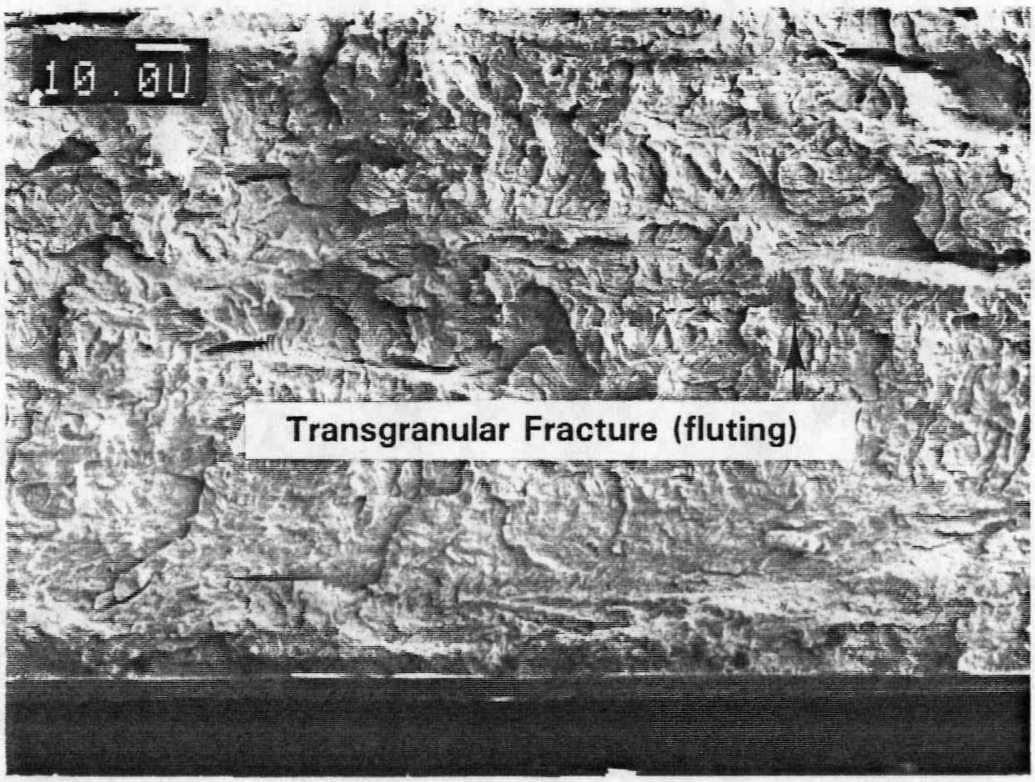

G7-11-6

FIGURE 17. Scanning Electron Microscope Micrographs Showing Detail of the Fracture Surface at the Outside Diameter. (The tightly adhering oxide film is about $4 \mathrm{~m}$ thick on samples

G7-11-6, I9-3-6, and G7-11-7. Sample G7-34-5 has an oxide film about $10 \mathrm{~m}$ thick and displays a medial fracture. The fracture surfaces just under the oxide film and appears to be due to brittle fracture. This region appears to extend inward from 10 to several hundred microns depending on the area.) (sheet 1 of 2) 


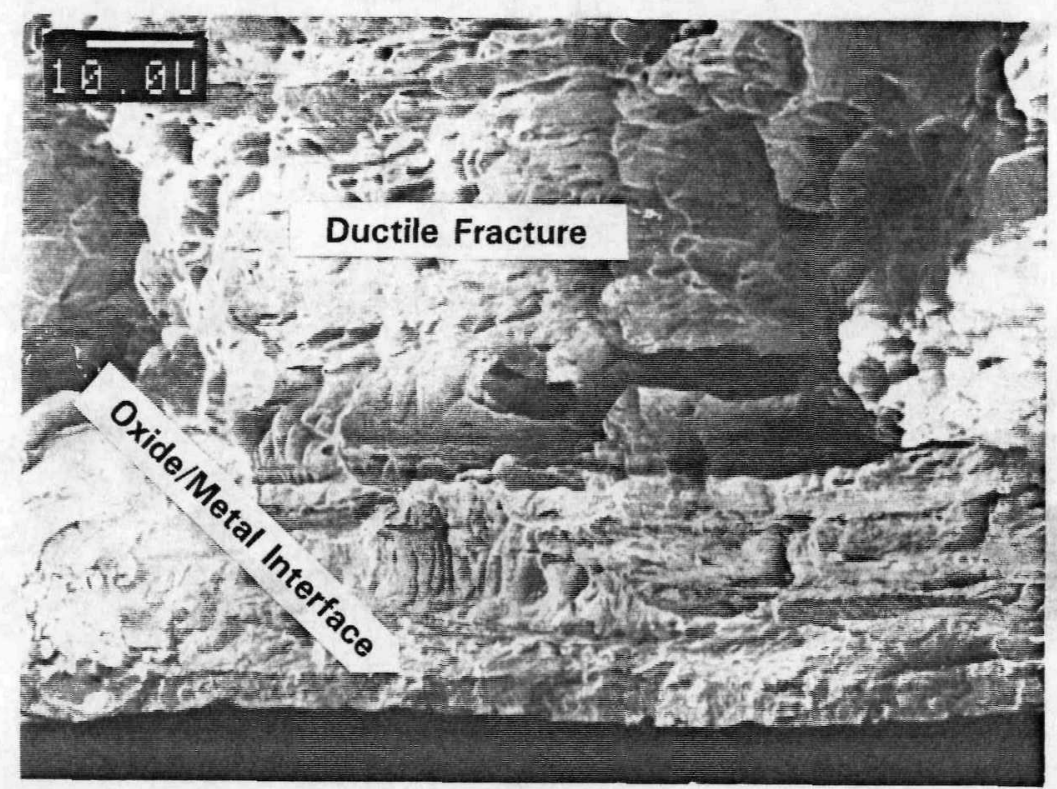

$19-3-6$

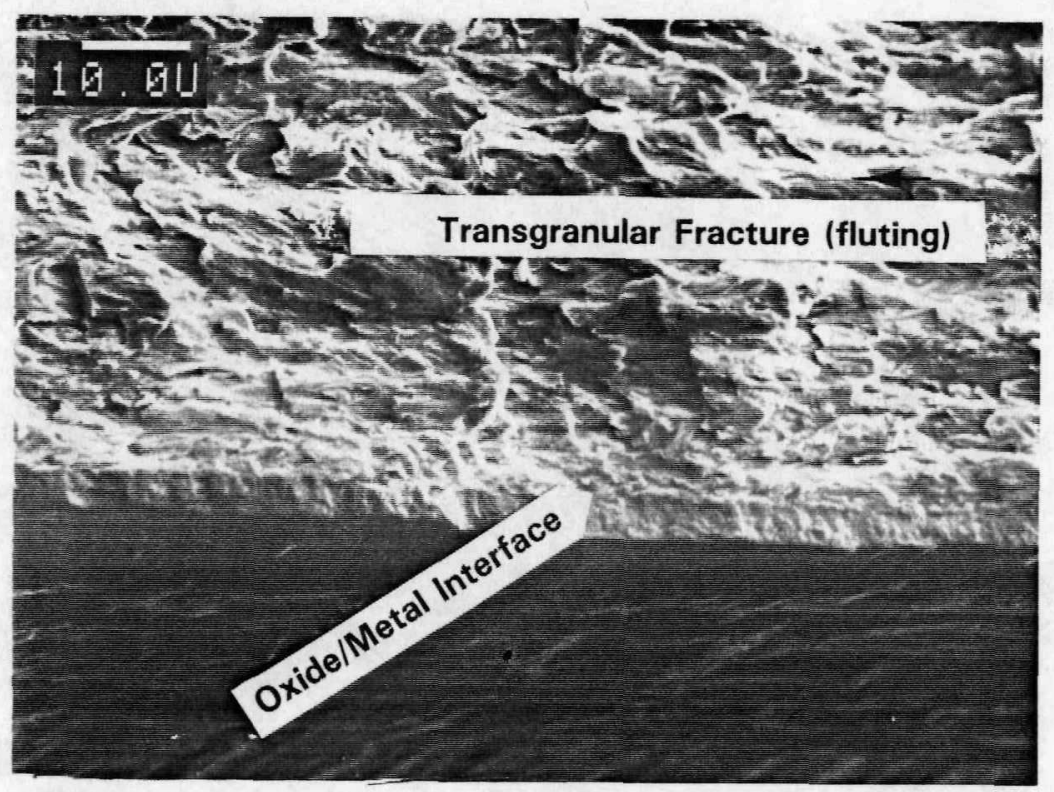

G7-11-7

FIGURE 17. Scanning Electron Microscope Micrographs Showing Detail of the Fracture Surface at the Outside Diameter. (The tightly adhering oxide film is about $4 \mathrm{~m}$ thick on samples G7-11-6, I9-3-6, and G7-11-7. Sample G7-34-5 has an oxide film about $10 \mathrm{~m}$ thick and displays a medial fracture. The fracture surfaces just under the oxide film and appears to be due to brittle fracture. This region appears to extend inward from 10 to several hundred microns depending on the area.) (sheet 2 of 2) 


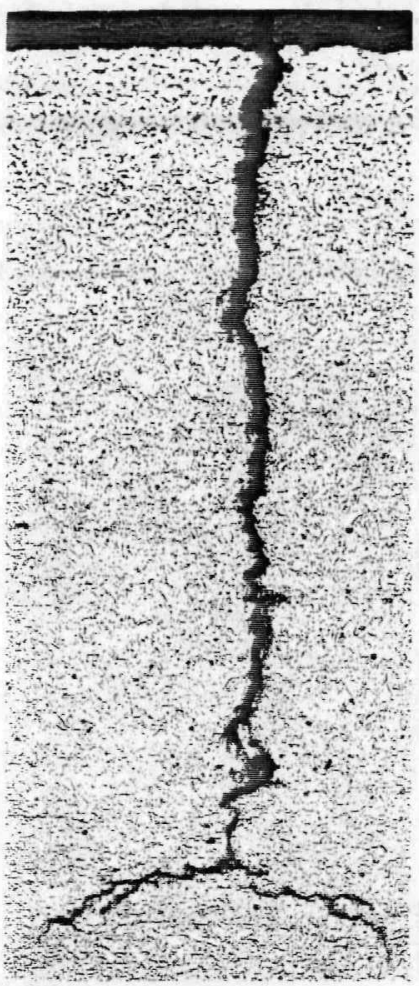

G7-34-6, 250X

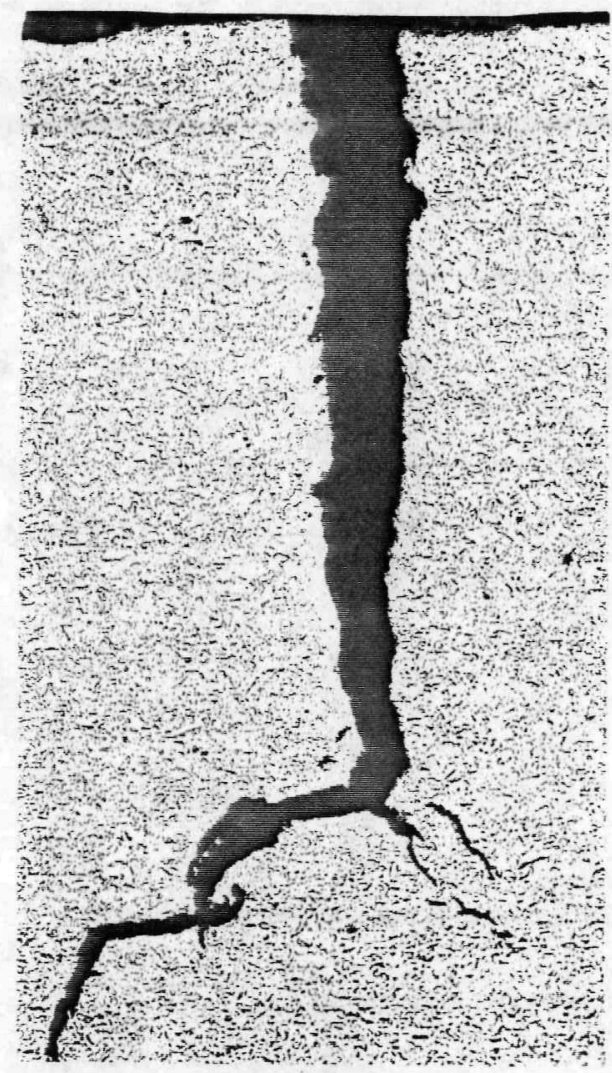

G7-34-8; 250X

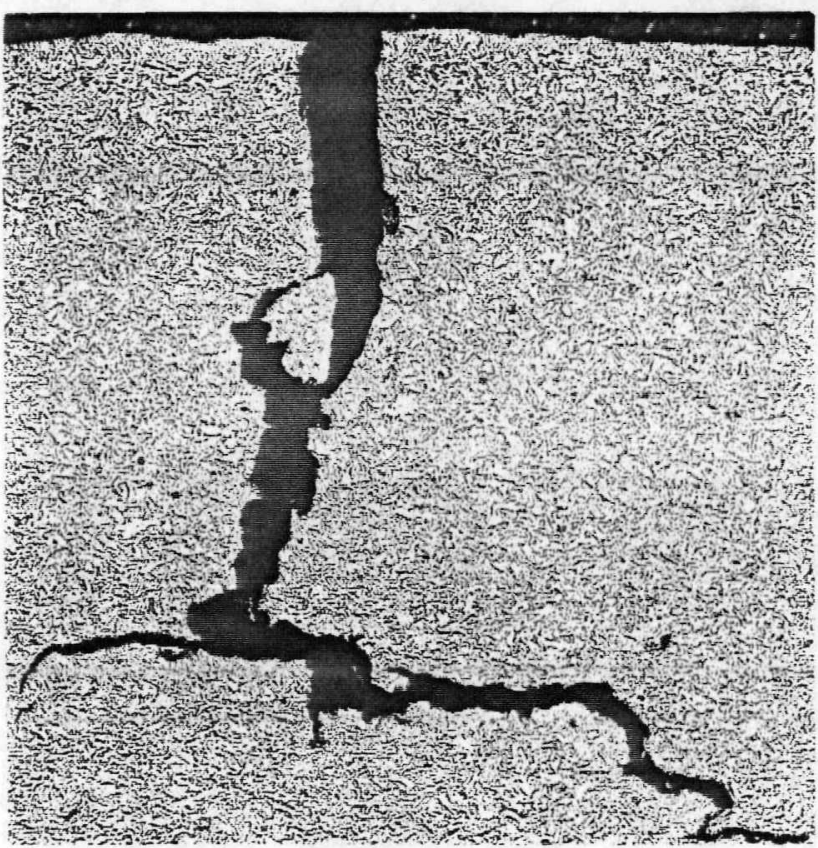

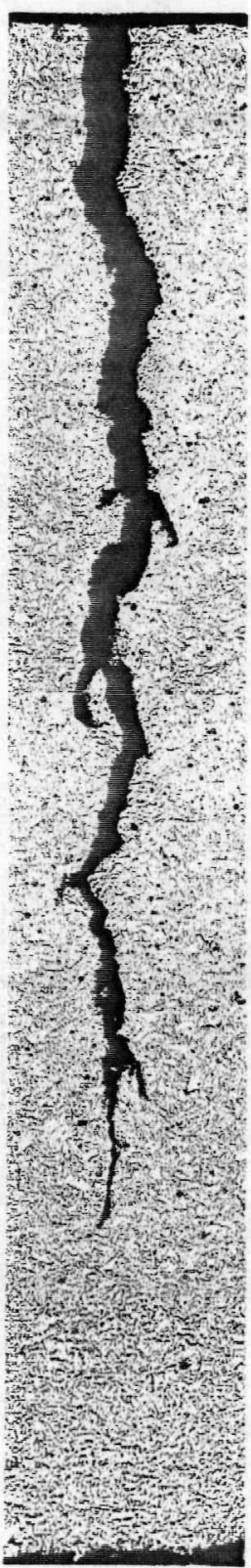

G7-11-4 $250 X$

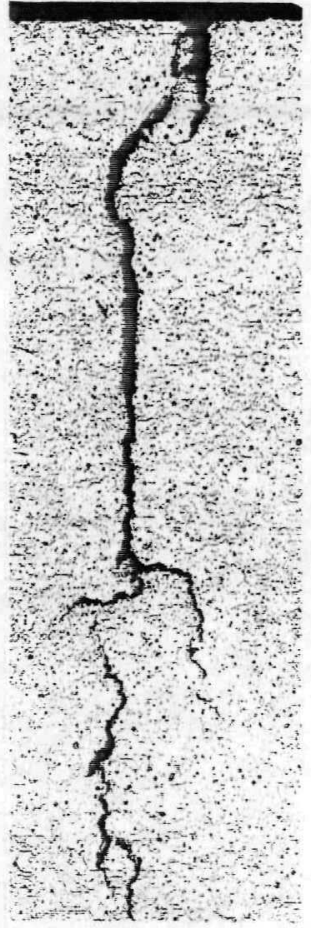

19-3-7 $250 x$

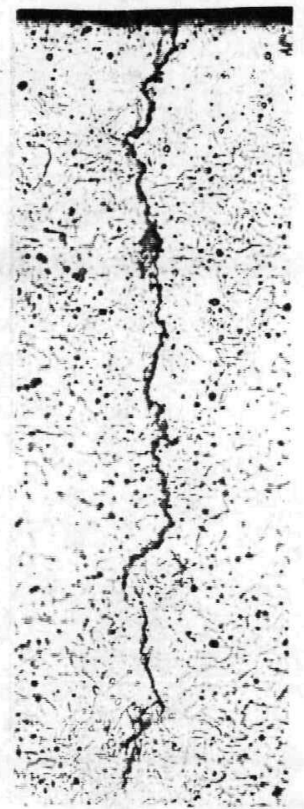

19-3-7 $500 x$

\section{G7-34-7, 250X}

FIGURE 18. Metallographic Polished and "B" Etched Cross Sections of Cracks at the Center of Unbroken C-Rings. (Each section has been polished and then given "B" etch. G7-34 specimens display a branched crack not really shown by the 19-3 or G7-11 specimens. The presence of hydrides may make the difference.) 


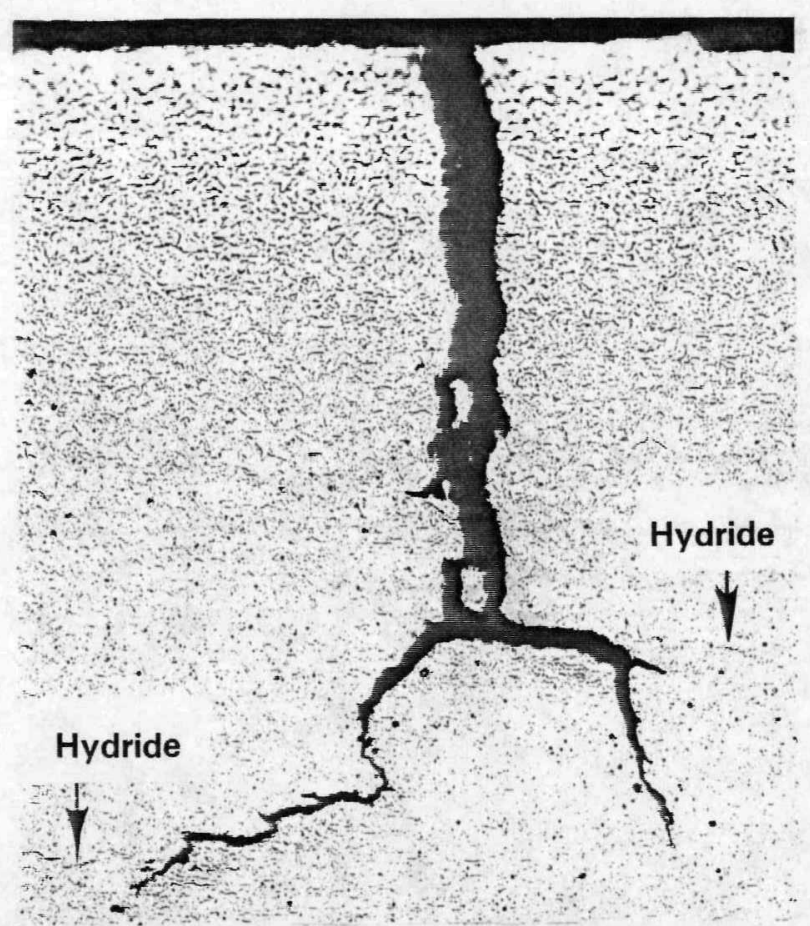

G7-34-6, 250X

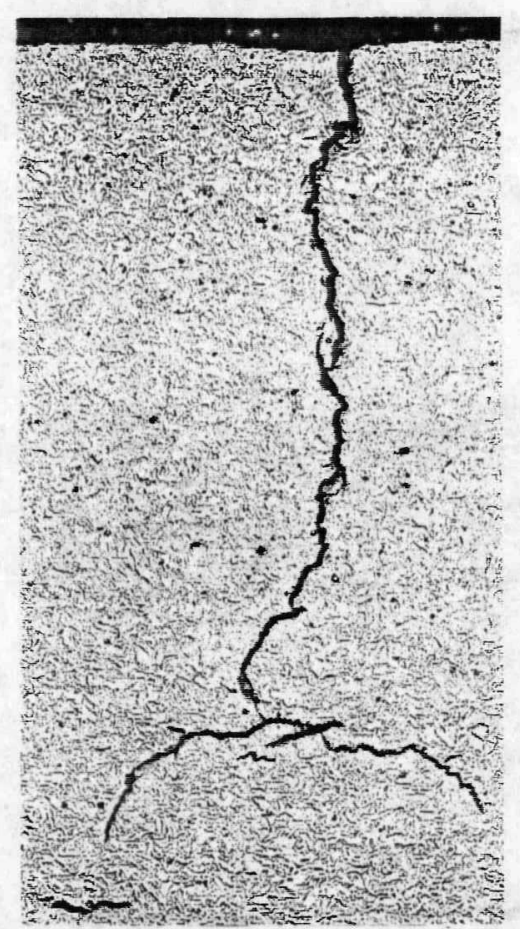

(a) G7-34-7, 250X

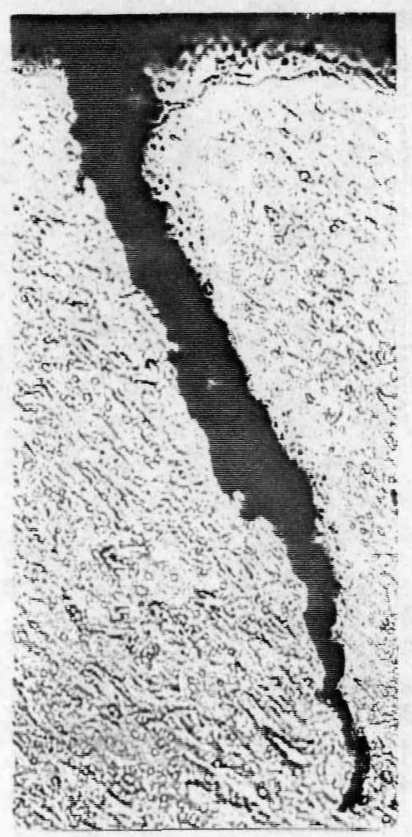

(a) G7-34-8, 500X

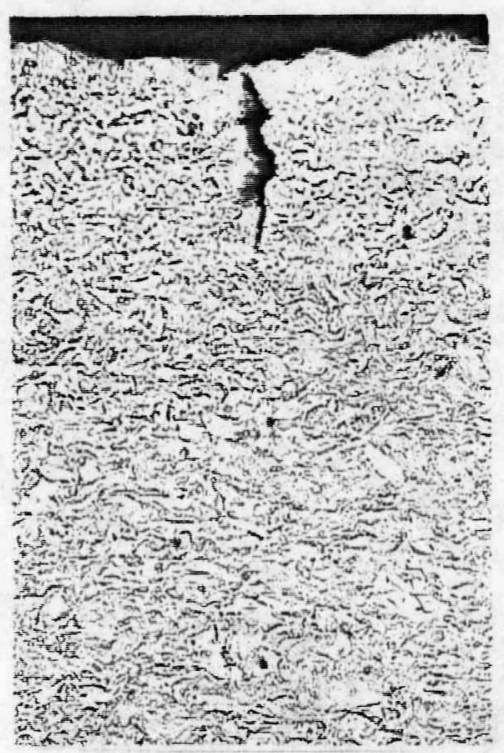

(b) G7-34-8, 500X

FIGURE 19. Metallographic Polished and "B" Etched Cross Sections of Cracks from the Ends of each Unbroken C-Ring. (G7-34-6, 7 specimens show branched fracture, again thought to be due to hydride distribution. Small crack shown in (b) 19-3-7 appears to have initiated on and running beside hydride which intersects the surface.)

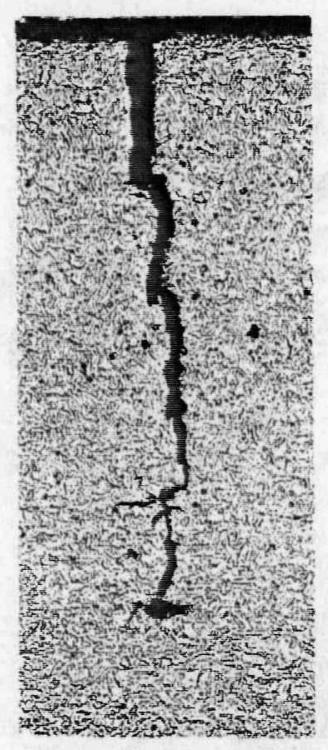

G7-11-4, 250X

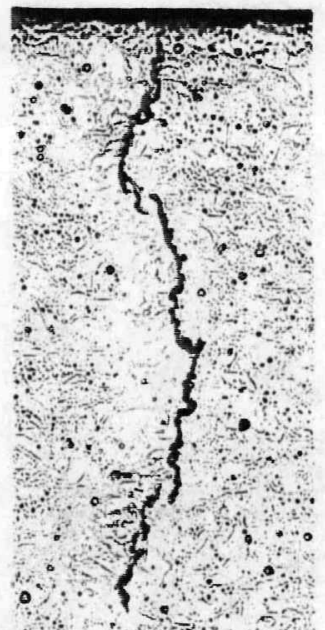

(b) G7-34-7, 500x

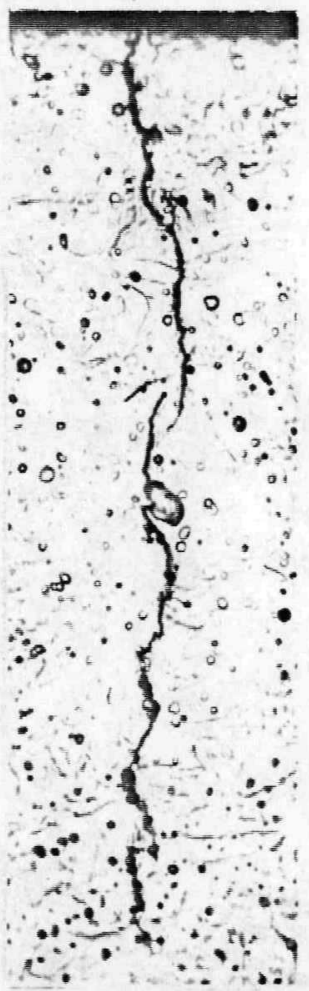

(a) 19-3-7, 1000x

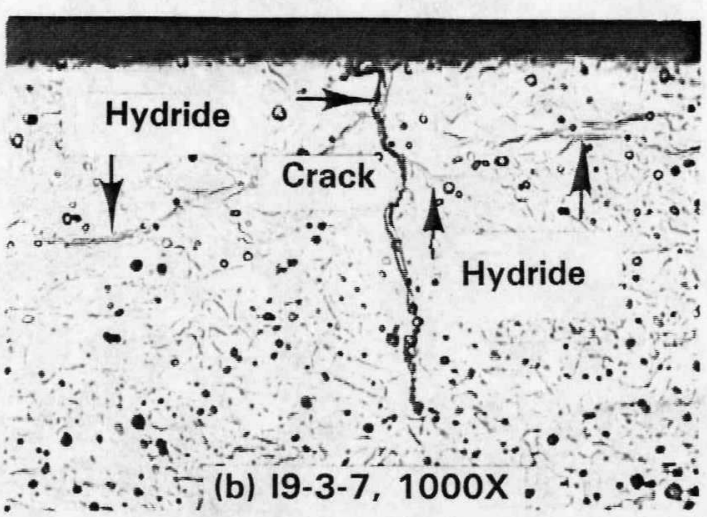




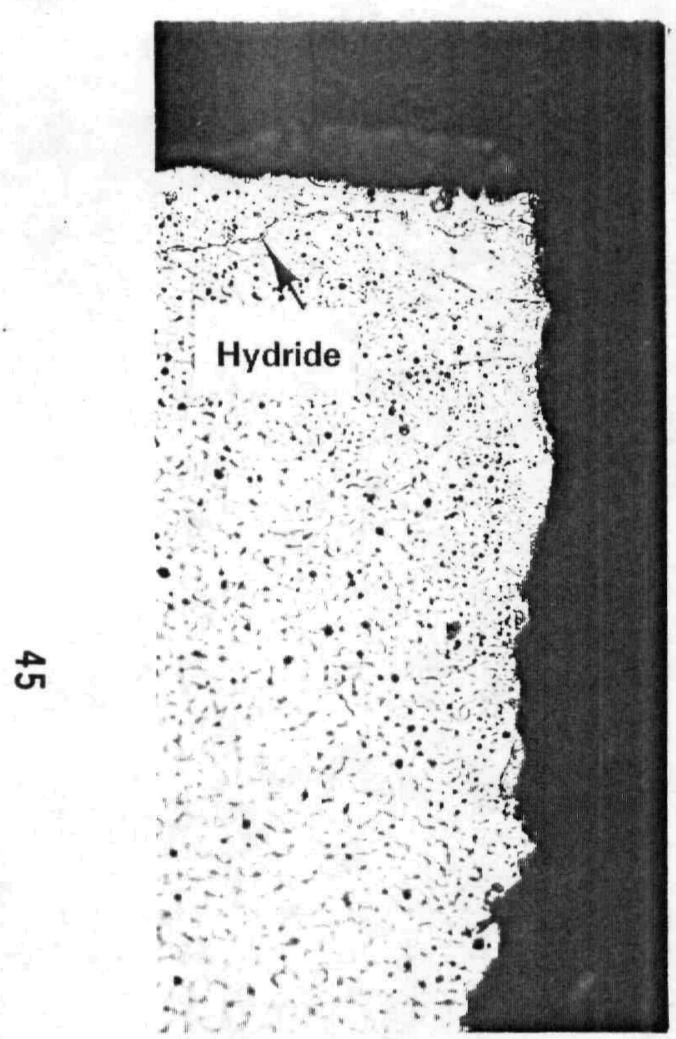

G7-34-5, 500X

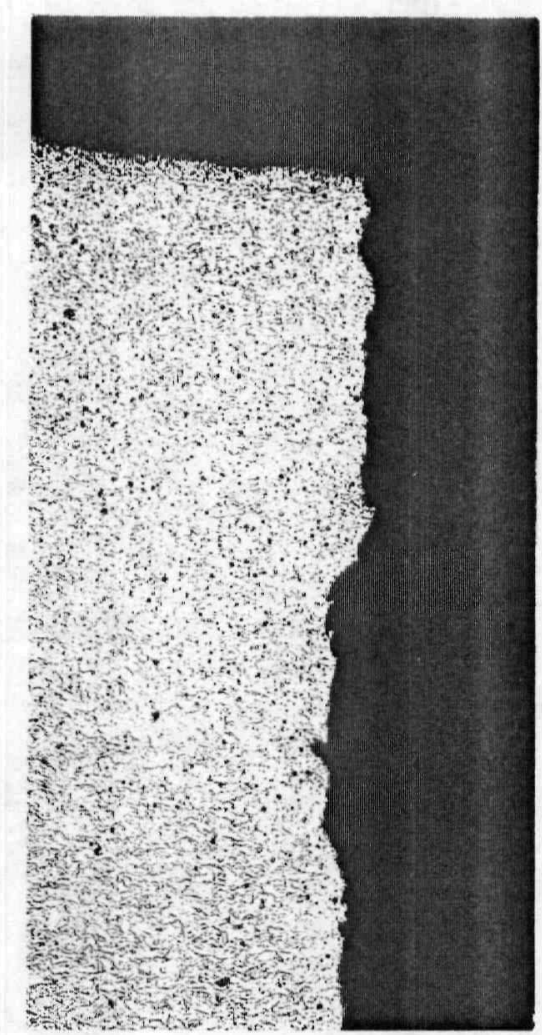

G7-11-6, 250X

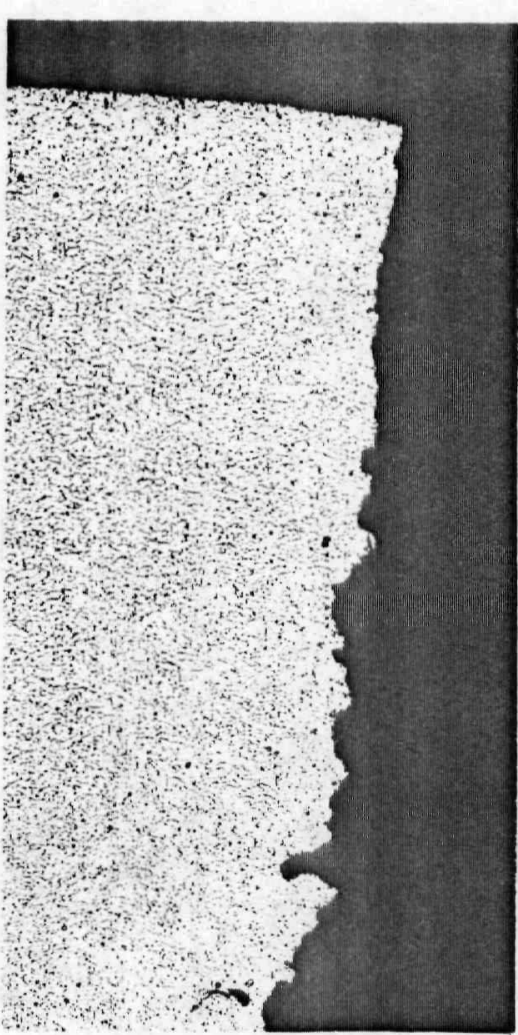

G7-11-7, 250X

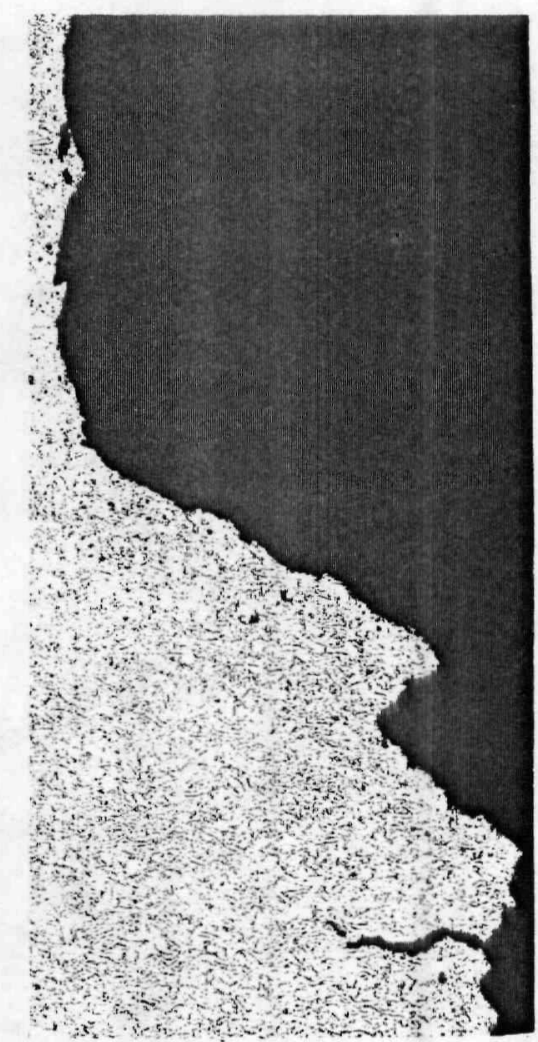

19-3-7, 250X

FIGURE 20. Metallographic Polished and "B" Etched Cross Sections of the Fracture Surface of Broken C-Rings. 


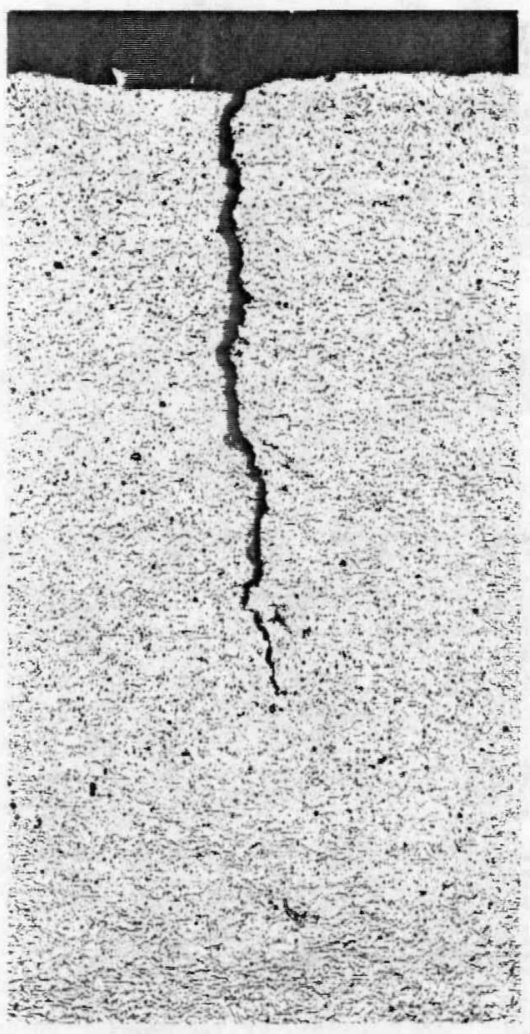

(a) G7-11-7, 250X

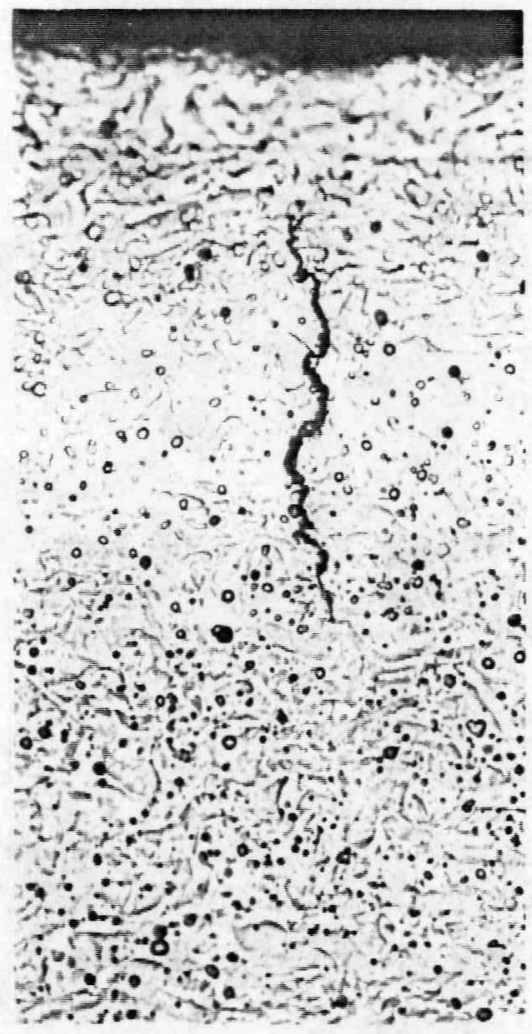

(b) G7-11-7, 1000X

FIGURE 21. Metallographic Polished and "B" Etched Cross Sections of Cracks Oriented Parallel to the Fracture Surface of G7-11-7 Shown in Figure 20. (b) Crack Appears to be Running Beneath the Surface, see page 34 . 


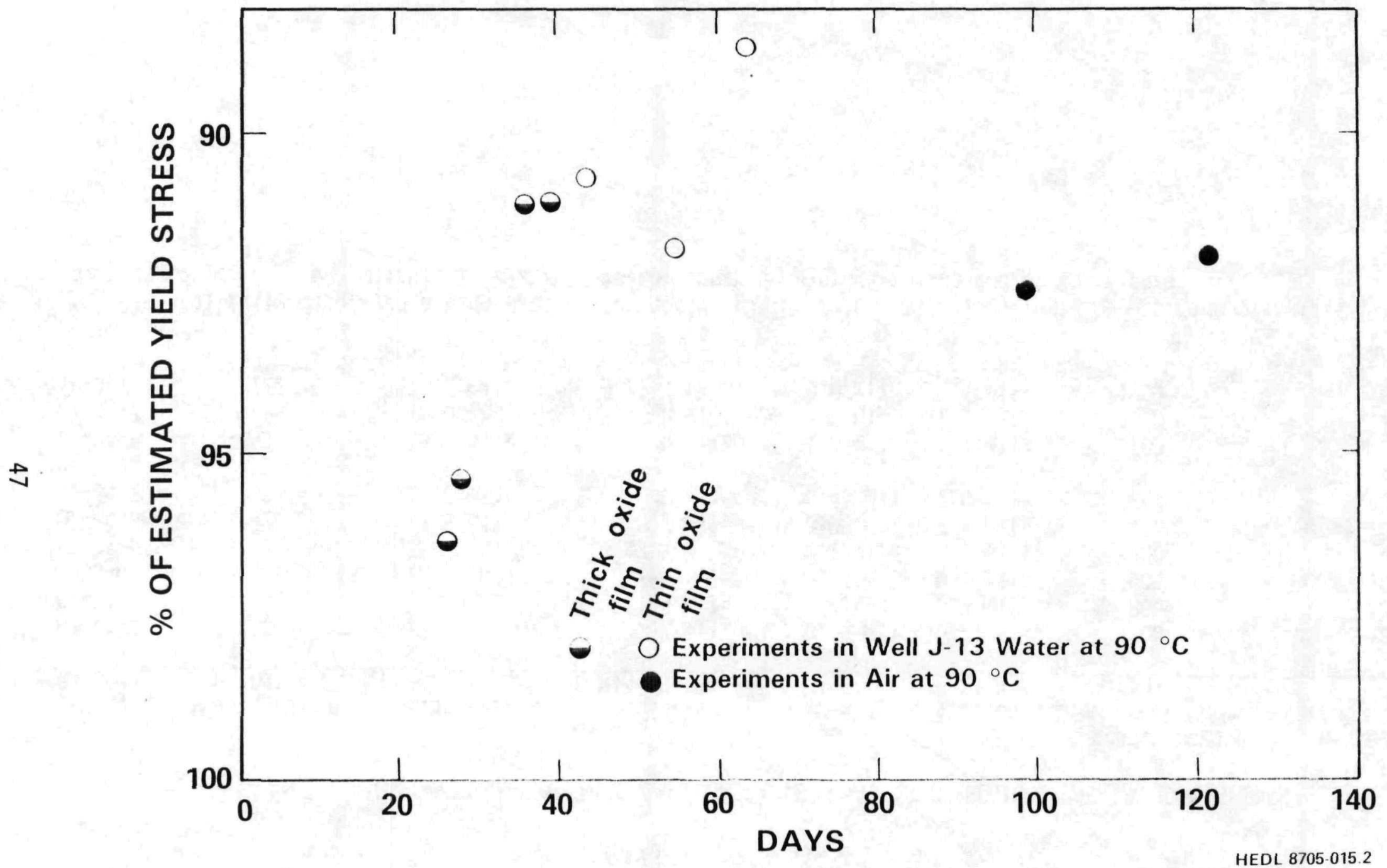

FIGURE 22. Empirical Relationship Between Observed Time to Failure and Stress Level Defined as the Percentage of the Measured Elastic Limit. 
TABLE 5

OBSERVED EXPERIMENTAL DATA FROM C-RING STRESS CORROSION CRACKING EXPERIMENTS

\begin{tabular}{|c|c|c|c|c|c|c|c|}
\hline $\begin{array}{l}\text { C-Ring } \\
\text { Specimen }\end{array}$ & $\begin{array}{l}\text { Time to Failure } \\
\text { (d) }\end{array}$ & $\begin{array}{c}\text { Observed } \\
\text { Fracture Depth }\end{array}$ & $\begin{array}{c}\text { Observed } \\
\text { C-Ring Deflection }\end{array}$ & $\begin{array}{l}\text { C-Ring D } \\
\text { At } 1 \mathrm{~h} \\
\end{array}$ & $\begin{array}{l}\text { flection } \\
24 \mathrm{~h} \\
\end{array}$ & $\begin{array}{l}\text { Approx. Period } \\
\text { Slow Crack Growth } \\
\text { (h) }\end{array}$ & $\begin{array}{c}\text { C-Ring Deflection } \\
\text { During Slow Crack Growth } \\
(\mathrm{mL} / \mathrm{h})\end{array}$ \\
\hline $\begin{array}{l}\text { G7-11-4 } \\
\text { G7-11-6 } \\
\text { I9-3-6 } \\
\text { G7-34-5 } \\
\text { G7-34-6 } \\
\text { G7-34-7 }\end{array}$ & $\begin{array}{l}64 \\
44 \\
55 \\
26 \\
28 \\
36\end{array}$ & $\begin{array}{l}19.4 \mathrm{mils} \\
\text { Through } \\
\text { Through } \\
\text { Through } \\
14.5 \mathrm{mils} \\
12.6 \mathrm{mils}\end{array}$ & $\begin{array}{r}7.7 \mathrm{mils} \\
11.6 \mathrm{mils} \\
11.6 \mathrm{mils} \\
19.7 \mathrm{mils} \\
8.7 \mathrm{mils} \\
6.7 \mathrm{mils}\end{array}$ & $\begin{array}{l}0.35 \mathrm{mil} \\
\text { (Noise) } \\
0.15 \mathrm{mil} \\
2.3 \mathrm{mils} \\
0.95 \mathrm{mil} \\
0.45 \mathrm{mil}\end{array}$ & $\begin{array}{l}0.7 \mathrm{mil} \\
0.7 \mathrm{mil} \\
0.5 \mathrm{mil} \\
2.5 \mathrm{mils} \\
2.4 \mathrm{mils} \\
1.0 \mathrm{mil}\end{array}$ & $\begin{array}{r}1200 \\
800 \\
900 \\
400 \\
420 \\
650\end{array}$ & $\begin{array}{c}12.4 \times 10^{-4} \\
13.4 \times 10^{-4} \\
10.41 \times 10^{-4} \\
4.65 \times 10^{-4} \\
6.44 \times 10^{-4} \\
13.2 \times 10^{-4} \\
\text { (Average) }\end{array}$ \\
\hline $\begin{array}{l}\text { G7 }-34-8 \\
\text { G7-11-7 } \\
\text { I9-3-7 }\end{array}$ & $\begin{array}{r}39 \\
99 \\
122\end{array}$ & $\begin{array}{l}16.7 \text { mils } \\
\text { Through } \\
14.5 \text { mils }\end{array}$ & $\begin{array}{l}16.0 \mathrm{mils} \\
15.0 \mathrm{mils} \\
11.3 \mathrm{mils}\end{array}$ & $\begin{array}{l}1.3 \mathrm{mils} \\
1.0 \mathrm{mil} \\
0.8 \mathrm{mil}\end{array}$ & $\begin{array}{l}1.7 \mathrm{mils} \\
2.8 \mathrm{mils} \\
1.5 \mathrm{mils}\end{array}$ & $\begin{array}{r}700 \\
1550 \\
1800\end{array}$ & $\begin{array}{l}9.26 \times 10^{-4} \\
7.86 \times 10^{-4} \\
5.43 \times 10^{-5}\end{array}$ \\
\hline
\end{tabular}

*G7-34-7 initially displayed a high rate of deflection $\left(34.36 \times 10^{-4} \mathrm{mil} / \mathrm{h}\right)$ followed by a period of relatively slow deflection $\left(2.16 \times 10^{-4} \mathrm{mil} / \mathrm{h}\right), 13.2 \times 10^{-4}$ is the observed average to the end of the experiment. 
be any obvious difference in the crack pattern between the center and the end position on the ring. In some cases (i.e., the "thick oxide" specimens G7-34-6, -7, and -8), the crack begins to branch after penetrating into the C-ring from 8.5 to $12.5 \mathrm{mil}$. Next, the path becomes more irregular, with small crack-1ike cavities opening up ahead of the crack tip in a number of cases (see Figures 18 and 19). The cracks themselves ranged in depth from 12.6 to $19.4 \mathrm{mil}$ and there did not seem to be any correlation with the observed C-ring deflection just prior to termination of the experiment (see Table 5). Figure 20 shows a fracture profile for each of the four rings that broke completely through. Note that the C-ring deflection in these instances was on the average about $4.5 \mathrm{mil}$ more than those that were removed from the experiment prior to breaking. These fracture profiles appear to have the same features as the walls of the fractures shown in Figures 18 and 20. In addition, Figure 21 shows some parallel fractures that were present in Specimen G7-11-7. The crack (Figure 21b) appears to have been generated beneath the surface, but is probably the leading edge of a crack running laterally. The crack shown there has a scalloped appearance such as might be generated if it was sectioned perpendicular to the direction it was propagating. The "scallops" are generated by individual "flutes" (see Figure 16) cut in cross section. This situation might be explained by the change in the stress intensity with position as one moves from the bottom of the crack to the point where the leading edge of the crack intersects the surface (of the cladding). A model for a semicircular flaw in the top of a beam in pure bending had a stress intensity $25 \%$ or greater at the edges near the surface of the beam than the stress at the bottom of the flaw. (5) This would cause the flaw to widen, and if the surface had a yield strength greater than the substrate metal, the flaw might underrun the surface as observed in Figure 21b.

Hydrides appear to be involved with the cracking process in some way, but at this time it is difficult to say whether "delayed hydrogen cracking" is occurring or hydrides are simply acting as crack initiation sites and planes of weakness. Delayed hydrogen cracking occurs when hydrogen in solution migrates to the high stress region at a crack tip, causing lower strength hydrides to form and the crack to advance when the hydrides fail. (15) However, since hydrides are already observed to be scattered throughout the cladding, 
it is difficult to say if they are migrating and reorienting because of the stress field. In Figure 19, Specimen G7-34-6 shows a branching crack in which the branches appear to be following hydride inclusions. The fact that the hydride content of cladding with a thick oxide film is higher than cladding with a thin oxide film, and that hydrides in other Turkey Point cladding specimens are observed to have hydride inclusions concentrated in about the position in which the fractures branch in the G7-34 specimens, strongly suggests that hydrides are causing the cracks to branch in those C-rings. Also, in Figure 19, Specimen 19-3-7(b) shows a very small crack that appears to have initiated along the side of a hydride inclusion that intersects the surface of the cladding. Hence, hydride inclusions are at least influencing the cracking process occurring in these experiments. 


\subsection{DISCUSSION OF RESULTS}

This experiment was designed to explore empirically the relationship between mechanical stress and the development of stress corrosion cracking under a repository-1ike environment. The results are summarized in Figure 22, in which the relative stress level at which a particular C-ring was stressed is plotted against the time that passed before it broke completely, or was judged about to fail because of the observed deflection rate. As shown, the C-rings exposed to the aqueous $(\mathrm{J}-13)$ environment form a distinct group cracking three times faster than those exposed only to hot cell air at similar stress levels. This indicates that the water environment definitely stimulates the cracking process. Also, as expected, the wet experiments show that the cracking process is a function of stress, with C-rings that run at lower stress levels taking longer to exhibit cracking. The trend shown by the wet experiment specimens appears to have negative curvature, so that without some kind of model to fit to the data, it is not possible to extrapolate it to lower stress levels and still retain any kind of predictive power.

At this stage of the investigation, it is still not clear how much material needs to be included in these experiments to ensure that the results are statistically valid. The factors that cause cracks to develop in the cladding in response to the stress have not yet been unambiguously identified; therefore, it cannot be determined at this stage whether or not the number/volume of the experimental specimens is adequate to allow recognition of the materials factors important to stress corrosion cracking in this environment. The fact that there are many physical cracking features in common between the cracked experimental samples, however, suggests that there are multiple stress corrosion crack initiation sites per specimen. This may also be suggested by the fact that six out of the seven specimens stressed under wet conditions appear to fall along a common trend, which is the worst observed case (i.e., the seventh specimen was more resistant to cracking). Further, it has been observed that all Turkey Point spent fuel cladding specimens subjected to the same experimental conditions have shown similar C-ring compression versus time profiles for a given stress (Figures 11 and 12) and developed similar straight surface flaws (Figure 14). The flaws tended to develop in 
and parallel to longitudinal surface scratches (Figure 15). Those scratches are believed to have been made during the original fabrication of the fuel assembly. The flaws were parallel, but not on exactly the same line, and they were connected by shear zones (Figure 15). The fracture surface characteristics were observed to change with distance into the cladding starting from the outer surface, progressing from cleavage fracture zones at the outside diameter through dimpling characteristic of ductile failure and rapid shearing at the inside diameter. It is believed that the cleavage fracture portion developed during the long, very slow, deformational phase of each experiment. Another crack initiation site appears to be zirconium hydride inclusions that intersect the surface. Such an inclusion, with a crack starting beside it at the cladding surface, is shown in Figure 19, 19-9-7(b). Further, it has been observed that the sudden increases of stress (i.e., failure of an adjacent specimen or an accidental rapid loading of a weight) may cause plastic deformation; however, this does not appear to increase the failure rate (7.0, "Experiment Results"). It is tentatively concluded, therefore, that the C-rings used in these experiments so far have all contained similar stress corrosion cracking initiation sites. Conversely, if there are other kinds of cladding defects that would generate a significantly different response to the experiment, they were not present in the high stress portion of the C-rings used in the experiments.

Miller et a1. (16) discuss both physical and chemical defects in cladding that may influence stress corrosion cracking of spent fuel cladding. They state that small chemical defects, $2 \%$ to $3 \%$ of the wall thickness in size, appear to have little effect on the SSC behavior of the cladding (however, cracks may still initiate on them), but defects on the order of $7 \%$ of the thickness definitely have an effect. Chemical defects (iron-rich inclusions) have not been identified as yet on the outside diameter of the Turkey Point cladding used in this study, although there are many very small $(\sim<1 \mu \mathrm{m})$ intermetallic inclusions. The hydride inclusions already mentioned are not considered by Miller et al., (16) most likely because the hydrogen is in solid solution with the metal at the temperatures $\left(-350^{\circ} \mathrm{C}\right)$ considered in this study. Finally, they predict that to include a maximum flaw size ( $10 \%$ of the wall thickness) in a study with greater than $95 \%$ confidence, more than $1 \mathrm{~m}^{2}$ of material must be studied. This is considerably more than the $\sim 3 \times 10^{-6} \mathrm{~m}^{2}$ of material 
included in the high-stress areas of the C-rings studied so far and suggests that there is a high probability that all of the defect sizes in the material studied to date are below the $2 \%$ to $3 \%$ of the wall thickness limit for affecting SSC behavior. From this, it is concluded that the SSC behavior observed so far is a property of the material and is not controlled by the presence of defects other than the surfaces grooving, which are already noted.

\subsection{STRESS CORROSION CRACKING EVIDENCE}

The fact that rings stressed under "dry" [dew point, $40^{\circ} \mathrm{F}$ to $50^{\circ} \mathrm{F}\left(4.44^{\circ} \mathrm{C}\right.$ to $\left.10^{\circ} \mathrm{C}\right)$ ] conditions behave differently than those stressed under wet conditions strongly suggests that the presence of water influenced the response of the cladding material to stress. Note that the dry conditions indicate exposure to air in the hot cell, which undoubtedly contains some water. It would be interesting to repeat the experiment under controlled, very dry conditions to see whether the presence of water actually causes cracking to occur or merely accelerates a cracking phenomenon that would occur anyway at these stress levels. James ${ }^{(17)}$ found that water increased the growth rate of fatigue cracks in Zircaloy-2 at $22^{\circ} \mathrm{C}$ and $38^{\circ} \mathrm{C}$, close to the conditions employed in the present study. This result appears to further support the conclusion that water influences the propagation of cracks.

Mattas et a1. (18) describes a case of iodine-induced stress corrosion cracking on the inside surface of Zircaloy-2 spent fuel cladding, by pressurizing the cladding in the presence of iodine at $325^{\circ} \mathrm{C}$. The crack pattern and fracture surface texture are almost identical to those generated in the present study, even though their fracture propagated outward from the inside surface, the opposite of what occurred in our experiments. The pattern of cracks in both cases consisted of long (up to several millimeters) cracks that overlap at their end and connect through shear zones. The fracture surface near the surface where the cracks originated is striated in some areas parallel to the surface (see Figure 14), and grades away from that surface into dimpling patterns suggestive of ductile failure. Hence, the cracking pattern and 
fracture surface texture observed in the C-ring study have been observed in other stress corrosion cracking experiments.

Steinberg et al. (19) again studying iodine-induced stress corrosion cracking, observed crack patterns and sizes in Zircaloy-4 cladding at $350{ }^{\circ} \mathrm{F}$ to $450{ }^{\circ} \mathrm{C}$ that are similar to those observed in this study. In this instance, they made extensive measurements of the length-to-depth ratios of cracks formed in the cladding surface (the inside diameter surface as in the previous study). The ratio of the crack length to depth in their study was always close to 4 . In the present study, apparently because of the stress pattern in the C-rings, the crack terminations tend to branch so it is difficult to determine equivalent crack depth. However, in Specimen G7-11-4, the crack did not branch, so a crack depth could be easily determined; in this case, the ratio was close to 4. Again the characteristics of cracking in the present study are consistent with a known instance of stress corrosion cracking in Zircaloy.

The similarity in cracking patterns in these two studies performed with pressurized cladding sections in the presence of iodine and the present C-ring study in the presence of water suggests that the Zircaloy-4 stress orientation and metal texture are working together. In the case of the C-rings, the tensile stress is generated perpendicular to the axis of the elongated metal grain so the preferred orientation of the cracks may be expected. In the case of pressurized tubes, the stress field is biaxial but has a predominant circumferential component. Hence, the cracking pattern remains the same, again suggesting that it is being controlled by the anisotropic cold worked texture and the stress field. This indicates that the $\mathrm{C}$-ring experiment results should correlate very well with those obtained in pressurized cladding tests.

\subsection{A POTENTIAL MODEL}

The topic of slow crack growth including stress corrosion cracking has been thoroughly reviewed by Atkins and Mai. (20) slow crack growth is characterized by three regions which are illustrated schematically in Figure $23 . K_{I}$ is the stress intensity factor at the tip of the growing crack, and $\dot{a}$ is the crack 


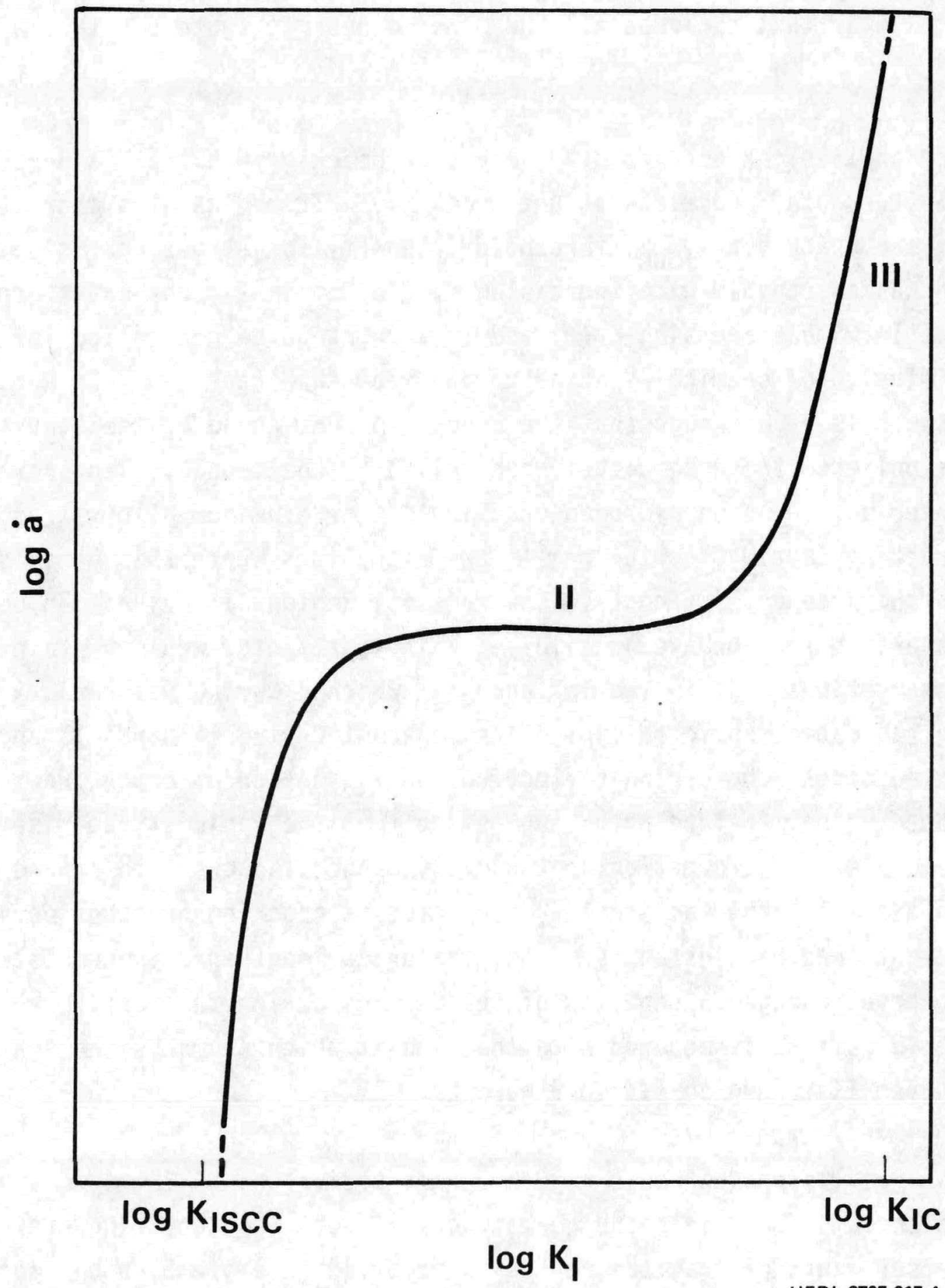

FIGURE 23. Schematic $K_{\text {I }}$ - à Diagram. 
growth rate. Typically $K_{I}=\sigma \sqrt{\pi a} Y$, where $\sigma$ is the applied stress (applied by the dead weight on the C-ring apparatus), $a$ is the crack length, and $Y$ is a parameter that includes all the other geometric factors (it is a function of a).

Region I is characterized by very slow crack growth that is dependent on environmental reactions at the crack tip. It begins at a characteristic stress

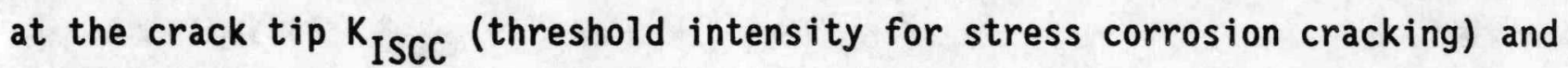
increases rapidly with increasing $K$. In Region II, the crack growth changes little with increasing $K(\sigma)$ and is thought to be controlled largely by diffusion of chemical species to and from the crack tip. In Region III, the stress is high enough that the crack tip runs ahead of the "environment" and is believed to be completely controlled by the mechanical properties of the material. Delayed hydrogen cracking ${ }^{(15)}$ or aluminum alloy stress corrosion cracking in a $\mathrm{NaCl}$ solution ${ }^{(21)}$ are situations where this behavior is observed. In the absence of a hostile environment, Region III may not be observed in materials that behave ductilely. This last factor would explain the observations made in two instances in which a C-ring was rapidly deformed due to the catastrophic failure of an adjacent C-ring (Figures 11 and 12). In those cases, the C-ring deflection (an indication of crack growth) returned to the original failure path, suggesting that the rapid stress rise had caused some plastic deformation, but had not caused the crack to extend significantly. In addition, the fact that $K_{I}$ increases as cracking proceeds because the dead weight load remains the same but the crack lengthens, is consistent with the observed change in behavior of the $C$-rings during the test. The onset of rapid failure is equated with the time at which $\mathrm{K}_{I}$ makes the transition from Region II to Region III in Figure 23.

The results presented in Figure 22 are equivalent to the traditional approach, which lumps materials and geometrical effects together. However, with the measurements of fracture depths as recorded in Table 5, and assuming that the proportionality between $\sigma$ and $K_{I}$ behaves in a similar way for all experiments run so far, the data in Figure 22 can be recast in terms of a "crack growth rate" and "K $\mathrm{K}_{\mathrm{I}}$ " or simply $\sigma$. In Figure 24, the crack growth rate for each specimen was approximated by assuming that the slow crack growth period for 


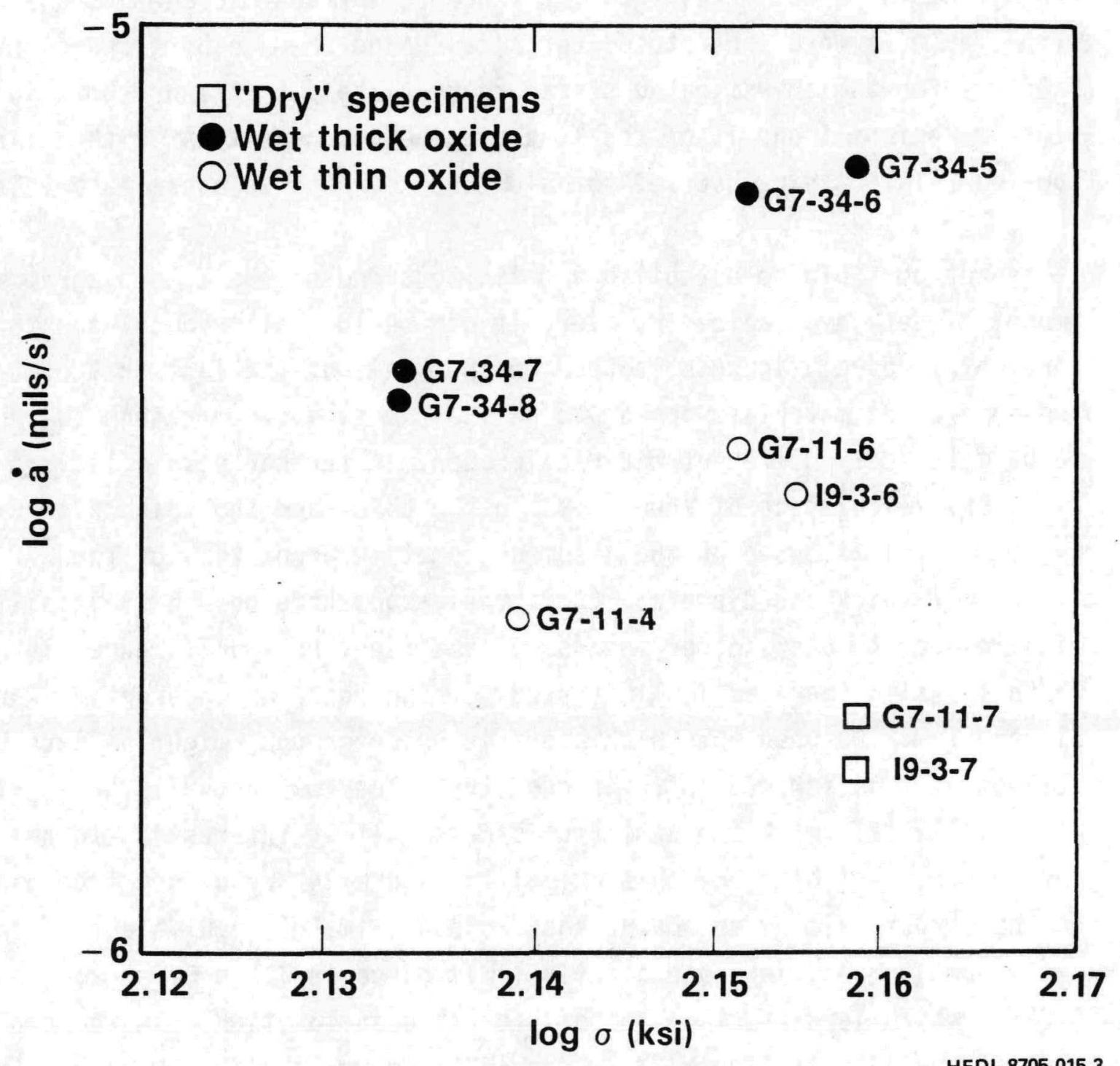

FIGURE 24. Interpretative Plot of the Experimental Data on a $\sigma$ - a Diagram. 
each specimen was the time before the $C$-ring cracked to the point at which $K_{I}$ entered the Region III condition and the specimen began to fail rapidly. This was taken to be the slow deflection part of the curves in Figures 11 and 12 (see estimates in Table 5). The average slow crack length was taken to be $\sim 10 \mathrm{mil}$ based on estimates from the fracture surface micrographs. Values of $\sigma$ (from Table 5) were substituted for $K_{I}$ assuming them to be proportional in the same way for the investigated stress range. The data trends shown in this plot in Regions I and II of the $K_{I^{-}}-\dot{a}$ diagram are consistent with a linear log-log relationship observed for slow crack growth in other materials.

It is not possible to establish a definite trend on the $K_{I}-\dot{a}$ diagram with the amount of data available. However, it can be logically speculated that the straight line relationship is true on the basis of the fact that both thick and thin oxide materials appear to define the same slope though they now appear to be distinctly different material groups. A further possibility is that, since the calculation of the stress in the thick and the thin oxide $C$-rings by, e.g., [1] is based on the assumed geometric properties of the $\mathrm{C}$-rings i.e., wall thickness diameter, etc., the groups have been artificially offset with respect to one another because of small but real differences in geometry. On that basis, the elastic limit study, which found an apparent difference in elastic limit between the thick and thin oxide groups, might be interpreted as reflecting a difference in their geometry. They may actually be starting to plastically deform at the same true stress. It is interesting to note that the two trends (thick and thin oxide) in Figure 24 are offset from one another on the stress axis by an amount that is approximately equivalent to the difference in their average elastic limit given in Table $3(\log 156-\log 148=$ 0.023 ), which lends further support for this speculation. In the empirical plot of the data in Figure 22, a single trend was observed when the two different elastic limits determined for thick and thin oxide film material, respectively, were used as a basis for calculating the percent of yield stress. Again, this would remove undetected differences in geometry from the comparison of experimental results. If these speculations are true, then the response of the cladding material with a thick oxide 
film is the same as that with a thin oxide film and the data points for the thick and thin oxide material can be shifted along the stress axis in Figure 24, which produces a single trend that is linear.

The linear trend displayed by the data in Figure 24 makes it relatively easy to compare crack growth rates at different stress levels and predict the lifetime of a C-ring if the stress is known. Calculations indicate that at $-80 \%$ of elastic limit, a C-ring should last approximately eight times longer than one at $-95 \%$ of the elastic limit. Therefore, it is expected that a $\mathrm{C}$-ring running at the $80 \%$ level in the present experiment should crack in about 200 to $220 \mathrm{~d}$. 
WHC-EP-0096

DO NOT MICROFILM

THIS PAGE 
The results obtained, to date, support several conclusions.

1. Cracking of irradiated Zircaloy-4 is affected by the environmental conditions under which it occurs. At $90^{\circ} \mathrm{C}$, cracking is significantly more rapid in Well J-13 water than in "hot cell" air. The fracture surface textures are similar to those seen in cracks resulting from iodine-induced stress corrosion cracking.

2. With appropriate assumptions concerning $\mathrm{a}, \mathrm{K}_{\mathrm{c}}$, and $\sigma$, a semiquantitative evaluation of the results suggests that the data can be fit to a standard slow crack growth model. An apparent linear log-log relationship is observed between the $\log$ of the crack propagation velocity and the $\log$ of the applied stress, though. It is predicted by the log-log relationship that the $80 \%$ stress level experiment will last 200 to $220 \mathrm{~d}$ or eight times longer than the $95 \%$ stress level experiments.

3. The conclusions drawn from this study data must be validated at lower stress levels in order to extrapolate down to $15 \mathrm{ksi}$, which is conservatively high for PWR cladding. More consideration also needs to be given to the materials questions such as: what controls the difference between cladding with thick and thin oxides; the cladding wall thickness, size of surface defects, or the presence of hydrides and delayed hydrogen cracking? and how does the performance of different spent fuel claddings compare? 


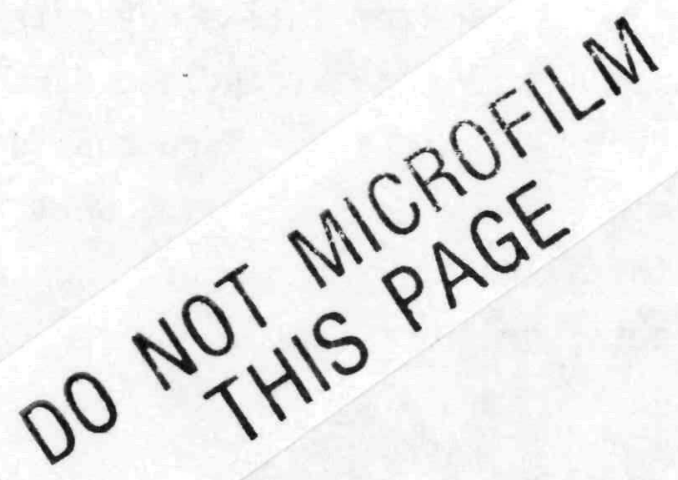


10.0 REFERENCES

1. H. D. Smith, "Zircaloy $\mathrm{Cladding} \mathrm{Corrosion} \mathrm{Degradation} \mathrm{in} \mathrm{a} \mathrm{Tuff}$ Repository," HEDL-7455, Rev. 1, Hanford Engineering Development Laboratory, Richland, Washington, July 1985.

2. H. L. Logan, "Stress Corrosion," Chapter 10, NACE Basic Corrosion Course, NACE, Houston, Texas, 1982.

3. J. Lankford et al., "Fatigue Crack Tip Plasticity, " Cyclic Stress-Strain and Plastic Deformation Aspects of Fatigue Crack Growth, ASTM STP637, pp. 36-55, American Society for Testing and Materials, Philadelphia, Pennsylvania, 1977.

4. J. H. Underwood and W. W. Gerberich, "Concepts of Fracture Mechanics," in Application of Fracture Mechanics for Selection of Metallic Structural Materials, J. E. Campbell, W. W. Gerberich, J. H. Underwood (eds.), American Society for Metals, Metals Park, Ohio, 1982.

5. A. S. Kobayashi, "Fracture Mechanics," in Experimental Techniques in Fracture Mechanics, ed. SESA Monog. I, Society for Experimental Stress Analysis, Westport, Connecticut, 1973.

6. R. E. Einziger and R. Kohli, "Low-Temperature Rupture Behavior of Zircaloy-Clad Pressurized Water Reactor Spent Fuel Rods under Dry Storage Conditions," Nuclear-Technology, Vol. 67, LaGrange Park, Illinois, 1984.

7. M. Bocek and C. Peterson, "The Influence of Oxide Coating on the Ductility of Zircaloy-4," Journal of Nuclear Materials, Vol. 80, 303-313, Amsterdam, Netherlands, 1979.

8. R. B. Davis and V. Pasupathi, Data Summary Report for the Examination of Rods G7, G9, J8, I9, and H6 from Turkey Point Fuel Assembly B17, HEDL-TME 80-85, Hanford Engineering Development Laboratory, Richland, Washington, April 1981.

9. H. D. Smith, C-Ring Stress Corrosion Cracking Scoping Experiment for Zircal oy Spent Fuel Cladding, HEDL-TC-7546, Hanford Engineering Development Laboratory, Richland, Washington, March 1986.

10. S. 0. Fernandez and G. F. Tisinai, "Stress Analysis of Unnotched C-Rings Used for Stress Cracking Studies, " Journal of Engineering for Industry, American Society for Mechanical Engineers, New York, New York, February 1968.

11. ASTM, "Making and Using C-Ring Stress-Corrosion Test Specimens," ASTM Procedure G-38-73, American Society for Testing and Materials, Philadelphia, Pennsylvania, 1973. 
12. L. M. Lowry et al., Evaluating Strength and Ductility of Irradiated Zircaloy - Task 5, NUREG/CR-1392, BMI-2066, Vol. I, Battelle Columbus Laboratories, Columbus, Ohio, May 1981.

13. F. Garofalo, P. R. Maleneck, and G. V. Smith, "The Influence of Temperature on the Elastic Constants of Some Commercial Steels, " Symposium on Determination of Elastic Constants, ASTM Spec. Tech. Publ. No. 129, 10-27, Philadelphia, Pennsylvania, 1952.

14. F. R. Shanley, Strength of Materials, McGraw-Hill, New York, New York, 1957.

15. R. Dutton, K. Nuttal1, M. P. Puls, and L. A. Simpson, "Mechanisms of Hydrogen Induced Delayed Cracking in Hydride Forming Materials, " Metallurgical Transactions, Vol. 8A, pp. 1553-1562, New York, New York, 1977a.

16. A. K. Miller et al., "SCCIG: A Phenomenological Model for Iodine Stress Corrosion Cracking of Zircaloy," Vol. I, NP-1798, Electric Power Research Institute, Palo Alto, California, April 1981.

17. L. A. James, "Environmentally Aggravated Fatigue Cracking of Zircaloy-2," Nuclear Applications and Technology, Vol. 9, Hinsdale, Illinois, August 1970.

18. R. F. Mattas, F. L. Yaggee, and L. A. Neimark, "Effect of Zirconium Oxide on the Stress-Corrosion Susceptibility of Irradiated Zircaloy Cladding," Zirconium in the Nuclear Industry: Fifth Conference, ASTM STP 754. D. G. Franklin (ed.), American Society for Testing and Materials, pp. 158-170, Philadelphia, Pennsylvania, 1982.

19. E. Steinberg, M. Peehs, and H. Stehle, "Development of the Crack Pattern During Stress Corrosion in Zircaloy-Tubes, " Journal of Nuclear Materials 118, pp. 286-293, North-Holland, Amsterdam, Netherlands, 1983.

20. A. G. Atkins and Y. W. Mai, Elastic and Plastic Fracture," John Wiley and Sons, New York, New York, 1985.

21. J. Blaine, J. Masounave, and J. J. Dickson, "A Comparison of SCC Velocity Measurements Under Conditions of Constant Load and Constant Displacement," Corrosion Science, Vol. 24, No. 1, pp. 1-12, Oxford, England, 1984 . 


\section{EXTERNAL DISTRIBUTION}

DOE-HQ/Office of Civilian

Radioactive Waste Management

Forrestal Building

Washington, DC 20585

$\begin{array}{ll}\text { CE Kay, Acting Director } & \mathrm{RW}-1 \\ \text { DH Alexander } & \mathrm{RW}-332 \\ \text { JC Bresee } & \mathrm{RW}-10 \\ \text { SJ Brocoum } & \mathrm{RW}-221 \\ \text { VJ Cassella } & \mathrm{RW}-123 \\ \text { MW Frei } & \mathrm{RW}-22 \\ \text { BG Gale } & \mathrm{RW}-23 \\ \text { TH Isaacs } & \mathrm{RW}-40 \\ \text { SH Kale } & \mathrm{RW}-20 \\ \text { G. Parker } & \mathrm{RW}-333 \\ \text { JD Saltzman } & \mathrm{RW}-20 \\ \text { S. Rousso } & \mathrm{RW}-10 \\ \text { R. Stein } & \mathrm{RW}-30\end{array}$

DOE/Nevada Operations Office

P.0. Box 98518

Las Vegas, NV 89193-8518

M. Bl anchard, WMPO

CP Gertz, Project Manager, Waste Management $P O$

MS -523 (5)

CL West, Director, Office of External Affairs

JL Fogg, Technical Information Office

PK Fitzsimmons, Director, Health Physics \& Envir. Div.

LP Skousen, WMPO

M. Valentine, WMPO

M. Cloninger

DOE-RL/Office of Asst Manager for Research and Projects

P.0. Box 550

Richland, WA 99352

DC Langstaff, General Engineer

DH Dahlen, Chief, BWIP Branch

Public Reading Room

A5 -90

A5-10
DOE/Office of Scientific

and Technical Information

Science and Technology Division

P.0. Box 62

Oak Ridge, TN 37831

AT Tamura

Argonne National Laboratory

Chemical Technology Division

9700 S. Cass Avenue, Bldg. 205

Argonne, IL 60439

J. Bates

E. Veleckis

Battelle Columbus Laboratory

505 King Avenue

Columbus, $\mathrm{OH} 43201$

ONWI Library

Berkeley Nuclear Laboratories Berkeley, Glouscestershire GL 13 9PB, UK

KA Simpson, Section Leader

Brookhaven National Laboratory Associated Universities, Inc. Upton, NY 11973

D. Schweitzer

Center for Nuclear Waste Regulatory Analys is 6220 Culebra Road

Drawer 28510

San Antonoio, TX 78284

Director 


\section{EXTERNAL DISTRIBUTION (Cont'd)}

City of Boulder City

P.0. Box 367

Boulder City, NV 89005

Director, Community Planning

City of Caliente

P.0. Box 158

Caliente, NV 89008

J. Foremaster

City of Henderson

Henderson, NV 89015

City Manager

City of Las Vegas

400 E. Stewart Avenue

Las Vegas, NV 89101

Economic Development Dept

City of North Las Vegas

P.0. Box 4086

North Las Vegas, NV 89030

Community Planning \& Development

Clark County

225 Bridger Avenue, 7th Floor

Las Vegas, NV 89155

Comprehensive PIanning Dept

Commission of the European Communities Rue de la Loi 200

B-1049 Brussels, Belgium
Desert Research Institute

Water Resources Center

P.0. Box 60220

Reno, NV 89506

J. Fordham

Desert Research Institute

Water Resources Center

2505 Chandler Avenue, Suite 1

Las Vegas, NV 89120

M. Mifflin

EG\&G Energy Measurements, Inc.

P.0. Box 1912

Las Vegas, NV 89125

E. Ezra, Manager, NNWSI GIS, MS H-02

Fenix \& Scisson, Inc.

Las Vegas Branch

P.0. Box 93265

Las Vegas, NV 89193-3265

JA Cross, Manager MS-514

Fenix \& Scisson, Inc.

101 Convention Center Drive, Suite 320

Las Vegas, NV 89109

RL Bullock, NNWSI Tech

Project Officer MS-403

Hahn Meitner Institut GmbH

Glienickerstr. 100

D-1000 Berlin 39

Federal Republic of Germany

Bernd Grambow 


\section{EXTERNAL DISTRIBUTION (Cont'd)}

Holmes \& Narver, Inc. Energy Support Division P.0. Box 93838

Las Vegas, NV 89193-3838

$$
\begin{aligned}
& \text { AE Gurrola, General } \\
& \text { Manager }
\end{aligned}
$$

MS -580

Holmes \& Narver, Inc.

101 Convention Center Drive, Suite 860 Las Vegas, NV 89109

$$
\begin{aligned}
& \text { JC Calovini, NNWSI Technical } \\
& \text { Project Officer }
\end{aligned}
$$

$$
\begin{aligned}
& \text { Lawrence Berkeley Laboratory } \\
& \text { Field Systems } \\
& \text { Bldg 50B/4235 } \\
& \text { Berkeley, CA } 94720 \\
& \quad \text { EP Binnall, Group Leader }
\end{aligned}
$$

Lawrence Livermore

National Laboratory

P.0. Box 808

Livermore, CA 94550
$L-219$

$L-206$

$L-219$

$L-219$

$L-206$

L-204

$\mathrm{L}-204$

L-204

$\mathrm{L}-204$

L-204

$L-202$

$L-196$

$L-201$

$L-202$

L-195

L-206

$L-231$

L-204

L-204

$L-206$
Lincoln County

Pioche, NV 89043

$$
\text { Lincoln County Commission }
$$

Los Al amos National Laboratory P.0. Box 1663 Los Alamos, NM 87545

K. Eggert

DT Oakley, NNWSI Technical Project Officer (4) J-521

Los Al amos National Laboratory

101 Convention Center Drive, Suite P230 Las Vegas, NV 89109

HN Kalia, Manager, Exploratory Shaft Test

MS-527

Mountain West Research-Southwest, Inc. 432 North 44th Street, Suite 400 Phoenix, AZ 85008

E. Anderson

E. Russel1

$L-197$

R. Ryerson

$L-201$

W. Sawka

$L-202$

R. Schock

L. Schwartz

$L-209$

H. Shaw (17)

$L-203$

D. Short

$\mathrm{L}-204$

R. Silva

$L-204$

R. Stout

L-396

H. Tewes

$L-200$

A. Tompson

L-204

R. Van Konynenburg

$L-206$

B. Viani

$\mathrm{H}$. Weed

$L-370$

A. Wijesinghe $L-200$

T. Wolery

$\mathrm{L}-219$

J. Yow

$L-206$

L. Younker

$L-209$

NWM Library (10) L-204 


\section{EXTERNAL DISTRIBUTION (Cont'd)}

National Bureau of Standards Division 450 Gaithersburg, MD 20899

C. Interrante B1dg $223 / \mathrm{Rm} A-245$

Nuclear Regulatory Commission Division of Waste Management Washington, DC 20555

M. Bel1 MS-WFI-4-H3 Chief, Repository Proj Branch Document Control Center NTS Section Leader

Nuclear Regulatory Commission 1050 East Flamingo Road, Suite 319 Las Vegas, NV 89119

PT Prestholt, Site Rep

Nye County

P.0. Box 153

Tonopah, NV 89049

Planning Dept

Reynolds Electrical

\& Engineering Co, Inc. (2)

P.0. Box 98521

Las Vegas, NV 89193-8521

DL Fraser, Gen Mgr

RF Pritchett, NNWSI Tech Project Officer

MS -555

MS-615

Royal Institute of Technology Department of Inorganic Chemistry S-100 44 Stockholm 70, Sweden

Jordi Bruno
Sandia National Laboratories

P.0. Box 5800

Albuquerque, NM 87185

TO Hunter, NNWSI Tech Project Officer (5) Org 6310

RW Lynch Org 6300

S. Sinnock

Savannah River Laboratory

Aiken, SC 29808

B. Kitchen Bldg 773-41A

J. Plodinec B1dg 773-A, Rm B-120

Science Applications

International Corporation

1626 Cole Boulevard, Suite 270 Golden, C0 80401

TG Barbour

Science Applications

International Corporation (3)

101 Convention Center Drive, Suite 407

Las Vegas, NV 89109

SAIC-T\&MSS Library

ME Spaeth, NNWSI Tech

Project Officer

State of Nevada

Office of the Governor

Capitol Complex

Carson City, NV 89710

T. Hay, Exec Assistant 


\section{EXTERNAL DISTRIBUTION (Cont'd)}

State of Nevada (4)

Nuclear Waste Project Office

Evergreen Center, Suite 252

1802 N. Carson Street

Carson City, NV 89701

$\mathrm{CH}$ Johnson, Tech Prog Mgr

RR Loux Jr., Exec Director

Studsvik $A B$

S-61182 Nyköping, Sweden

RW Forsyth

Svensk Karnbranslehantering $A B$ Box 5864

S-102 48 Stockholm, Sweden

Dr. Lars Werme

Systems Support Inc.

P.0. Box 1432

Manassas, VA 22110

R. Moler

University of California Dept. of Nuclear Engineering Berkeley, CA 94720

TH Pigford

$\frac{\text { U.S. Geological Survey }}{\text { P.0. Box } 25046}$

421 Federal Center

Denver, C0 80225

VW Glanzman Rm 913

LR Hayes, NNWSI Tech

Project Officer
U.S. Geological Survey

Engineering Geology

106 National Center

12201 Sunrise Valley Drive

Reston, VA 22092

JR Rollo, Deputy Asst Dir

Technical Research Centre of Finland

Reactor Laboratory

Otakaari $3 \mathrm{~A}$

SF-02150 Espoo 15, Finland

$$
\text { Kaija } 011 \text { ila }
$$

Roy F. Weston, Inc. (3)

955 L'Enfant Plaza SW, Suite 800 Washington, DC 20024
E. Benz WM Hewitt, Prog Manager
Technical Information Center

West Valley Nuclear Services Co, Inc. Process Technology \& Testing P.0. Box 191

West Valley, NY 14171-0191

J. Pope, Manager

Whiteshe11

Nuclear Research Establishment

Atomic Energy of Canada Ltd.

Pinawa, Manitoba ROE 1LO, Canada

C. Davison, GWT Branch

K. Dormuth, FWT Branch

L. Johnson, FWT Branch

FP Sargent

D. Shoesmith, RC Branch

G. Simmons, FWT Branch

S. Stroes-Gascoyne, FWT Branch

S. Sunder, RC Branch 


\section{INTERNAL DISTRIBUTION}

Pacific Northwest Laboratories (40)

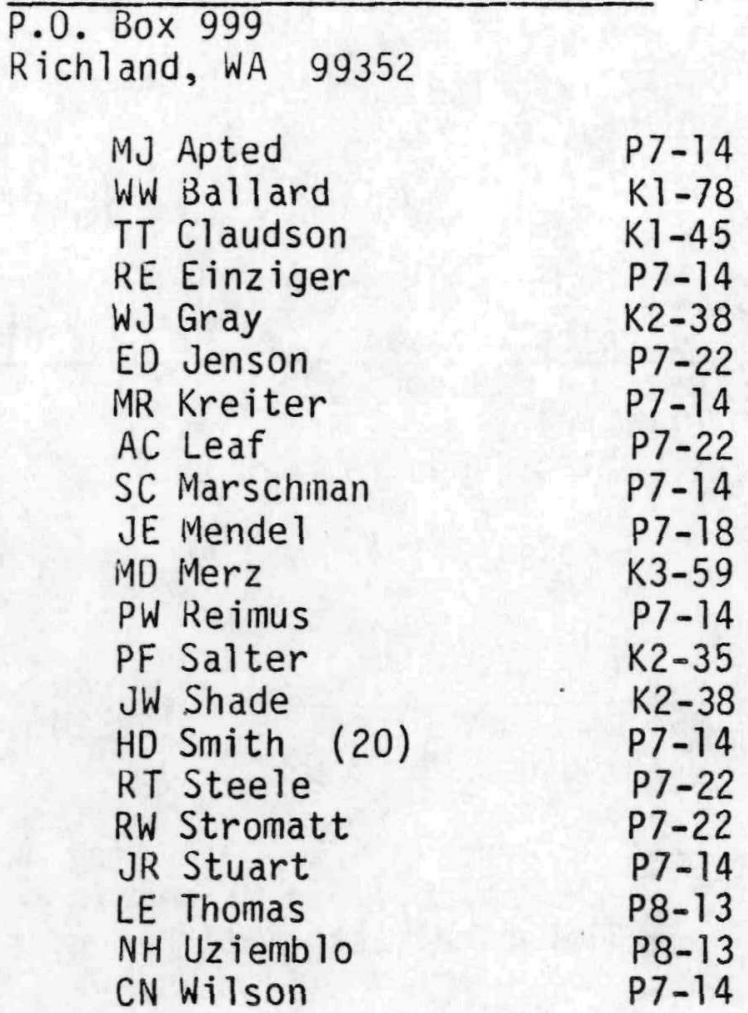

Westinghouse Hanford Co.

(9)

P.0. Box 1970

Richland, WA 99352

DG Farwick

S1 -52

GT Harper

H9- 19

RL Knecht

L5-59

W. Yunker

L4-51

BWIP Library

(2)

H9-16

Documentation

(3)

L8-15 